This item was submitted to Loughborough's Research Repository by the author.

Items in Figshare are protected by copyright, with all rights reserved, unless otherwise indicated.

\title{
Deriving the operational procedure for the Universal Thermal Climate Index
} (UTCl)

PLEASE CITE THE PUBLISHED VERSION

http://dx.doi.org/10.1007/s00484-011-0454-1

PUBLISHER

C ISB (Springer)

VERSION

AM (Accepted Manuscript)

LICENCE

CC BY-NC-ND 4.0

\section{REPOSITORY RECORD}

Broede, Peter, Dusan Fiala, Krzysztof Blazejczyk, Ingvar Holmer, Gerd Jendritzky, Bernhardt Kampmann, Birger Tinz, and George Havenith. 2019. "Deriving the Operational Procedure for the Universal Thermal Climate Index (UTCI)". figshare. https://hdl.handle.net/2134/9294. 
This item was submitted to Loughborough's Institutional Repository (https://dspace.lboro.ac.uk/) by the author and is made available under the following Creative Commons Licence conditions.

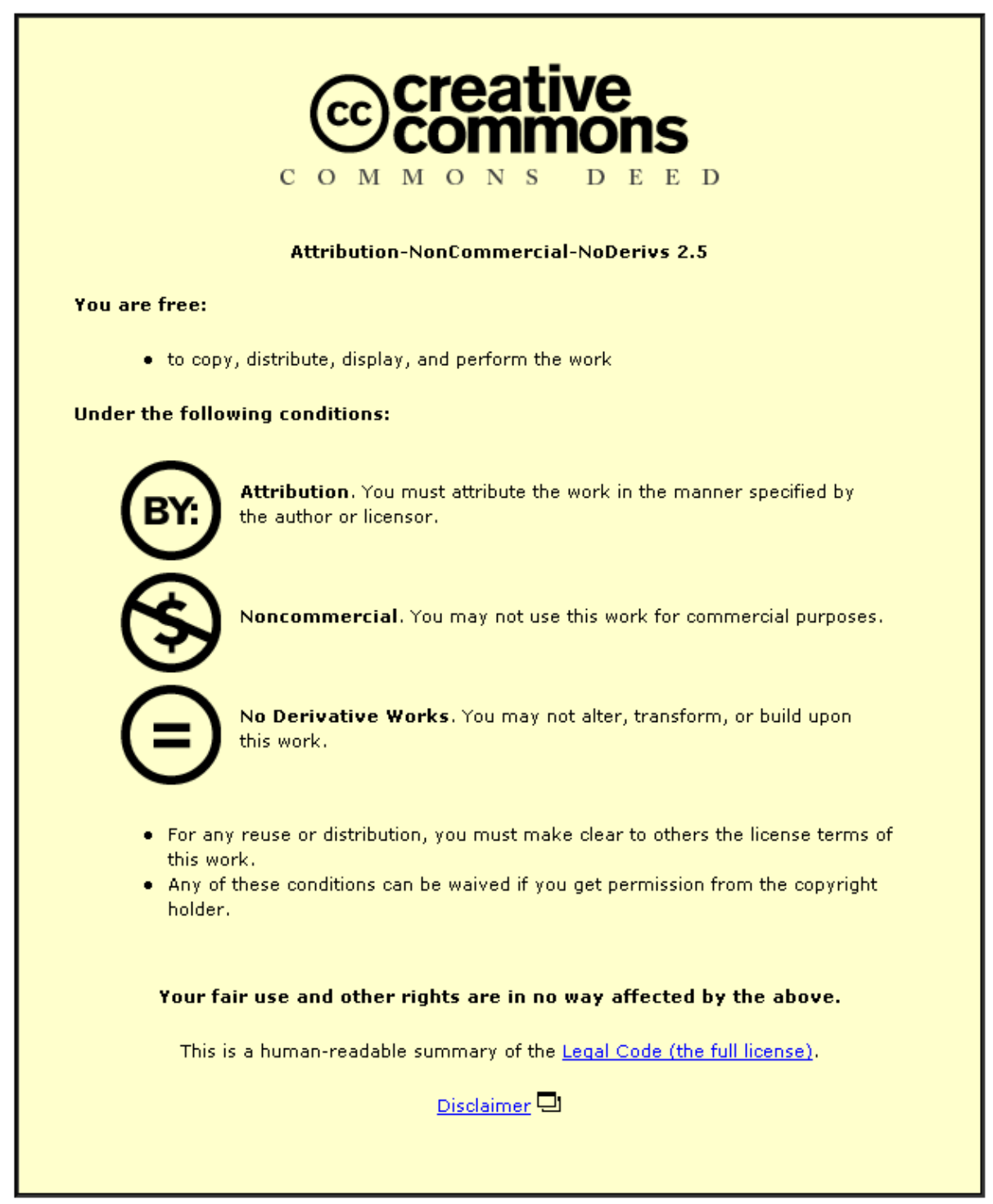

For the full text of this licence, please go to: http://creativecommons.org/licenses/by-nc-nd/2.5/ 


\section{Deriving the Operational Procedure for the Universal Thermal Climate Index UTCI}

Peter Bröde ${ }^{1}$, Dusan Fiala ${ }^{2,3}$, Krzysztof Błażejczyk $^{4}$, Ingvar Holmér ${ }^{5}$, Gerd Jendritzky $^{6}$, Bernhard Kampmann ${ }^{7}$, Birger Tinz ${ }^{8}$, George Havenith ${ }^{9}$

(1) Leibniz Research Centre for Working Environment and Human Factors (IfADo), Ardeystr. 67, 44139 Dortmund, Germany

(2) Ergonsim - Comfort Energy Efficiency, Stuttgart, Germany

(3) Institute of Building Technologies, IBBTE, University of Stuttgart, Germany

(4) Institute of Geography and Spatial Organization, Polish Academy of Sciences, Warsaw, Poland

(5) Department of Design Sciences, EAT, Lund University, Sweden

(6) Meteorological Institute, University of Freiburg, Germany

(7) Department of Safety Engineering, Bergische Universität Wuppertal, Germany

(8) German Meteorological Service, Department Climate Monitoring, Hamburg, Germany

(9) Environmental Ergonomics Research Centre, Loughborough Design School, Loughborough University, $U K$

$\triangle$ Corresponding author:

Peter Bröde

Phone +49 2311084225

Fax +49 2311084400

e-mail: broede@ifado.de

http://www.ifado.de

\section{Abstract}

The Universal Thermal Climate Index (UTCI) aimed for a one-dimensional quantity adequately reflecting the human physiological reaction to the multi-dimensionally defined actual outdoor thermal environment. The human reaction was simulated by the UTIC-Fiala multi-node model of human thermoregulation, which was integrated with an adaptive clothing model. Following the concept of an equivalent temperature, UTCI for a given combination of wind speed, radiation, humidity and air temperature was defined as the air temperature of the reference environment, which according to the model produces an equivalent dynamic physiological response.

Operationalising this concept involved (i) the definition of a reference environment with 50\% relative humidity (but vapour pressure capped at $20 \mathrm{hPa}$ ), with calm air and radiant temperature equalling air temperature and (ii) the development of a one-dimensional representation of the 
multivariate model output at different exposure times. The latter was achieved by principal component analyses showing that the linear combination of 7 parameters of thermophysiological strain (core, mean and facial skin temperatures, sweat production, skin wettedness, skin blood flow, shivering) after $30 \mathrm{~min}$ and $120 \mathrm{~min}$ exposure time accounted for two thirds of the total variation in the multi-dimensional dynamic physiological response. The operational procedure was completed by a scale categorising UTCI equivalent temperature values in terms of thermal stress, and by providing simplified routines for fast but sufficiently accurate calculation, which included look-up tables of pre-calculated UTCI values for a grid of all relevant combinations of climate parameters and polynomial regression equations predicting UTCI over the same grid.

The analyses of the sensitivity of UTCI to humidity, radiation and wind speed showed plausible reactions as well in the heat as in the cold, and indicate that UTCI may in this regard be universally useable in the major areas of research and application in human biometeorology.

Keywords: outdoor climate; index; thermal stress; thermophysiology; simulation model; thermal comfort.

\section{Introduction}

Initiated by Commission 6 of the International Society of Biometeorology, and developed with support from the European Union within the COST Action 730, the Universal Thermal Climate Index UTCI aims at the assessment of the outdoor thermal conditions in the major fields of human biometeorology. The UTCI (Jendritzky et al. 2007) ultimately should provide a one-dimensional quantity which adequately reflects the human physiological reaction to the multidimensionally defined actual thermal condition. In an attempt to extend available approaches using human heat budget models (Vanos et al. 2010; Kenny et al. 2009a; Höppe 1999), the human reaction was simulated by a multi-node model of human thermoregulation, which was integrated with an adaptive clothing model. As illustrated in Figure 1, the index value will be calculated from the multivariate dynamic output of that model. The term "dynamic" refers to the time-dependency of physiological responses in non-moderate conditions before reaching steadystates. The concept was chosen to account for differences in the assessment of indoor and outdoor climate conditions; the latter being characterised by diverse dynamic effects in the human response to the wide range of outdoor environments. Especially under exposure to cold, steady-state conditions might not be achieved even after several hours (Höppe 2002). 
Following the pioneering work of Stolwijk (1971), a number of multi-segmental thermoregulatory models emerged, which are more deeply discussed in this special issue by Fiala et al. (2011). After accessible models of human thermoregulation had been evaluated, the advanced multi-node 'Fiala' thermoregulation model was selected (Fiala et al. 1999; Fiala et al. 2001), which also provides for predicted votes of the dynamic thermal sensation based on core and skin temperature signals (Fiala et al. 2003). Within the COST Action 730 the physiological model was extensively validated (Psikuta et al. 2011), adapted and extended for purposes of the project (Fiala et al. 2011). In the next step a state-ofthe-art adaptive clothing model was developed and integrated (Havenith et al. 2011). This model considers

1. the behavioural adaptation of clothing insulation observed for the general urban population in relation to the actual environmental temperature,

2. the distribution of the clothing over different body parts providing local insulation values for the different model segments, and

3. the reduction of thermal and evaporative clothing resistances caused by wind and the movement of the wearer.

UTCI was then developed following the concept of an equivalent temperature. This involved the definition of a reference environment, to which all other climatic conditions are compared. Equal physiological conditions are based on the equivalence of the dynamic physiological response predicted by the model for the actual and the reference environment. As this dynamic response is multidimensional (body core temperature, sweat rate, skin wettedness etc. at different exposure times), a response index had to be calculated as single dimensional representation of the model response, cf. Figure 1. The UTCI equivalent temperature for a given combination of wind speed, radiation, humidity and air temperature is then defined as the air temperature of the reference environment, which produces the same response index value.

As calculating the UTCI equivalent temperatures by running the thermoregulation model repeatedly would on the one hand require expert knowledge to operate with the complex simulation software and, on the other hand, could be too timeconsuming for climate simulations and numerical weather forecasts, several options for the operational procedure of UTCI to simplify this calculation were considered. Some applications may also require the computed UTCI values to be 
categorised in terms of thermal stress (Staiger et al. 1997; Koppe and Jendritzky 2005).

The following sections delineate how the simulation model was used to derive UTCI, how UTCI responds to wind, humidity and radiation under heat and cold stress conditions, and how UTCI may be calculated and categorised by the operational procedure in routine application.

\section{Deriving UTCI from the model of thermoregulation}

As described in introductory contributions to this special issue and also by Gonzalez et al. (1974), expressing index values in terms of an equivalent temperature constitutes a commonly applied concept which had already been applied to develop the Effective Temperature (ET, Houghten and Yagloglou 1923), with later extensions such as ET* (Gagge et al. 1971) or the Standard Effective Temperature (SET*, Gagge et al. 1986; Gonzalez et al. 1974) followed by more recent modifications and developments (Parsons 2003; Höppe 1999; Staiger et al. 1997). As operationalised here, the UTCI is defined as the air temperature $(\mathrm{Ta})$ of the reference condition causing the same model response as the actual condition. The offset, i.e. the deviation of UTCI from air temperature depends on the actual values of air and mean radiant temperature $(\operatorname{Tr})$, wind speed (va) and humidity, expressed as water vapour pressure (pa) or relative humidity $(\mathrm{rH})$, cf. Figure 1. This may be written in mathematical terms as

$$
U T C I(T a, T r, v a, p a)=T a+O f f \operatorname{set}(T a, T r, v a, p a)
$$

Applying this characterization requires the identification of both the reference condition and the dynamic model response. The approach chosen by UTCI is outlined below.

\section{Reference condition}

To convert climate impact to a single value and to facilitate the interpretation and understanding of UTCI, reference conditions must be a) defined in terms conforming to most people's experiences and b) relevant across the whole spectrum of climate zones to which UTCI is going to be applied. Therefore the non-meteorological variables metabolic rate MET and the thermal properties of clothing (insulation, vapour resistance, air permeability) are of great importance. 
Unlike earlier approaches that assumed a sedentary person with low metabolic heat production (Houghten and Yagloglou 1923; Gagge et al. 1971; Gonzalez et al. 1974), the ISB Commission on UTCI already defined in 2000 a representative outdoor activity to be that of a person walking with a speed of $4 \mathrm{~km} / \mathrm{h}(1.1 \mathrm{~m} / \mathrm{s})$ which is lower than the 3 miles $/ \mathrm{h}(1.34 \mathrm{~m} / \mathrm{s})$ used in the new Wind Chill Index (Osczevski and Bluestein 2005). There are only few studies on walking speed e.g. (Levine and Norenzayan 1999; Morgenroth 2007; Wiseman 2010) showing distinct differences between cultures and cities (e.g. $6.82 \mathrm{~km} / \mathrm{h}$ in Singapore, $4.15 \mathrm{~km} / \mathrm{h}$ in Berne / Switzerland). Additionally effects of age, gender, aim, and mood are evident. An interesting approach is given by Bruse (2009) who modelled pedestrian traffic using agents which individually adapt their walking velocity.

The working group of COST Action 730 agreed upon the former suggestion of $4 \mathrm{~km} / \mathrm{h}$ as a representative walking speed although the mentioned studies showed even higher values. The rate of metabolic heat production was assumed to be 2.3 MET $\left(135 \mathrm{~W} \cdot \mathrm{m}^{-2}\right)$. Although there is some evidence that people adapt behaviourally, e.g. to warm conditions by reducing their activity level, a fixed value of metabolic heat production was kept for this action.

For the reference environment it was decided to use a wind speed, measured in 10 $\mathrm{m}$ height following meteorological convention, of $0.5 \mathrm{~m} / \mathrm{s}$ (corresponding to approximately $0.3 \mathrm{~m} / \mathrm{s}$ at $1.1 \mathrm{~m}$ above ground level), with mean radiant temperature equalling air temperature and with a relative humidity of $50 \%$. Different approaches to define reference humidity have been used in the past (Gonzalez et al. 1974), assuming saturated vapour pressure (Houghten and Yagloglou 1923) or 50\% relative humidity (Gagge et al. 1971) or a constant vapour pressure of $12 \mathrm{hPa}$ (Höppe 1999). An overview of combinations of temperature and humidity on a global scale from the control run (1971-1980) of the general circulation model ECHAM 4 (Stendel and Roeckner 1998) indicated that it was unrealistic to stay with the reference humidity of $50 \%$ at high air temperatures as most observed humidity values would be lower at these temperatures (Figure 2). Therefore the reference humidity was capped at a vapour pressure of $20 \mathrm{hPa}$ for $\mathrm{Ta}>29^{\circ} \mathrm{C}$. 


\section{The dynamic physiological response}

The derivation of UTCI for an actual climatic condition is illustrated by Figure 1 . The offset to Ta is found by comparing the actual model response to the response under reference conditions. For explicitly performing these comparisons, the multivariate dynamic model response had to be condensed into a one-dimensional representation, which may be termed as response index.

\section{Multivariate analyses}

The dynamic physiological response was considered to constitute a latent variable, i.e. to be not directly observable by a single quantity, but to be hidden within the output parameters from the physiological model. Simulation data covering the relevant range of climatic conditions were produced, to which subsequently multivariate techniques of dimension reduction were applied. Two datasets were generated by repeatedly running the UTCI combined physiological and clothing model (Figure 1) for different climatic conditions with values of the output variables as listed in Table 1 after simulated exposure times of 30, 60, 90 and $120 \mathrm{~min}$ :

1.) Reference data $(\mathrm{N}=926)$, containing the results of simulation runs for the reference conditions with air temperature covering the expected range of UTCI predictions. The climatic parameters were defined as:

○ Air temperature: $-110^{\circ} \mathrm{C} \leq \mathrm{Ta} \leq+75^{\circ} \mathrm{C}(0.2 \mathrm{~K}$ increment $)$

○ Mean radiant temperature: $\operatorname{Tr}=\mathrm{Ta}$,

○ Wind speed (10 $\mathrm{m}$ above ground level): $\mathrm{va}=0.5 \mathrm{~m} / \mathrm{s}$,

○ Humidity: $\mathrm{rH}=50 \%\left(\mathrm{Ta} \leq 29^{\circ} \mathrm{C}\right), \mathrm{pa}=20 \mathrm{hPa}\left(\mathrm{Ta}>29^{\circ} \mathrm{C}\right)$

2.) Grid data $(\mathrm{N}=104643)$ with the output of the physiological model for actual, non-reference conditions defined over a grid of meteorological input variables, for which UTCI values will be required. The climatic parameters were defined as:

○ Air temperature: $-50{ }^{\circ} \mathrm{C} \leq \mathrm{Ta} \leq+50{ }^{\circ} \mathrm{C}(1 \mathrm{~K}$ increment $)$,

○ Mean radiant temperature: $-30{ }^{\circ} \mathrm{C} \leq \mathrm{Tr}-\mathrm{Ta} \leq+70{ }^{\circ} \mathrm{C}(5 \mathrm{~K}$ increment),

○ Wind speed (10 $\mathrm{m}$ above ground level):

- $\quad \mathrm{va}=0.5,0.8,1.2,1.8,2.7,4.0,6.0,9.0,13.5,20.2,30.3$ $\mathrm{m} / \mathrm{s}$, 
○ Humidity:

- $\mathrm{rH}=5,50,100 \%\left(\mathrm{Ta} \leq 0{ }^{\circ} \mathrm{C}\right)$,

- $\mathrm{rH}=5, \ldots(6$ steps $) \ldots, 100 \%$ or max. $\mathrm{pa}=50 \mathrm{hPa}$

$\left(\mathrm{Ta}>0{ }^{\circ} \mathrm{C}\right)$

Multivariate analyses of the model response were carried out for the part of the grid data with $\mathrm{Tr}-\mathrm{Ta} \geq-10{ }^{\circ} \mathrm{C}(\mathrm{N}=82916)$. In order to determine an appropriate characterisation of the physiological model response, hierarchical cluster analyses (Härdle and Simar 2007) were performed on the variables as listed in Table 1. Figure $3 \mathrm{~A}$ visualises the results of the cluster analysis as dendrograms. The vertical line outermost to the right indicates the proportion of variation between the variables explained by the first principal component (1st PC). This linear combination of all variables accounted for $67 \%$ of the variability in the whole dataset. The clustering algorithm then split the set of variables into two groups and again calculated the 1st PC separately for both groups. The variables were grouped so that the increase in the proportion of explained variance was maximised. This process was iterated until for each group the 1st PC accounted for more than $90 \%$ of the variance between the single quantities, i.e. the variables forming the final groups may be considered as containing almost identical information.

The variables representing different time points of the same quantity were almost always grouped together, only the 30 min values were occasionally grouped into separate clusters, e.g. for sweat rate, skin wettedness, shivering or metabolic heat production. From these results, which are supported by similar outcomes in an earlier version of the reference dataset (Bröde et al. 2009; Kampmann et al. 2008a), it may be concluded that the dynamics of the model response are sufficiently accounted for by considering the values after $30 \mathrm{~min}$ and $120 \mathrm{~min}$, the intermediate values do not add significantly to the information. On the other hand these results also indicate that a single reference time point, e.g. $60 \mathrm{~min}$ as used previously (Gagge et al. 1971; Gagge et al. 1986; Gonzalez et al. 1974) was not sufficient to describe the whole model response to all considered climatic conditions, thus confirming the relevance of the dynamic response for outdoor conditions (Höppe 2002). 


\section{Response index}

It was also observed from Figure 3A that all final groups of variables formed by the cluster analysis were represented by the values after 30 and $120 \mathrm{~min}$ of a subset of 7 variables: rectal, mean skin and facial temperatures, sweat production, skin wettedness, skin blood flow, shivering. Figure 3B presents the resulting dendrogram for this set of 14 variables. Parallel to the results for the complete set of 48 quantities, the 1st PC of that subset also explained about two thirds (66\%) of the variance. Furthermore, in the reference conditions the resulting response index was very similar for both sets of variables. As illustrated in Figure 4, even in case when there were differences in the response to the reference conditions between the two sets, similar differences also occurred for the non-reference conditions, and thus the derived UTCI values were similar again. These results suggest that the model response was suitably summarised by the 1st PC computed from these 14 variables.

Table 2 provides the information which is necessary for calculating the response index as 1st PC from the single output variables of the physiological model. It also shows that rectal and mean skin temperatures as well as skin blood flow and sweat rate were highly correlated to the resulting response index, and that moderate correlations appeared for face skin temperature and skin wettedness, whereas shivering showed a weaker correlation to the response index. From the standardised scoring coefficients, which represent the contribution of a single variable's 1SD (standard deviation) increase to the response index, it can be deduced that an increase in rectal and skin temperatures, skin blood flow, sweat rate and skin wettedness also increases the response index value, while an increase in shivering (as well as a decrease in rectal and skin temperatures and blood flow) is associated with a decrease of the response index.

Therefore the response index may be interpreted as an integrated characteristic value of thermal strain with high values pointing to heat strain, whereas low values indicate cold strain.

\section{Determining values of UTCI}

Applying the definition of the reference conditions and of the response index, the calculation of UTCI values for all conditions of the grid data then proceeded in 3 steps: 
1. Calculate the response index value as linear combination from the values of the 7 output variables at 30 and 120 min using the formula and parameters (sample arithmetic means, standard deviations and standardised scoring coefficients) as provided in Table 2,

2. Find the corresponding response index value from the reference data (cf. Figure $1 \& 4$ ) by the binary search (bisection) algorithm (Sedgewick 1992), and

3. Store UTCI as the air temperature of that reference condition.

\section{Sensitivity of UTCI to humidity, wind, radiation}

The following sections separately discuss how UTCI is affected by humidity, wind speed and thermal radiation, respectively, by fixing the non-considered meteorological variables to the reference condition.

\section{Humidity}

The effect of humidity on UTCI at low air temperatures was small, as shown in Figure 5 presenting the offset, i.e. the difference UTCI - Ta (cf. Figure 1, Equation 1), with wind and thermal radiation according to the reference condition. At moderate temperatures, relative humidity values above the reference $(50 \%)$ cause a slight increase in UTCI, whereas UTCI was marginally reduced for lower humidity values.

The influence of humidity related to air temperature in warm climates is depicted in a psychrometric diagram (Figure 6). The resulting contour lines were bent leftwards indicating an increase of UTCI with increasing humidity. The greater the angle subtended between UTCI isotherms and a vertical line, the greater the physiological effects of humidity. The psychrometric chart illustrates a much stronger influence of humidity on UTCI values at higher air temperatures and higher vapour pressures, as one would expect.

\section{Wind speed}

Figure 7 presents the offset (= UTCI - Ta) related to air temperature and wind speed with thermal radiation and humidity according to the reference condition. An interaction of wind and temperature is evident as the effect of rising wind speed depends on air temperature. Wind contributes to heat stress if temperatures 
exceed about $35^{\circ} \mathrm{C}$, which is near the characteristic value of mean skin temperature. On the other hand, the cold stress at low temperatures is considerably increased by high wind speeds.

\section{Thermal radiation}

Figure 8 shows UTCI related to the intensity of thermal radiation expressed as $\mathrm{Tr}$ - Ta for different air temperatures with wind and humidity according to the reference condition. UTCI increases linearly with radiation intensity by about $3 \mathrm{~K}$ per $10 \mathrm{~K}$ increment in mean radiant temperature, as indicated by the regression function. The regression equation confirms that UTCI almost perfectly (0.995) agrees with $\mathrm{Ta}$ for reference conditions with $\mathrm{Tr}=\mathrm{Ta}$, as could be expected from the definition of UTCI. At very low air temperatures and with increased wind speed, the radiation effects were attenuated (Figure 9).

\section{The operational procedure}

The operation of the complex simulation software implementing the coupled UTCI-Fiala and clothing models requires a certain level of expert knowledge. In addition, in routine applications like weather forecasting in geographical grids about 1 million UTCI calculations per day, corresponding to approximately 20 calculations per second or even more will be requested (Jendritzky 2007). These requests cannot be served by real time execution of the physiological model with the subsequent index calculations because of its processing time. Therefore, simplified procedures for accelerating the computation of UTCI were developed. Furthermore, some applications may require the categorization of the different values of UTCI equivalent temperature in terms of thermal stress. The present approach looks at the responses under the reference conditions and tries to deduct load (i.e. heat stress or cold stress) from these.

\section{Assessment scale categorising thermal stress}

The restriction to the reference conditions appears to be justified, because the UTCI value for an actual condition, which is identified by the values of air temperature, mean radiant temperature, water vapour pressure and wind speed, is defined in terms of an equivalent temperature as the air temperature of the 
reference condition yielding the same physiological response of the UTCI simulation model as for the actual condition.

As described above the physiological response is characterized by the model's dynamic multivariate output. Thus, different combinations of rectal and skin temperatures, sweat rate, shivering etc. might indicate "identical" strain causing non-unique values for single variables like rectal or mean skin temperature in different climatic conditions with identical UTCI value. However, due to the high correlation of the single variables with the calculated one dimensional integrated characteristic value of thermal strain (cf. Table 2), this variation was limited, as indicated in Figure 10A for the rectal temperature after two hours. Furthermore, the median response to UTCI was in good agreement with the values obtained for the reference conditions.

Similar results were observed for variables not used for the derivation of UTCI, as shown for the averaged dynamic thermal sensation vote (Fiala et al. 2003) in Figure 10B and for further variables in the Online Resource ESM 1a, b. This observation seems to provide further justification to restrict our considerations to the reference conditions.

By inspecting the development of the early $(30 \mathrm{~min})$ and late $(2 \mathrm{~h})$ reactions of the single variables as well as the responses averaged over the $2 \mathrm{~h}$ of simulated exposition time in relation to UTCI, which are provided as Online Resources ESM $1 b$ and 1c, we identified UTCI threshold values for the occurrence of strain reactions, e.g. the onset of shivering in the cold or the onset of profound sweating in the heat, or when the responses stayed below or above a certain limit value or showed structural changes. A list of criteria was compiled in a Table presented as Online Resource ESM 2.

Table 3 presents the labelled stress categories derived from these criteria. It shows an asymmetric distribution with more categories on the cold side, which may partly reflect the sensitivity of the UTCI model to wind speed (cf. Figure 7). It can be further noted from Figure 10B and Table ESM 2 that with respect to the averaged dynamic thermal sensation UTCI values between 18 and $26{ }^{\circ} \mathrm{C}$ may be considered to comply closely with the definition of the "thermal comfort zone" supplied in the Glossary of Terms for Thermal Physiology (The Commission for Thermal Physiology of the International Union of Physiological Sciences 2003) as: "The range of ambient temperatures, associated with specified mean radiant 
temperature, humidity, and air movement, within which a human in specified clothing expresses indifference to the thermal environment for an indefinite period".

\section{Simplified UTCI computation}

Two alternative approaches to simplified UTCI calculation without the repetitive need to run the actual physiological model but rather using a one off calculation of all relevant conditions, were developed and consist of 2 steps:

1. Calculate the model output and the resulting UTCI once for all input data on a defined grid

2. Implement a direct relation between the input data and UTCI by using alternatively

a. a look-up table, or

b. an approximating regression function.

\section{Regression function}

For simple and fast computation, the offsets of UTCI to Ta (= UTCI - Ta, cf. Equation 1) for the observations in the grid dataset were approximated by a polynomial in $\mathrm{Ta}$, va, $\mathrm{pa}, \mathrm{Tr}-\mathrm{Ta}$ including all main effects and interaction terms up to 6th order. A table with the least square estimates of the 210 coefficients is presented in the Online Resource ESM 3. A FORTRAN subroutine computing 1 million UTCI values in $3.7 \mathrm{~s}$ on a common desktop computer was implemented and is available at the project's website (http://www.utci.org). The root mean squared error (rmse) of the predictions to the observed UTCI values for the grid data was $1.1 \mathrm{~K}, 50 \%$ of all observed errors were within $\pm 0.6 \mathrm{~K}, 80 \%$ within $\pm 1.3 \mathrm{~K}, 90 \%$ within $\pm 1.9 \mathrm{~K}$. Extreme absolute deviations occurred with up to $6.2 \mathrm{~K}$.

\section{Look-up table}

As a potentially more accurate alternative to a regression function, a lookup-table approach was also considered. In a proof-of-concept simulation study (Bröde et al. 2008), the computing speed (\#calculations $\cdot \mathrm{s}^{-1}$ ) of using on background storage a lookup-table defined over a four-dimensional grid by $\mathrm{Ta}, \mathrm{Tr}-\mathrm{Ta}$, va and $\mathrm{rH}$ was determined for two variants: (i) interpolating linearly from the values of the 16 
$\left(=2^{4}\right)$ neighbouring grid points, (ii) retrieving the component wise nearest neighbour without interpolation. The simulations demonstrated the expected trade-off between the two categories of performance, speed and accuracy. The approach with interpolation performed more accurately, but slower (70-80 calculations $\left.\cdot \mathrm{s}^{-1}\right)$ than the nearest neighbour algorithm (150-220 calculations $\left.\cdot \mathrm{s}^{-1}\right)$, although they both met the minimum requirements concerning computing speed $\left(\sim 20\right.$ calculations $\left.\cdot \mathrm{s}^{-1}\right)$. The measurements indicated that total speed was mainly determined by the I/O (input-output) operations accompanied by low CPU (central processing unit) load, suggesting that the approach is suitable in multitasking applications on server environments. Storing the data table in the central memory may further accelerate total speed. E.g. a grid with 100 steps in each of the 4 dimensions defined by the climatic parameters will require about 0.2 GBytes, if UTCI data are stored in two byte integers. This is possible when the information on climate may be implicitly included in the table position on a regular grid.

In order to facilitate the implementation of this approach, users may refer to the Online Resource ESM 4 providing for a table of the offsets (= UTCI - Ta, cf. Equation 1) for the thermal conditions covered by the grid dataset.

\section{Accuracy of simplified computation}

Three alternative approaches to the calculation of UTCI have been considered, which vary in computing speed (\#calculations $\cdot \mathrm{s}^{-1}$ ): (i) use of the physiological model $\left(\sim 1 \mathrm{~s}^{-1}\right)$, (ii) look-up table with grid interpolation $\left(\sim 100 \mathrm{~s}^{-1}\right)$, (iii) polynomial regression function $\left(>100000 \mathrm{~s}^{-1}\right)$.

In order to make a statement on the accuracy, the calculated values should desirably be compared to a-priori known analytical solutions. For the reference conditions UTCI should be equal to air temperature by definition, so Figure 11 shows the offsets, i.e. the deviations to air temperature of the UTCI values computed by the three methods for the reference conditions with Ta ranging from $-50{ }^{\circ} \mathrm{C}$ to $+50{ }^{\circ} \mathrm{C}$. The deviations for the UTCI values directly computed by the physiological model were limited by the air temperature resolution $(0.2 \mathrm{~K})$ of the reference data applied in the UTCI calculations, with rmse $<0.1 \mathrm{~K}$. Using the lookup-table with grid interpolation also showed small deviations with rmse < $0.1 \mathrm{~K}$. However, the interpolated values were obtained from a grid with $1 \mathrm{~K}$ 
resolution in air temperature, and with humidity, thermal radiation and wind speed according to the reference conditions. As a result, the interpolation was carried out in one dimension (Ta) only, not in four dimensions. Thus the obtained deviations for the reference conditions might be too optimistically small when extrapolating to the general case. The polynomial regression yielded a small median bias of $0.2 \mathrm{~K}$ with rmse $=0.5 \mathrm{~K}$, which was about half the value obtained from the model fit to all conditions (cf. above). The maximum absolute deviations were somewhat above $1 \mathrm{~K}$.

The error in approximating UTCI by the two simplified calculation methods was further assessed by running the physiological simulation model for a random sample of 1000 control run conditions of the general circulation model ECHAM 4 (cf. Figure 2) and by comparing the computed UTCI to the values approximated by interpolation from the lookup table and by the regression function, respectively. Figure 12 illustrates the approximation errors demonstrating an absolute median bias lower than $0.1 \mathrm{~K}$ for both calculation methods, but a lower rmse of $0.4 \mathrm{~K}$ for the grid interpolation scheme compared to the rmse of $2.8 \mathrm{~K}$ for the polynomial regression function, which showed large errors especially at higher wind speeds above $20 \mathrm{~m} / \mathrm{s}$. Excluding the 51 observations with va $>20 \mathrm{~m} / \mathrm{s}$ from the analysis reduced the rmse to $1.2 \mathrm{~K}$ for the regression function and to $0.3 \mathrm{~K}$ for the look-up table.

Summarised, depending on the requirements on precision of the special application scenario the fast calculation of UTCI seems to be possible with acceptable accuracy by using a polynomial regression function. The accuracy might be improved by the application of a look-up table with grid interpolation.

\section{Usage guidelines}

Computing UTCI values according to Eq. 1 by utilising the detailed information on the simplified calculation procedures from the Online Resources ESM 3 and ESM 4, or by using the software and the web-based application available from the project's website (http://www.utci.org), is straightforward, given the user has the required input on air temperature, wind speed, humidity and mean radiant temperature at hand. This section provides some details which have to be considered in the practical application of the operational procedure. 


\section{Range of validity}

The regression function as well as the look-up table approach to accelerated UTCI computation rely on the simulation data calculated on a grid of relevant combinations of Ta, Tr, va, pa. Thus these procedures are only valid within the bounds of this data grid: $-50{ }^{\circ} \mathrm{C} \leq \mathrm{Ta} \leq+50{ }^{\circ} \mathrm{C},-30{ }^{\circ} \mathrm{C} \leq \mathrm{Tr}-\mathrm{Ta} \leq+70{ }^{\circ} \mathrm{C}$, $0.5 \mathrm{~m} / \mathrm{s} \leq \mathrm{va} \leq 30.3 \mathrm{~m} / \mathrm{s}, 5 \% \leq \mathrm{rH} \leq 100 \%$ (with pa $<50 \mathrm{hPa}$ ).

The range of the meteorological parameters obtained from the control run (19711980) of the general circulation model ECHAM 4 (Stendel and Roeckner 1998) showed that these boundaries do not impose any severe restrictions for routine application. For wind speeds and relative humidity values below $0.5 \mathrm{~m} / \mathrm{s}$ or $5 \%$, respectively, the user is advised to use the lower bounds for the calculations. Similarly, for Ta $<-50{ }^{\circ} \mathrm{C}$, the offset, i.e. the difference UTCI - Ta (cf. Equation 1), should be calculated for the lower bound and then applied to compute UTCI according to Equation 2.

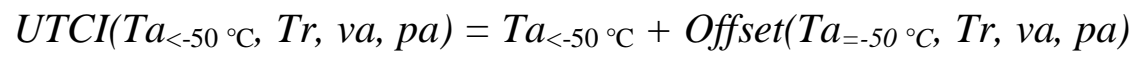

\section{Input of wind speed}

Following meteorological conventions (e.g. Spagnolo and De Dear 2003), wind speed (va) is taken as the value $10 \mathrm{~m}$ above the ground level. The UTCI-Fiala model of thermoregulation internally applies a formula (Oke 1987) to calculate the local wind speed profile at the body level. If wind speed measurements are only available from a height $(\mathrm{x} \mathrm{m})$ different from $10 \mathrm{~m}$, the user should apply the same formula to convert the measured wind speed $\left(\mathrm{va}_{\mathrm{xm}}\right)$ to the required input va according to Equation 3.

$$
v a=v a_{x m} \cdot \operatorname{LOG}(10 / 0.01) / \operatorname{LOG}(x / 0.01)
$$

\section{Mean radiant temperature}

The mean radiant temperature $(\mathrm{Tr})$ is an input parameter into UTCI integrating the effects of short wave and long wave radiant heat fluxes from solar irradiation and from surroundings with different surface temperatures. Tr is defined as "the temperature of an imaginary isothermal black enclosure in which a solid body or occupant would exchange the same amount of heat by radiation as in the actual nonuniform enclosure“ (The Commission for Thermal Physiology of the 
International Union of Physiological Sciences 2003; Gonzalez et al. 1974). The calculation of the mean radiant temperatures for biometeorological applications is often complex and several procedures exist to determine $\operatorname{Tr}$ for indoor or outdoor settings (ISO 7726 1998; Matzarakis et al. 2010; Lindberg et al. 2008; Thorsson et al. 2007; Blazejczyk et al. 1993). These were considered by the COST Action 730 Working Group 2 "Meteorological and environmental data", who also provided the error analysis with respect to UTCI calculations (see Weihs et al. 2011 in this special issue).

\section{Discussion}

UTCI was calculated as an equivalent temperature for a data grid resulting from more than 100000 thermophysiological simulations performed by the UTCI-Fiala multi-node model which cover the relevant range of meteorological input parameters in terms of air and mean radiant temperatures, water vapour pressure and wind speed. Summarising the main characteristics of UTCI, it can be noted that

the approach adopts the definition of UTCI as the air temperature of the reference condition with the same dynamic response of the physiological model incorporating an adaptive clothing model as calculated for the actual condition;

the reference condition is characterised by an activity level corresponding to walking $4 \mathrm{~km} / \mathrm{h}$ and by an environment determined by calm air (wind speed $0.5 \mathrm{~m} / \mathrm{s} 10 \mathrm{~m}$ above the ground, corresponding to approximately 0.3 $\mathrm{m} / \mathrm{s}$ at the person level), no additional thermal irradiation and $50 \%$ relative humidity, but vapour pressure capped at $20 \mathrm{hPa}$;

- the dynamic response was determined by principal component analysis as the linear combination of the short term $(30 \mathrm{~min})$ and long term $(120 \mathrm{~min})$ reactions of 7 parameters of thermal strain (rectal, mean skin and face temperatures, sweating, skin wettedness, skin blood flow, shivering);

- the consistency of the approach was demonstrated by the good agreement with air temperature $(\mathrm{UTCI}=\mathrm{Ta})$ for the reference conditions.

The good agreement of the median response of single variables to UTCI with the values obtained for the reference conditions suggested that the categorization of 
climatic situations into conditions of heat or cold stress could be based on the responses to the reference conditions.

As calculating the UTCI equivalent temperatures by running the thermoregulation model repeatedly could be too complicated and time-consuming for routine applications, several options to simplify this calculation were considered for the operational procedure. The user may chose between the more accurate look-up table of pre-calculated index values for a grid of all relevant combinations of climate parameters, and the polynomial regression equation predicting the UTCI equivalent temperature values over the same grid, providing for very fast calculation procedures.

The results of sensitivity analyses performed within this action indicate that UTCI reflects the expected effects of wind speed, thermal radiation and humidity. The psychrometric chart describing the mutual effects of temperature and humidity in warm climates was in good agreement with the charts obtained for physiological data from human experiments as described elsewhere (Kampmann 2000) and also in this issue (Kampmann et al. 2011). The extra heat load by thermal radiation and its interaction with wind speed was also recently observed with work clothes (Bröde et al. 2010b). In the cold, UTCI indicated more pronounced effects of wind speed compared to the wind chill temperature (Bröde et al. 2010a). This is probably related to different assumptions underlying both approaches. Whereas the wind chill temperature focuses on facial cooling under steady state conditions with an assumed core temperature of $38^{\circ} \mathrm{C}$ (Osczevski and Bluestein 2005), UTCI considers the dynamic response of the whole body under clothing conditions which tend to 'under-dress' the people (Havenith et al. 2011). In summary, the plausible responses to wind speed, humidity and thermal radiation as well in the heat as in the cold suggest that in this regard UTCI may be universally useable in the research and in the major areas of application of human biometeorology.

\section{Future developments}

After the operational procedure has been made available, UTCI has to demonstrate its potential in future applications. First encouraging results from using UTCI to predict thermal comfort in a subtropical urban area are presented in this issue (Bröde et al. 2011). 
Although UTCI is distinguished from other approaches to assess the outdoor thermal comfort (Kenny et al. 2009a; Höppe 1999; Huang 2007) by the degree of detail applied in modelling the influence of human thermoregulation and of clothing on the human response to the outdoor thermal environment, some aspects need further development.

The influence of physiological adaptation or acclimation is currently not reflected by the physiological model and thus by UTCI. One approach may be to adapt the criteria applied in assessing the thermal environment (Koppe and Jendritzky 2005), however, a more consistent and flexible alternative might be to incorporate the effects of acclimation into the model, e.g. by considering the physiological processes leading to the reduction of resting core temperature (Kampmann et al. 2008b; De Dear 1989), but also by considering adaptation in the psychological part of the model (Lin et al. 2011).

Currently, UTCI focuses on the assessment of the thermal environment as characterised by temperature, radiation, wind speed and humidity, but uses fixed values of metabolic rate and, conditional on air temperature, of clothing insulation. However, the outdoor thermal comfort may also be influenced by the activity level, i.e. metabolic rate (Vanos et al. 2010; Kenny et al. 2009b), special clothing, as e.g. required when assessing the thermal load of the working population (Bröde et al. 2010b; Havenith et al. 2008; Kjellstrom et al. 2009), and by rain and wet clothing (Havenith et al. 2009; Munir et al. 2010). Further applications may also aim at providing guidance on the choice of clothing depending on the climatic conditions and activity level (Morabito et al. 2008). The concept underlying UTCI to simulate the human response by a sophisticated model provides for a flexibility which would also allow extending the index by systematically varying metabolic rate and clothing properties in extensive simulation runs. But as the effort increases exponentially with the number of dimensions considered, this has to be left to future research activities.

\section{Acknowledgements}

This work was supported within the COST Action 730 "Towards a Universal Thermal Climate Index UTCI for Assessing the Thermal Environment of the Human Being". The stimulating input from the lively discussions with our colleagues within this action is thankfully appreciated. COST is supported by the EU RTD Framework Programme. 


\section{References}

Blazejczyk K, Nilsson H, Holmér I (1993) Solar Heat Load on Man - Review of Different Methods of Estimation. Int J Biometeorol 37:125-132 doi: 10.1007/BF01212621

Bröde P, Fiala D, Kampmann B, Havenith G, Jendritzky G (2009) Der Klimaindex UTCI Multivariate Analyse der Reaktion eines thermophysiologischen Simulationsmodells. In: Gesellschaft für Arbeitswissenschaft (ed.) Arbeit, Beschäftigungsfähigkeit und Produktivität im 21 Jahrhundert. GfA-Press, Dortmund, pp 705-708

Bröde P, Jendritzky G, Fiala D, Havenith G (2010a) The Universal Thermal Climate Index UTCI in operational use. In: Adapting to change: new thinking on comfort. Network for Comfort and Energy Use in Buildings, London, 6pp.

Bröde P, Kampmann B, Havenith G, Jendritzky G (2008) Effiziente Berechnung des klimatischen Belastungs-Index UTCI. In: Gesellschaft für Arbeitswissenschaft (ed.) Produkt- und ProduktionsErgonomie - Aufgabe für Entwickler und Planer. GfA-Press, Dortmund, pp 271-274

Bröde P, Krüger EL, Rossi FA, Fiala D (2011) Predicting Urban Outdoor Thermal Comfort by the Universal Thermal Climate Index UTCI - A Case Study from Southern Brazil. Int J Biometeorol in this special issue

Bröde P, Kuklane K, Candas V, den Hartog EA, Griefahn B, Holmér I, Meinander H, Nocker W, Richards M, Havenith G (2010b) Heat Gain From Thermal Radiation Through Protective Clothing With Different Insulation, Reflectivity and Vapour Permeability. Int J Occup Saf Ergon 16:231244

Bruse M (2009) Analysing human outdoor thermal comfort and open space usage with the MultiAgent System BOTworld. Seventh International Conference on Urban Climate (ICUC-7). ICUC, Yokohama, 4 pp on DVD

De Dear RJ (1989) Diurnal and seasonal variations in the human thermal climate of Singapore. Singapore Journal of Tropical Geography 10:13-26

Fiala D, Havenith G, Bröde P, Kampmann B, Jendritzky G (2011) UTCI-Fiala multi-node model of human temperature regulation and thermal comfort. Int $\mathrm{J}$ Biometeorol in this special issue doi: 10.1007/s00484-011-0424-7

Fiala D, Lomas KJ, Stohrer M (1999) A computer model of human thermoregulation for a wide range of environmental conditions: the passive system. J Appl Physiol 87:1957-1972

Fiala D, Lomas KJ, Stohrer M (2001) Computer prediction of human thermoregulatory and temperature responses to a wide range of environmental conditions. Int J Biometeorol 45:143-159 Fiala D, Lomas KJ, Stohrer M (2003) First principles modeling of thermal sensation responses in steady-state and transient conditions. ASHRAE Transactions 109:179-186

Gagge AP, Fobelets AP, Berglund PE (1986) A standard predictive index of human response to the thermal environment. ASHRAE Transactions 92:709-731.

Gagge AP, Stolwijk JA, Nishi Y (1971) An effective temperature scale based on a simple model of human physiological regulatory response. ASHRAE Transactions 77:247-262 
Gonzalez RR, Nishi Y, Gagge AP (1974) Experimental evaluation of standard effective temperature a new biometeorological index of man's thermal discomfort. Int J Biometeorol 18:1 15 doi: 10.1007/BF01450660

Härdle W, Simar L (2007) Applied Multivariate Statistical Analysis. Springer-Verlag, Berlin Havenith G, Bröde P, Candas V, den Hartog E, Holmér I, Kuklane K, Meinander H, Nocker W, Richards M, Wang X (2009) Evaporative cooling in protective clothing: efficiency in relation to distance to skin. In: Castellani JW, Endrusick TL (eds.) Environmental ergonomics XIII. University of Wollongong, Wollongong, pp 20-24

Havenith G, Fiala D, Blazejczyk K, Richards M, Bröde P, Holmér I, Rintamäki H, Benshabat Y, Jendritzky G (2011) The UTCI-Clothing Model. Int J Biometeorol in this special issue Havenith G, Richards MG, Wang X, Bröde P, Candas V, den Hartog E, Holmér I, Kuklane K, Meinander H, Nocker W (2008) Apparent latent heat of evaporation from clothing: attenuation and "heat pipe" effects. J Appl Physiol 104:142-149 doi: 10.1152/japplphysiol.00612.2007

Höppe P (1999) The physiological equivalent temperature - a universal index for the biometeorological assessment of the thermal environment. Int J Biometeorol 43:71-75 doi: $10.1007 / \mathrm{s} 004840050118$

Höppe P (2002) Different aspects of assessing indoor and outdoor thermal comfort. Energy and Buildings 34:661-665 doi: 10.1016/S0378-7788(02)00017-8

Houghten FC, Yagloglou CP (1923) Determining lines of equal comfort. Trans Am Soc Heat Ventil Eng 29:163-176

Huang J (2007) Prediction of air temperature for thermal comfort of people in outdoor environments. Int J Biometeorol 51:375-382 doi: 10.1007/s00484-006-0083-2

ISO 7726 (1998) Ergonomics of the thermal environment - Instruments for measuring physical quantities. International Organisation for Standardisation, Geneva

Jendritzky G (2007) Scientific Report. In: COST Domain Committee "ESSEM" (ed) COST 730 Monitoring Progress Report 06/02/2005 - 31/12/2006. COST Office, Bruxelles, pp 7-13 Jendritzky G, Havenith G, Weihs P, Batchvarova E, De Dear RJ (2007) The universal thermal climate index UTCI goal and state of COST action 730. In: Mekjavic IB, Kounalakis SN, Taylor NAS (eds.) Environmental ergonomics XII. Biomed, Ljubljana, pp 509-512

Kampmann B (2000) Zur Physiologie der Arbeit in warmem Klima. Ergebnisse aus Laboruntersuchungen und aus Feldstudien im Steinkohlenbergbau. Bergische Universität, Wuppertal

Kampmann B, Bröde P, Fiala D (2011) Physiological responses to temperature and humidity compared to the assessment by UTCI, WGBT and PHS. Int J Biometeorol in this special issue doi: 10.1007/s00484-011-0410-0

Kampmann B, Bröde P, Havenith G, Jendritzky G (2008a) Der Entwicklungsstand des klimatischen Belastungs-Index UTCI (Universal Thermal Climate Index). In: Gesellschaft für Arbeitswissenschaft (ed.) Produkt- und Produktions-Ergonomie - Aufgabe für Entwickler und Planer. GfA-Press, Dortmund, pp 243-246 
Kampmann B, Bröde P, Schütte M, Griefahn B (2008b) Lowering of resting core temperature during acclimation is influenced by exercise stimulus. Eur J Appl Physiol 104:321-327 doi: 10.1007/s00421-007-0658-6

Kenny N, Warland J, Brown R, Gillespie T (2009a) Part A: Assessing the performance of the COMFA outdoor thermal comfort model on subjects performing physical activity. Int $\mathbf{J}$

Biometeorol 53:415-428 doi: 10.1007/s00484-009-0226-3

Kenny N, Warland J, Brown R, Gillespie T (2009b) Part B: Revisions to the COMFA outdoor thermal comfort model for application to subjects performing physical activity. Int J Biometeorol 53:429-441 doi: 10.1007/s00484-009-0227-2

Kjellstrom T, Gabrysch S, Lemke B, Dear K (2009) The 'Hothaps' programme for assessing climate change impacts on occupational health and productivity: an invitation to carry out field studies. Glob Health Action 2: doi: 10.3402/gha.v2i0.2082

Koppe C, Jendritzky G (2005) Inclusion of short-term adaptation to thermal stresses in a heat load warning procedure. Meteorologische Zeitschrift 14:271-278 doi:10.1127/0941-2948/2005/0030 Levine RV, Norenzayan A (1999) The Pace of Life in 31 Countries. Journal of Cross-Cultural Psychology 30:178-205

Lin TP, de Dear R, Hwang RL (2011) Effect of thermal adaptation on seasonal outdoor thermal comfort. International Journal of Climatology 31:302-312 doi: 10.1002/joc.2120

Lindberg F, Holmer B, Thorsson S (2008) SOLWEIG 1.0 - Modelling spatial variations of 3D radiant fluxes and mean radiant temperature in complex urban settings. Int J Biometeorol 52:697713 doi: 10.1007/s00484-008-0162-7

Matzarakis A, Rutz F, Mayer H (2010) Modelling radiation fluxes in simple and complex environments: basics of the RayMan model. Int J Biometeorol 54:131-139 doi: 10.1007/s00484009-0261-0

Morabito M, Crisci A, Cecchi L, Modesti P, Maracchi G, Gensini G, Orlandini S (2008) A biometeorological procedure for weather forecast to assess the optimal outdoor clothing insulation. Eur J Appl Physiol 104:221-228 doi: 10.1007/s00421-008-0686-X Morgenroth O (2007) Die Gehgeschwindigkeit als Merkmal des Lebenstempos. Zeit und Handeln - Psychologie der Zeitbewältigung. W. Kohlhammer GmbH, Stuttgart, pp 108-155

Munir A, Takada S, Matsushita T, Kubo H (2010) Prediction of human thermophysiological responses during shower bathing. Int J Biometeorol 54:165-178 doi: 10.1007/s00484-009-0265-9 Oke TR (1987) Boundary Layer Climates, $2^{\text {nd }}$ edn. Routledge, London Osczevski R, Bluestein M (2005) The new wind chill equivalent temperature chart. Bulletin Am Meteorol Soc 86:1453-1458

Parsons KC (2003) Human Thermal Environments: The Effects of Hot, Moderate and Cold Environments on Human Health, Comfort and Performance, $2^{\text {nd }}$ edn. Taylor and Francis, London Psikuta A, Fiala D, Lascheschwski.G., Jendritzky G, Richards M, Blazejczyk K, Mekjavic IB, Rintamäki H, De Dear RJ, Havenith G (2011) Evaluation of the Fiala multi-node thermophysiological model for UTCI application. Int J Biometeorol in this special issue Sedgewick R (1992) Algorithms in C++. Addison-Wesley, Reading 
Spagnolo J, De Dear RJ (2003) A human thermal climatology of subtropical Sydney. International Journal of Climatology 23:1383-1395 doi: 10.1002/joc.939

Staiger H, Bucher K, Jendritzky G (1997) Gefühlte Temperatur. Die physiologisch gerechte Bewertung von Wärmebelastung und Kältestress beim Aufenthalt im Freien in der Maßzahl Grad Celsius. Annalen der Meteorologie 33:100-107

Stendel M, Roeckner E (1998) Impacts of horizontal resolution on simulated climate statistics in ECHAM4. MPI Report 253. Max-Planck-Institute for Meteorology, Hamburg Stolwijk JAJ (1971) A mathematical model of physiological temperature regulation in man. NASA contractor report, NASA CR-1855, Washington DC

The Commission for Thermal Physiology of the International Union of Physiological Sciences (2003) Glossary of terms for thermal physiology. Journal of Thermal Biology 28:75-106 doi: 10.1016/S0306-4565(02)00055-4

Thorsson S, Lindberg F, Eliasson I, Holmer B (2007) Different methods for estimating the mean radiant temperature in an outdoor urban setting. International Journal of Climatology 27:19831993 doi: 10.1002/joc. 1537

Vanos J, Warland J, Gillespie T, Kenny N (2010) Review of the physiology of human thermal comfort while exercising in urban landscapes and implications for bioclimatic design. Int $\mathrm{J}$ Biometeorol 54:319-334 doi: 10.1007/s00484-010-0301-9

Weihs P, Staiger H, Tinz B, Batchvarova E, Rieder H, Vuilleumier L, Maturilli M, Jendritzky G (2011) The uncertainty of UTCI due to uncertainties in the determination of radiation fluxes derived from measured and observed meteorological data. Int J Biometeorol in this special issue doi: 10.1007/s00484-011-0416-7

Wiseman R (2010) Pace of Life - a Quirkology experiment. http://www.paceoflife.co.uk/. Accessed 2 July 2010 


\section{Tables}

Table 1 Variables available from the output of the UTCI-Fiala thermophysiological model after simulated exposure times of 30, 60, 90 and $120 \mathrm{~min}$

\begin{tabular}{lll} 
Variable & Abbreviation & Unit \\
\hline rectal temperature & Tre & ${ }^{\circ} \mathrm{C}$ \\
mean skin temperature & Tskm & ${ }^{\circ} \mathrm{C}$ \\
facial skin temperature & Tskfc & ${ }^{\circ} \mathrm{C}$ \\
hand skin temperature & Tskhn & ${ }^{\circ} \mathrm{C}$ \\
total net heat loss & Qsk & $\mathrm{W}$ \\
evaporative (latent) heat loss & Esk & $\mathrm{W}$ \\
sweat rate & Mskdot & $\mathrm{g} / \mathrm{min}$ \\
metabolic heat production & Metab & $\mathrm{W}$ \\
heat generated by shivering & Shiv & $\mathrm{W}$ \\
skin wettedness & wettA & $\%$ of body area \\
skin blood flow & VblSk & $\%$ of basal value \\
cardiac output & sVbl & $\%$ of basal value
\end{tabular}


Table 2 Arithmetic means (AM) and standard deviations (SD) of 7 indicators of thermal strain after 30 and $120 \mathrm{~min}$, as well as the standardised scoring coefficients (sc) obtained by principal component analysis and correlation coefficients (r) of each variable with the response index computed from the individual values (x) by $\sum_{i} s c_{i} \times \frac{x_{i}-A M_{i}}{S D_{i}}$

\begin{tabular}{|c|c|c|c|c|c|}
\hline Variable (unit) & Minute & $\mathbf{A M}$ & SD & sc & $\mathbf{r}$ \\
\hline \multirow{2}{*}{ rectal temperature $\left({ }^{\circ} \mathrm{C}\right)$} & 30 & 36.99 & 0.39 & 0.097 & 0.90 \\
\hline & 120 & 37.43 & 1.15 & 0.101 & 0.93 \\
\hline \multirow{2}{*}{ mean skin temperature $\left({ }^{\circ} \mathrm{C}\right)$} & 30 & 31.44 & 4.09 & 0.101 & 0.93 \\
\hline & 120 & 30.18 & 5.62 & 0.103 & 0.95 \\
\hline \multirow{2}{*}{ facial skin temperature $\left({ }^{\circ} \mathrm{C}\right)$} & 30 & 22.40 & 15.75 & 0.087 & 0.80 \\
\hline & 120 & 19.63 & 18.77 & 0.089 & 0.82 \\
\hline \multirow{2}{*}{ skin blood flow (\% of basal value) } & 30 & 195.87 & 330.82 & 0.100 & 0.92 \\
\hline & 120 & 247.97 & 406.01 & 0.099 & 0.91 \\
\hline \multirow{2}{*}{ sweat rate $(\mathrm{g} / \mathrm{min})$} & 30 & 3.61 & 9.38 & 0.090 & 0.82 \\
\hline & 120 & 7.59 & 14.40 & 0.098 & 0.90 \\
\hline \multirow{2}{*}{ skin wettedness ( $\%$ of body area) } & 30 & 10.72 & 11.39 & 0.076 & 0.70 \\
\hline & 120 & 17.10 & 14.85 & 0.070 & 0.64 \\
\hline \multirow{2}{*}{ heat generated by shivering (W) } & 30 & 1.18 & 6.32 & -0.036 & -0.33 \\
\hline & 120 & 8.96 & 23.18 & -0.056 & -0.52 \\
\hline
\end{tabular}


Table 3 UTCI equivalent temperatures categorised in terms of thermal stress

\section{UTCI range $\left({ }^{\circ} \mathrm{C}\right)$ Stress category}

\begin{tabular}{ll}
\hline above +46 & extreme heat stress \\
+38 to +46 & very strong heat stress \\
+32 to +38 & strong heat stress \\
+26 to +32 & moderate heat stress \\
+9 to +26 & no thermal stress ${ }^{\text {a }}$ \\
+9 to 0 & slight cold stress \\
0 to -13 & moderate cold stress \\
-13 to -27 & strong cold stress \\
-27 to -40 & very strong cold stress \\
below -40 & extreme cold stress
\end{tabular}

\footnotetext{
${ }^{\mathrm{a}}$ The UTCI subinterval $+18{ }^{\circ} \mathrm{C}$ to $+26^{\circ} \mathrm{C}$ within this category complies with the definition of the "thermal comfort zone" (The Commission for Thermal Physiology of the International Union of Physiological Sciences 2003).
} 


\section{Figure Captions}

Figure 1 Concept of UTCI derived as equivalent temperature from the dynamic multivariate response of the thermophysiological UTCI-Fiala model, which was coupled with a clothing model Figure 2 Air temperatures and vapour pressure values from more than 65000 land grid points of the control run (CTRL) of the general circulation model ECHAM 4 (Stendel and Roeckner 1998) with running averages (dotted line) and with the humidity values of the reference condition (black solid line)

Figure 3 Dendrograms resulting from hierarchically clustering 48 (A) and 14 (B) variables, respectively (cf. Table 1 for abbreviations)

Figure 4 Response index values calculated from 48 variables (black) and 14 variables (grey), respectively, for reference conditions (solid lines) and for two non-reference conditions (dots) with derived UTCI values indicated by dashed lines

Figure 5 Effect of relative humidity $(\mathrm{rH})$ on the offset (= UTCI - Ta, cf. Equation 1) calculated for $\operatorname{Tr}=\mathrm{Ta}$ and $\mathrm{va}=0.5 \mathrm{~m} / \mathrm{s}$ at air temperatures below $20^{\circ} \mathrm{C}$

Figure 6 Psychrometric chart with UTCI calculated for $\operatorname{Tr}=\mathrm{Ta}$ and $\mathrm{va}=0.5 \mathrm{~m} / \mathrm{s}$ in relation to air temperatures above $20^{\circ} \mathrm{C}$ and to water vapour pressure. The dark grey line marks the level of humidity for the reference condition

Figure 7 Effect of different wind speeds $10 \mathrm{~m}$ above ground (va) on the offset (= UTCI - Ta, cf. Equation 1) in relation to air temperature with humidity and mean radiant temperature set according to the reference condition

Figure 8 UTCI in relation to radiant heat load expressed as $\mathrm{Tr}$ - Ta with individual linear regression lines for different values of Ta and with humidity and wind speed set according to the reference condition. The overall regression equation was calculated for the UTCI data with Ta increasing from $20^{\circ} \mathrm{C}$ to $50{ }^{\circ} \mathrm{C}$ in steps of $1 \mathrm{~K}$

Figure 9 The offset (= UTCI - Ta, cf. Equation 1) in relation to air temperatures below $20{ }^{\circ} \mathrm{C}$ calculated at different levels of radiant heat load expressed as $\mathrm{Tr}-\mathrm{Ta}$ for reference wind speed (va $=0.5 \mathrm{~m} / \mathrm{s}$, black lines) and increased wind speed (va $=13.5 \mathrm{~m} / \mathrm{s}$, dark grey lines). Relative humidity was set to $50 \%$ according to the reference condition

Figure 10 Rectal temperature after $2 \mathrm{~h}$ (A) and dynamic thermal sensation averaged over $2 \mathrm{~h}$ exposure time (B) related to UTCI. Box-Plots were derived with UTCI rounded to $2 \mathrm{~K}$ wide bins. Dots mark the 5th and 95th percentile, solid lines mark values under reference conditions

Figure 11 Offsets (= UTCI - Ta, cf. Equation 1) computed for the reference conditions, which are indicative under these conditions for the error in calculating UTCI by direct use of the physiological model's output, by applying a grid interpolation scheme and by a 6th order regression polynomial, respectively 
Figure 12 Error of approximating UTCI values that were computed applying the physiological model for 1000 randomly chosen control runs of the general circulation model ECHAM 4 (Stendel and Roeckner 1998), either by a grid interpolation scheme (grey dots) or by a polynomial regression function (dark dots, open circles denote data with wind speed above $20 \mathrm{~m} / \mathrm{s}$ ). Box plots of the errors are provided for all data on the right side with diamonds marking the $5^{\text {th }}$ and $95^{\text {th }}$ percentiles for the regression function (left box plot) and for the interpolation scheme (right box plot), respectively 
Tskm_120

Tskm_90

Tskm_60

Tskm_30

Tskfc_120

Tskfc_90

Tskfc_60

Tskfc_30

Tskhn_120

Tskhn_90

Tskhn_60

Tskhn_30

Qsk 120

Qsk_90

Qsk_60

Qsk 30

wett $\bar{A} \_120$

wettA-90

Tre_120

Tre_90

Tre_60

Tre-30

Mskdot 30

sVbl_120

sVbl-90

sVbl-60

sVbl 30

Esk_120

Esk 90

Esk_60

Esk_30

Mskdot_120

Mskdot 90

Mskdot 60

VbISk_120

VblSk-90

VblSk_60

VbISk_30

wettA 60

wettA 30

Shiv_-120

Shiv_90

Shiv_60

Metāb_120

Metab-90

Metab_60

Shiv_30

Metab_30

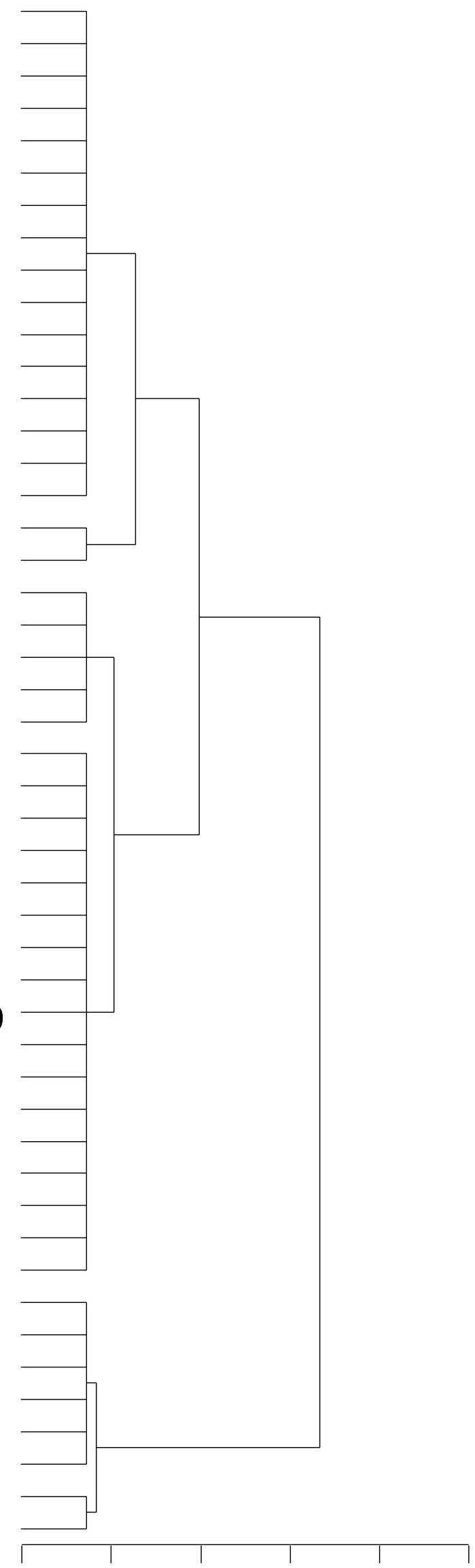

$\begin{array}{llllll}1.0 & 0.9 & 0.8 & 0.7 & 0.6 & 0.5\end{array}$

Proportion of variance explained
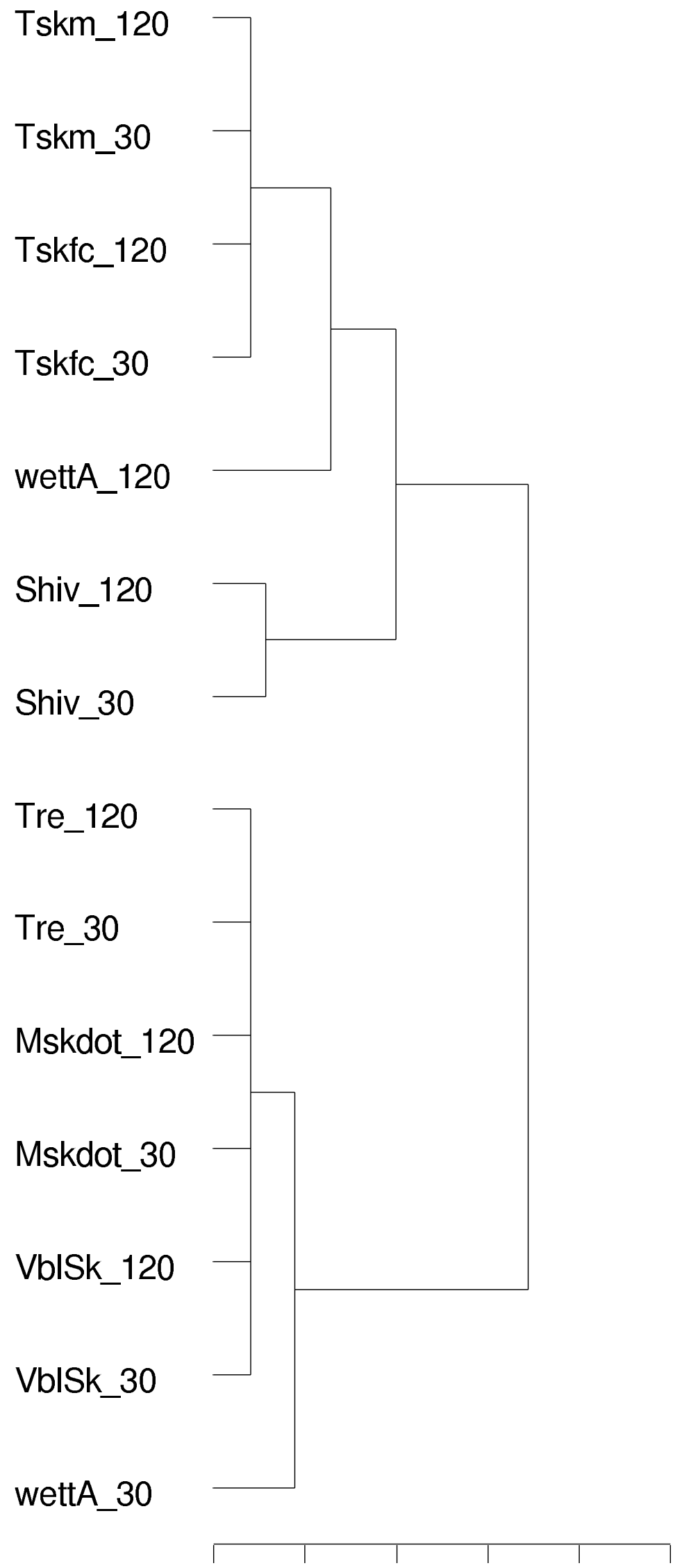

$\begin{array}{llllll}1.0 & 0.9 & 0.8 & 0.7 & 0.6 & 0.5\end{array}$ Proportion of variance explained 


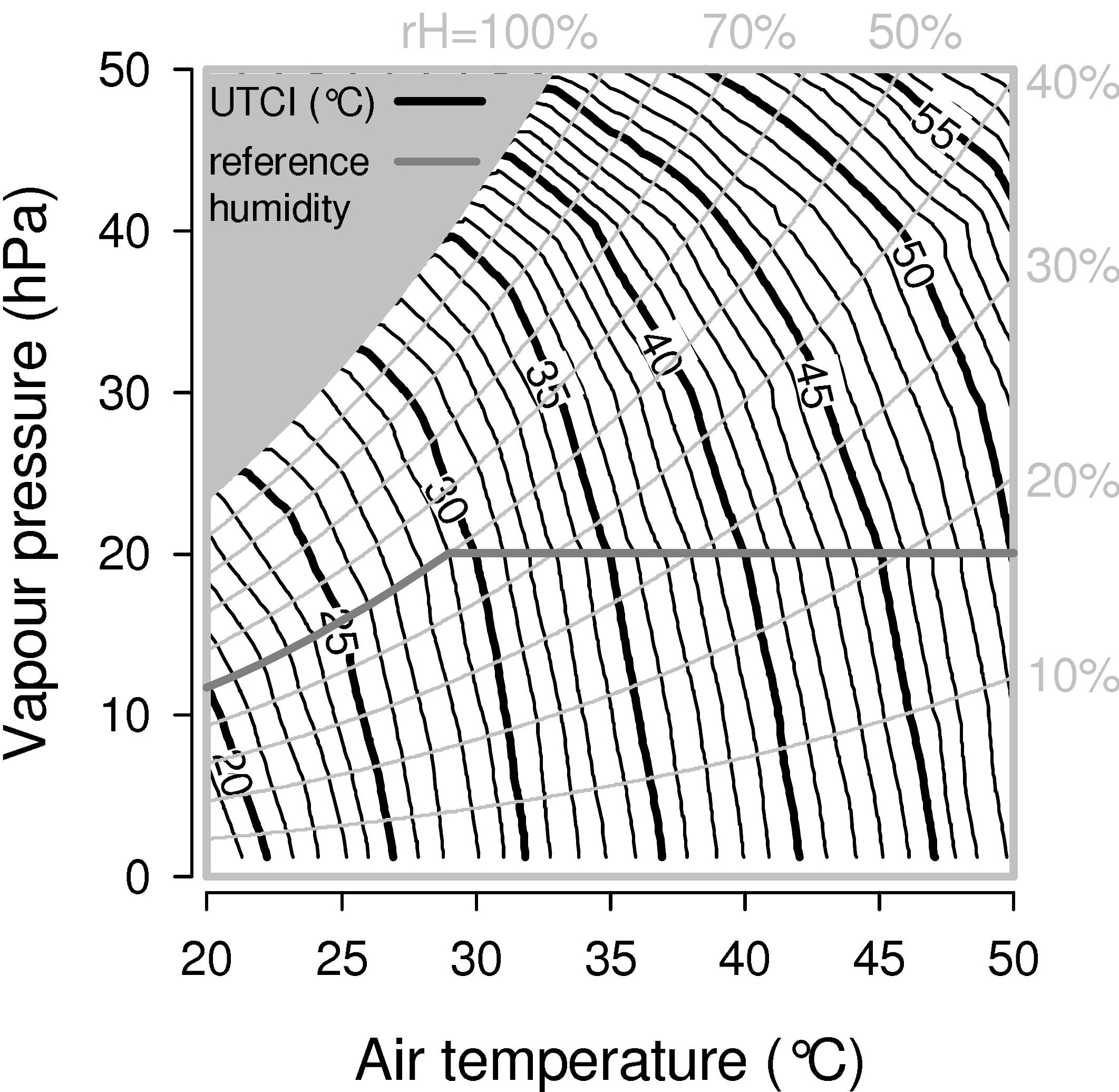


Figure 7

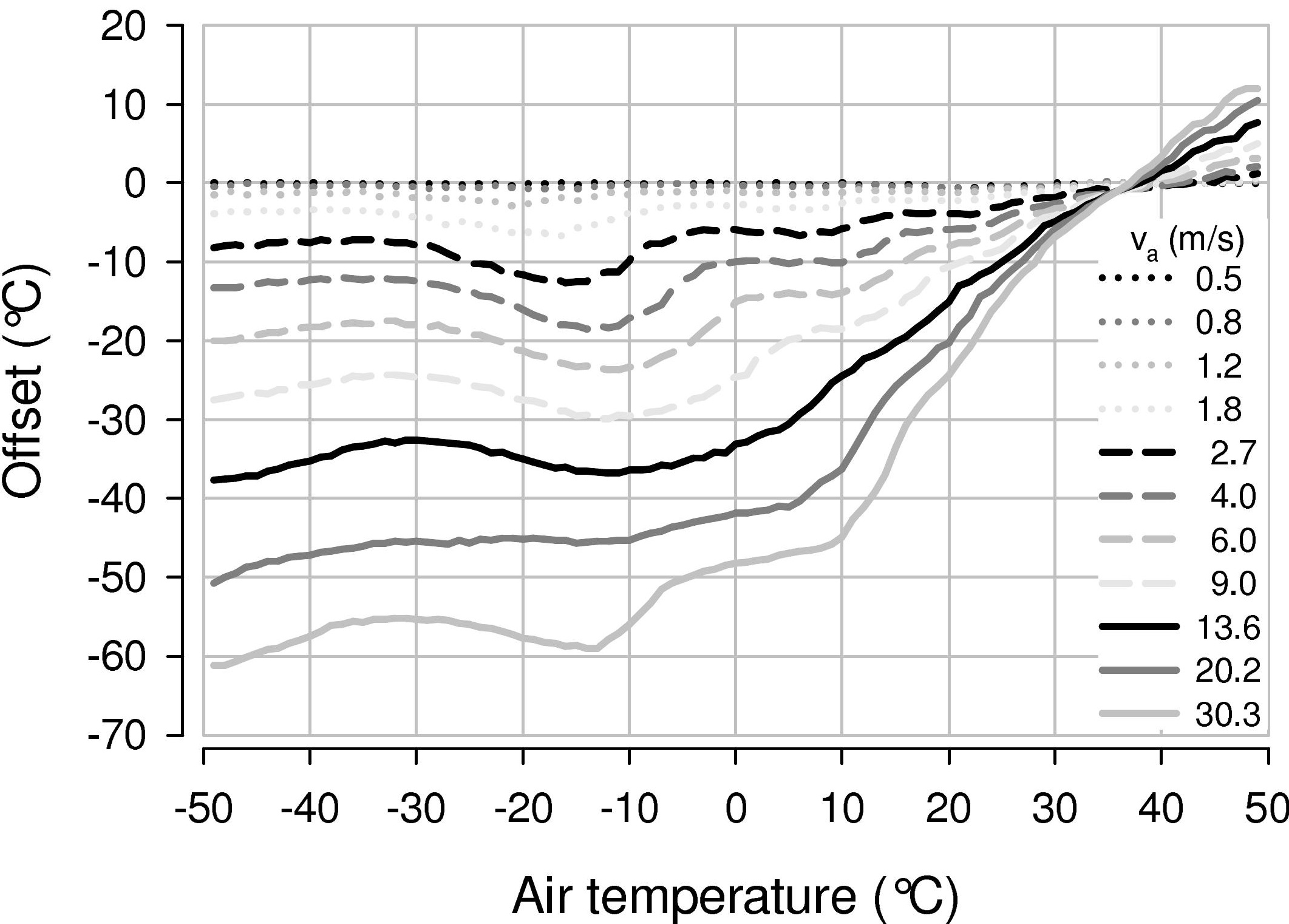


Figure 9

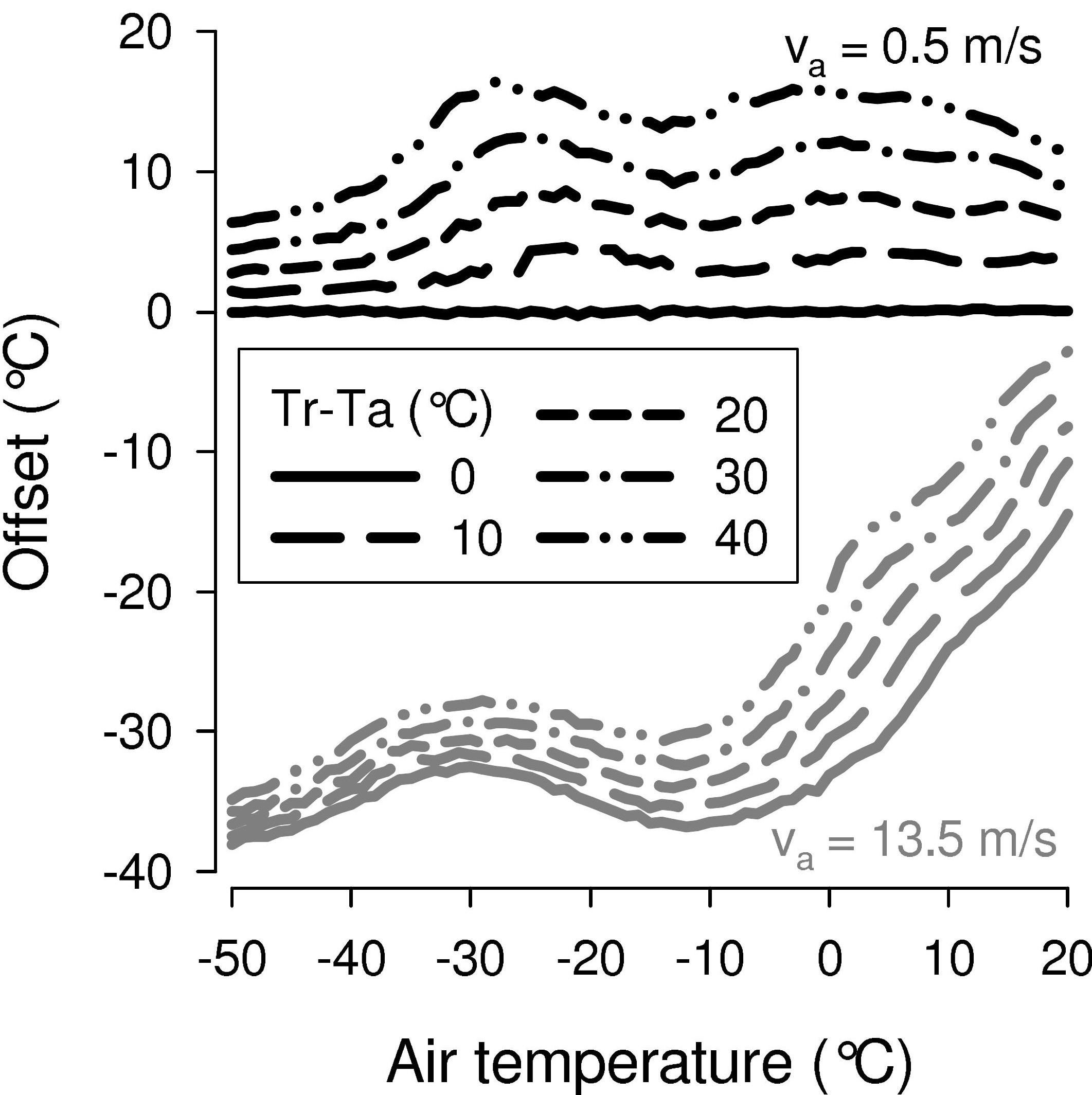


Apure 10

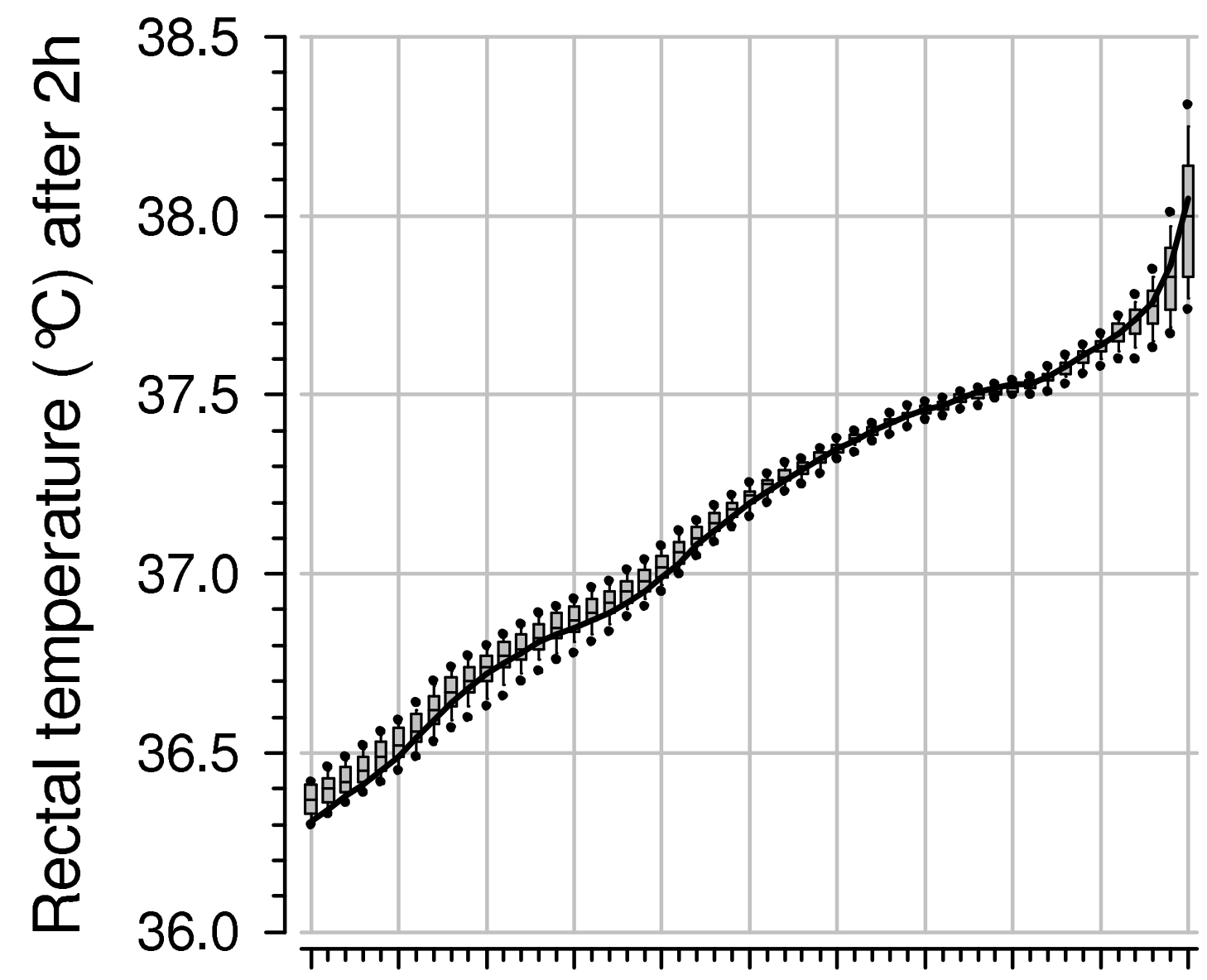

$B$

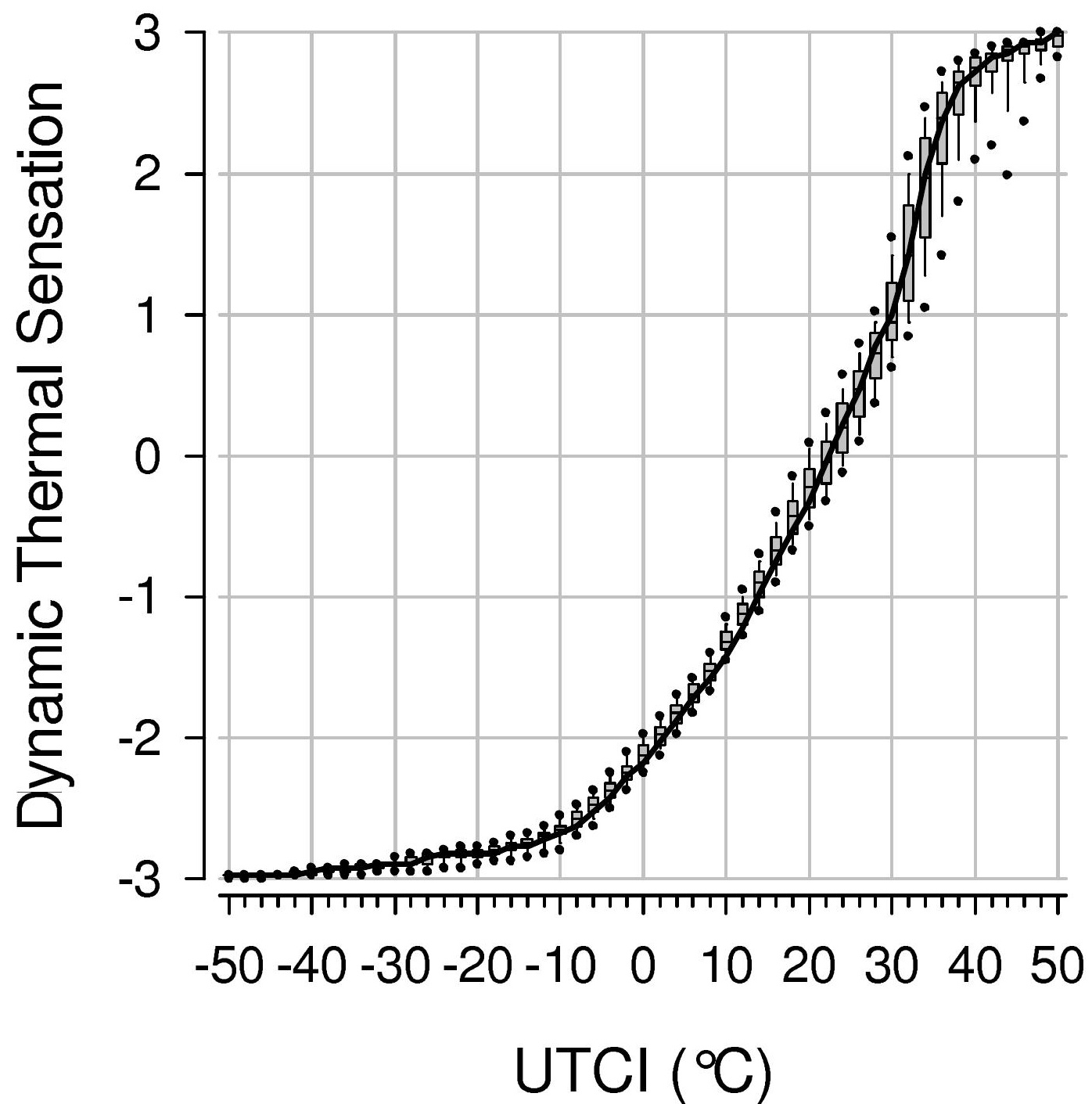




$$
\text { (1.5 }
$$

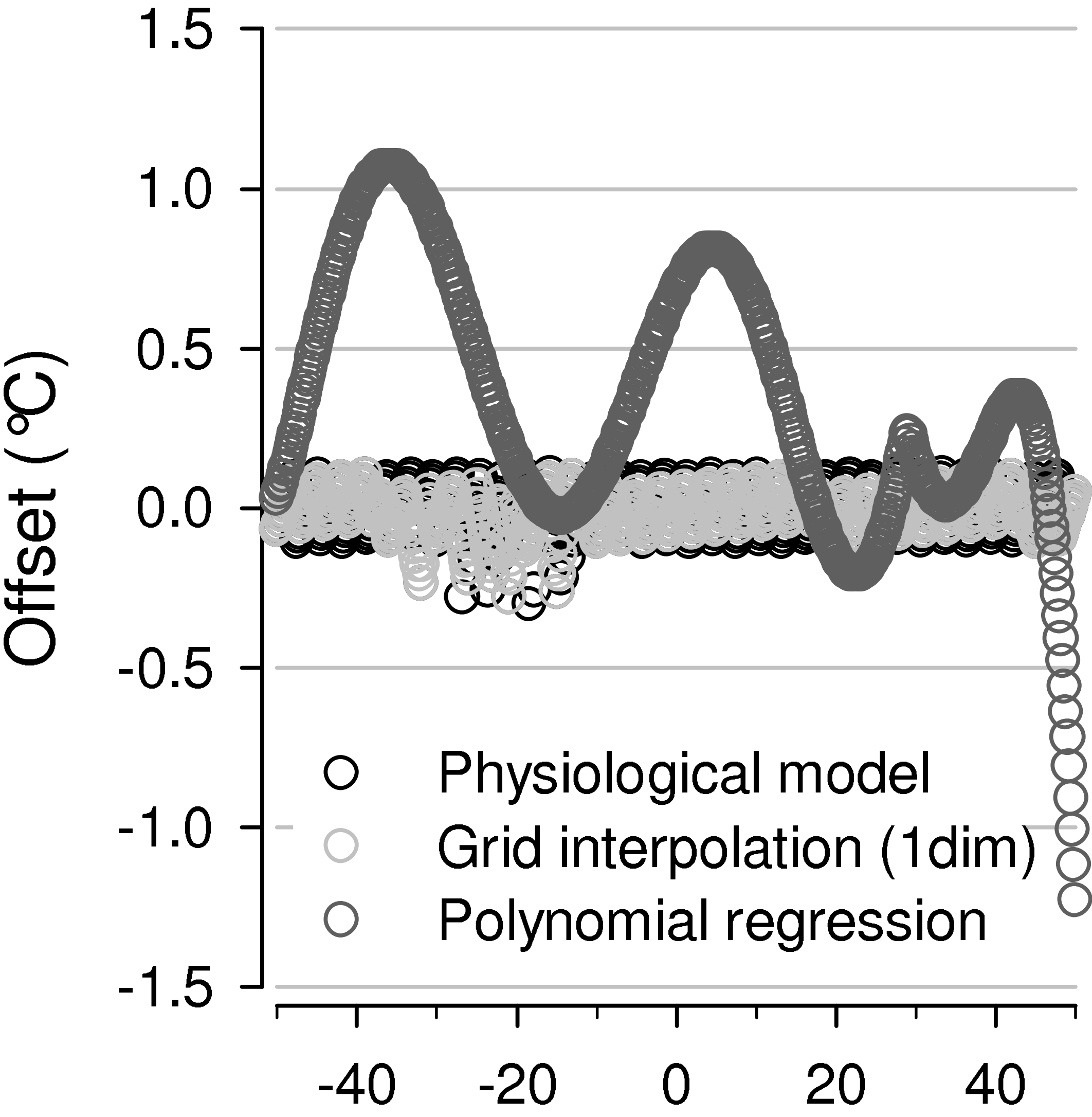

\section{Air temperature $\left({ }^{\circ} \mathrm{C}\right)$}


This Online Resource contains electronic supplementary material (ESM) accompanying the following article submitted to the

International Journal of Biometeorology - Special Issue (UTCI)

Deriving the Operational Procedure for the Universal Thermal Climate Index UTCI

Peter Bröde, Dusan Fiala, Krzysztof Błażejczyk, Ingvar Holmér, Gerd Jendritzky, Bernhard Kampmann, Birger Tinz, George Havenith

Corresponding author:

Peter Bröde

Leibniz Research Centre for Working Environment and Human Factors (IfADo)

Ardeystr. 67, 44139 Dortmund, Germany

Phone +49 2311084225

Fax +49 2311084400

e-mail: broede@ifado.de

ESM 1 Responses to UTCI for the following single variables calculated from the output of the UTCI simulation model

ESM 1a Responses averaged over values after 30, 60, 90 and 120 min vs. UTCI

ESM 1b Responses averaged over values after 30, 60, 90 and 120 min vs. UTCI for the Reference Conditions only

ESM 1c Early (30 $\mathrm{min})$ and late $(120 \mathrm{~min})$ responses vs. UTCI for the Reference Conditions

ESM 2 Criteria used for categorizing values of UTCI in terms of thermal stress

ESM 3 Coefficients of a $6^{\text {th }}$ order polynomial regression function approximating the Offset $=$ UTCI $\mathrm{Ta}$ ) in ${ }^{\circ} \mathrm{C}$ from input values of air temperature $(\mathrm{Ta})$ in ${ }^{\circ} \mathrm{C}$, of wind speed $10 \mathrm{~m}$ above ground level (va) in $\mathrm{m} / \mathrm{s}$, of water vapour pressure (pa) in $\mathrm{kPa}$ and of the difference between mean radiant temperature and air temperature $(\mathrm{tm})$ in ${ }^{\circ} \mathrm{C}$. The equation is valid for the input parameters ranging as follows:

$-50{ }^{\circ} \mathrm{C} \leq \mathrm{Ta} \leq+50{ }^{\circ} \mathrm{C}$,

va $\leq 30.3 \mathrm{~m} / \mathrm{s}$

$-30^{\circ} \mathrm{C} \leq \mathrm{tm} \leq+70^{\circ} \mathrm{C}$

pa $\leq 5 \mathrm{kPa}$ (relative humidity $\leq 100 \%$ )

ESM 4 The TAB-delimited file "ESM_4_Table_Offset.Dat" tabulates values of the Offset (= UTCI - Ta) in ${ }^{\circ} \mathrm{C}$ for different input values of:

Ta: air temperature in ${ }^{\circ} \mathrm{C}$ (range: $-50^{\circ} \mathrm{C}$ to $+50{ }^{\circ} \mathrm{C}$ )

Tr-Ta: difference between mean radiant temperature $(\mathrm{Tr})$ and air temperature in ${ }^{\circ} \mathrm{C}$ $\left(-30{ }^{\circ} \mathrm{C}\right.$ to $\left.+70{ }^{\circ} \mathrm{C}\right)$

va: $\quad$ wind speed in $\mathrm{m} / \mathrm{s}$ measured $10 \mathrm{~m}$ above ground level $(0.5 \mathrm{~m} / \mathrm{s}$ to $30.3 \mathrm{~m} / \mathrm{s})$

$\mathrm{rH}: \quad$ relative humidity in $\%(5 \%$ to $100 \%)$

pa: water vapour pressure in $\mathrm{kPa}(0 \mathrm{kPa}$ to $5 \mathrm{kPa})$ 
Bröde P, Fiala D, Błażejczyk K, Holmér I, Jendritzky G, Kampmann B, Tinz B, Havenith G Deriving the Operational Procedure for the Universal Thermal Climate Index UTCI

ESM 1: Responses to UTCI for the following single variables calculated from the output of the UTCI simulation model

\begin{tabular}{|c|c|c|c|}
\hline & Variable & Abbreviation & Unit \\
\hline 1. & rectal temperature & Tre & ${ }^{\circ} \mathrm{C}$ \\
\hline 2. & mean skin temperature & Tskm & ${ }^{\circ} \mathrm{C}$ \\
\hline 3. & face skin temperature & Tskfc & ${ }^{\circ} \mathrm{C}$ \\
\hline 4. & hand skin temperature & Tskhn & ${ }^{\circ} \mathrm{C}$ \\
\hline 5. & total net heat loss & Qsk & W \\
\hline 6. & evaporative (latent) heat loss & Esk & W \\
\hline 7. & sweat production & SR & $g / h$ \\
\hline 8. & metabolic heat production & Metab & W \\
\hline 9. & heat generated by shivering & Shiv & W \\
\hline 10. & skin wettedness & wettA & $\%$ of body area \\
\hline 11. & skin blood flow & VbISk & $\%$ of basal value \\
\hline 12. & cardiac output & sVbl & $\%$ of basal value \\
\hline 13. & core to skin temperature gradient (Tre-Tskm) & $\mathrm{K}$ & ${ }^{\circ} \mathrm{C}$ \\
\hline 14. & step change in Tskm after entering climate & Tsk_dot & $\mathrm{K} / \min$ \\
\hline 15. & Dynamic Thermal Sensation $(-3 \ldots+3)$ & DTS & nd \\
\hline 16. & time gradient in rectal temperature & D_Tre & $\mathrm{K} / \mathrm{h}$ \\
\hline 17. & time gradient in mean skin temperature & D_Tskm & $\mathrm{K} / \mathrm{h}$ \\
\hline
\end{tabular}

ESM 1a: Responses averaged over values after 30, 60, 90 and 120 min vs. UTCI

ESM 1b: Responses averaged over values after 30, 60, 90 and 120 min vs. UTCI for the Reference Conditions only

ESM 1c: Early (30 min) and late (120 min) responses vs. UTCI for the Reference Conditions 


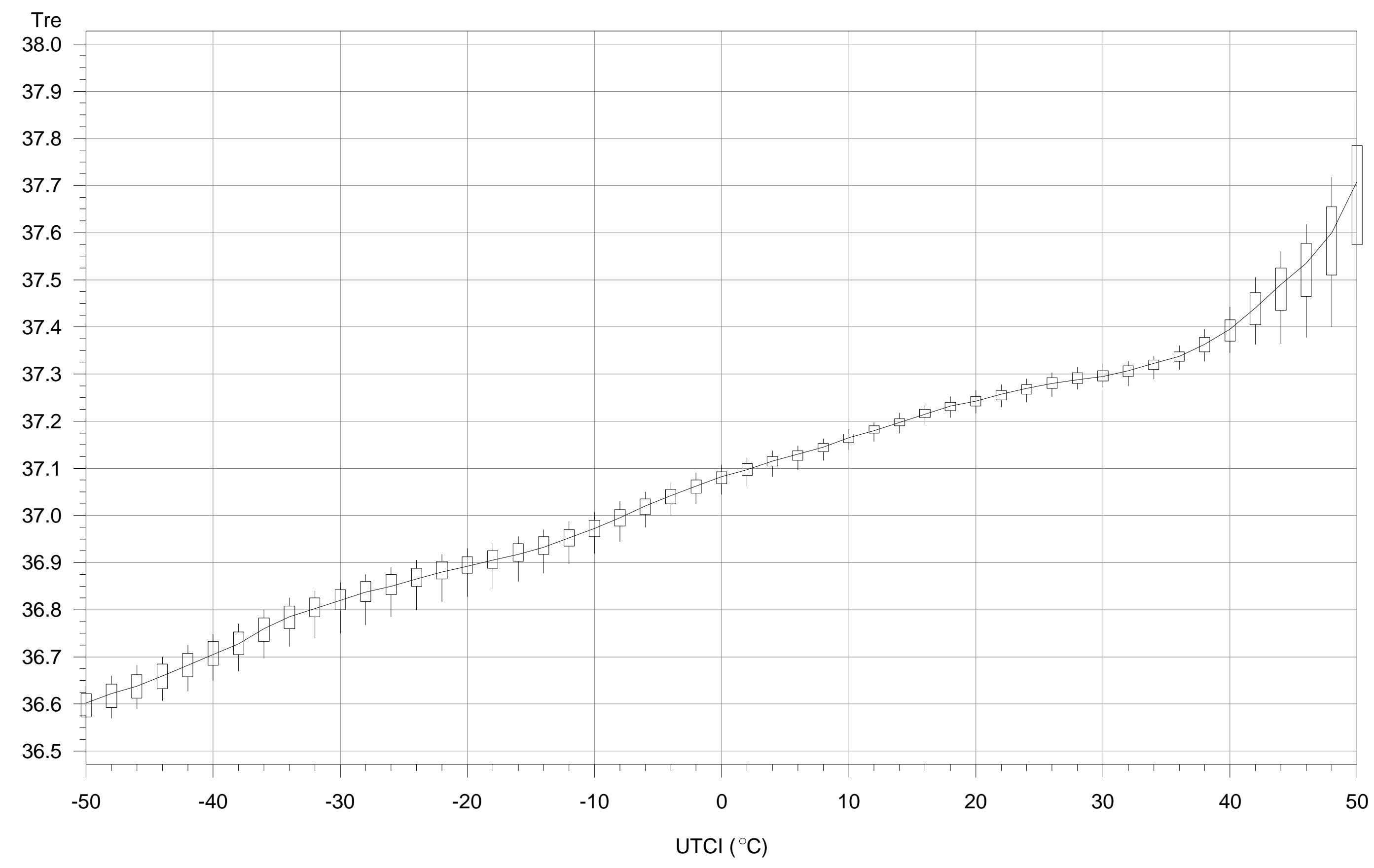

averaged over responses after 30,60, 90 and $120 \mathrm{~min}$ (Box-Plots with joined medians derived with UTCI rounded to $2 \mathrm{~K}$ wide bins) 


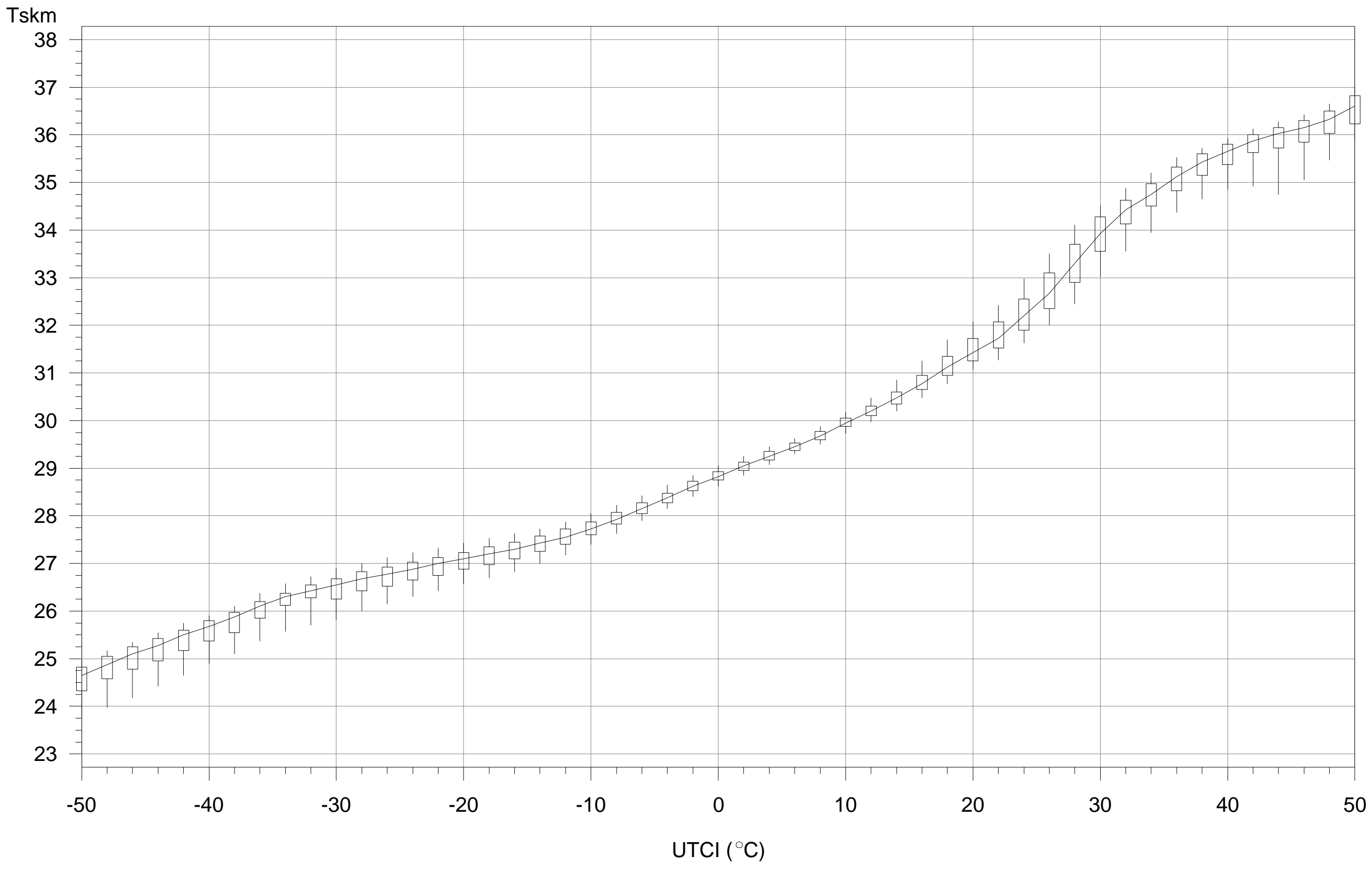

averaged over responses after 30,60, 90 and $120 \mathrm{~min}$ (Box-Plots with joined medians derived with UTCI rounded to $2 \mathrm{~K}$ wide bins) 


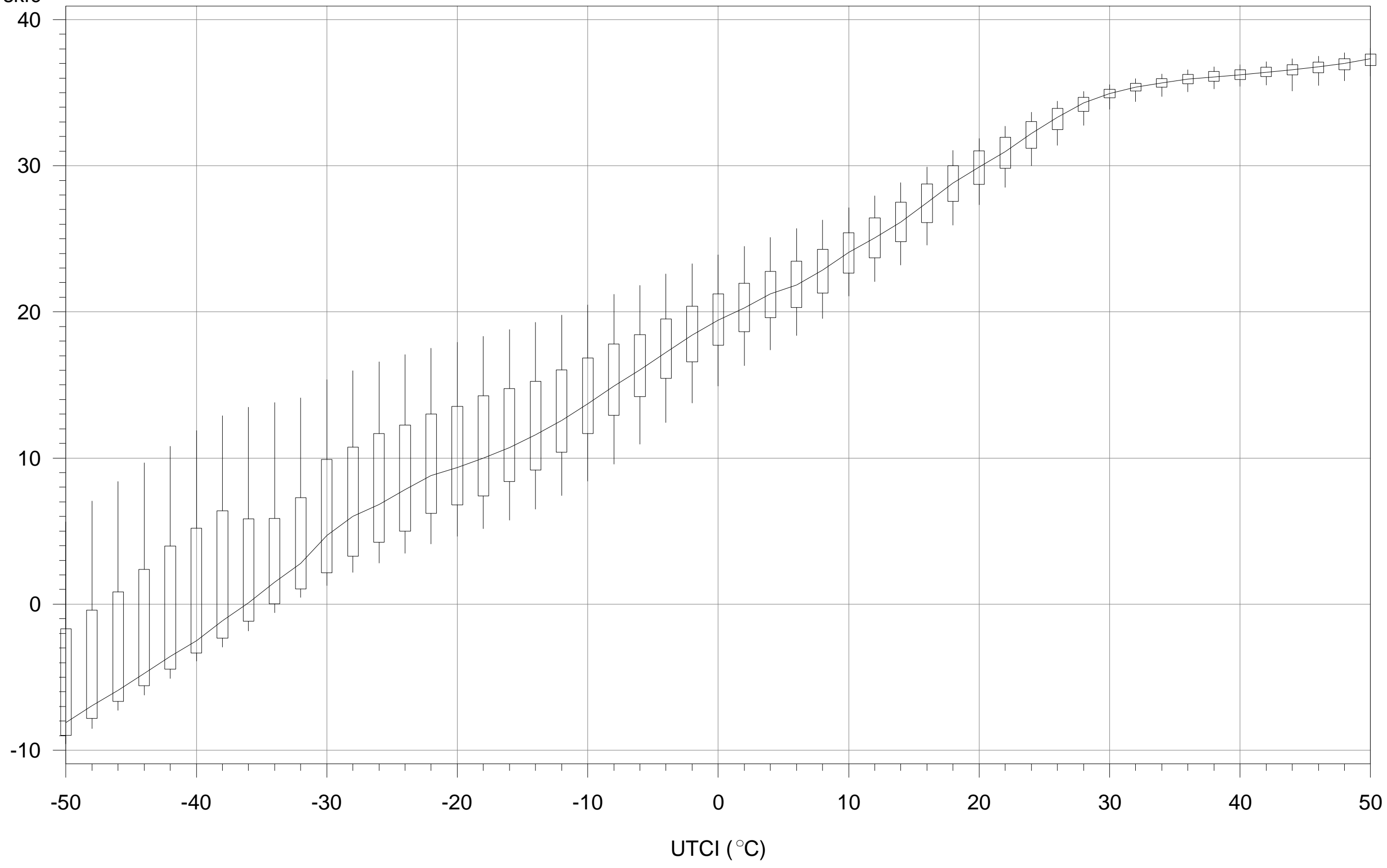

averaged over responses after 30,60, 90 and $120 \mathrm{~min}$ (Box-Plots with joined medians derived with UTCI rounded to $2 \mathrm{~K}$ wide bins) 


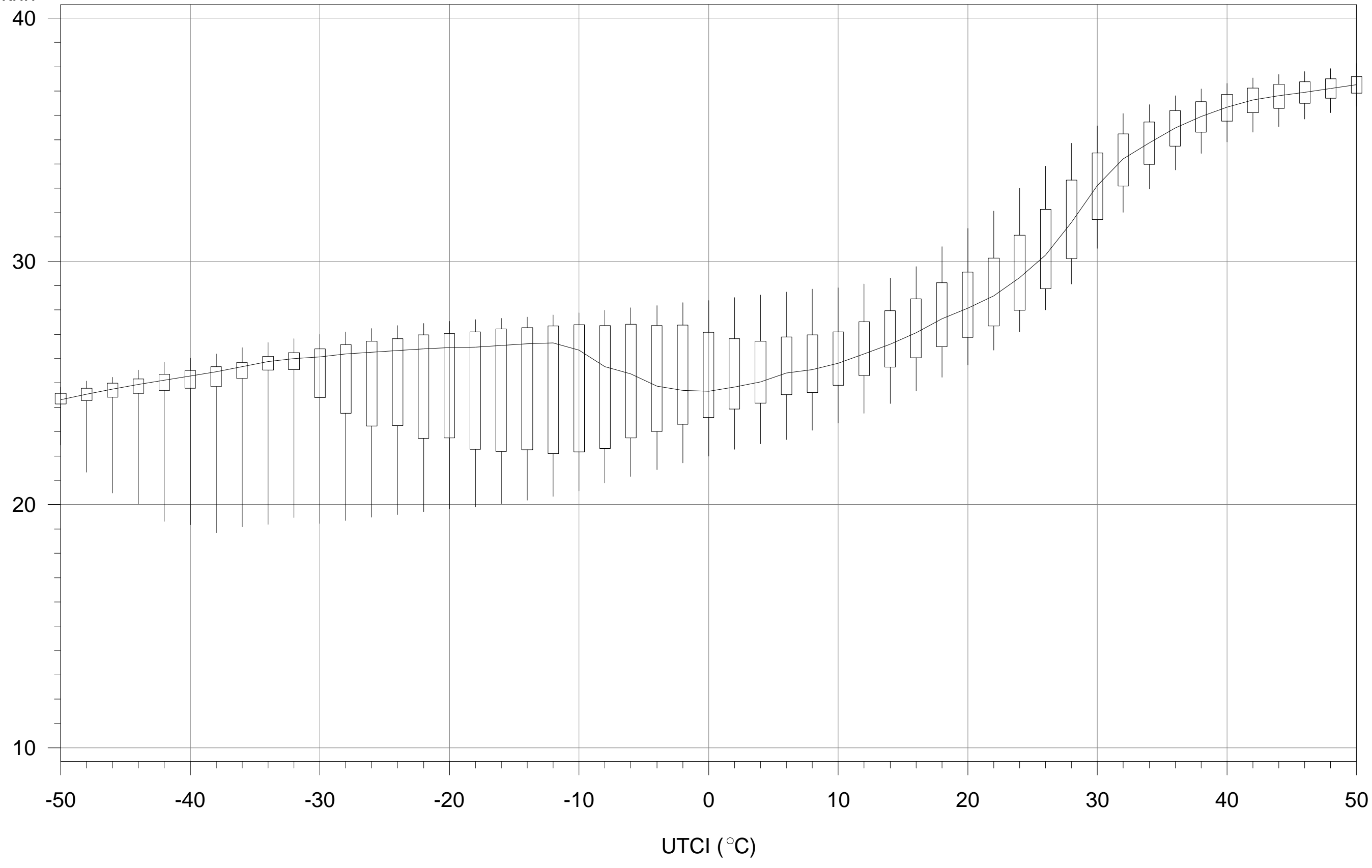

averaged over responses after 30,60, 90 and 120 min (Box-Plots with joined medians derived with UTCI rounded to $2 \mathrm{~K}$ wide bins) 


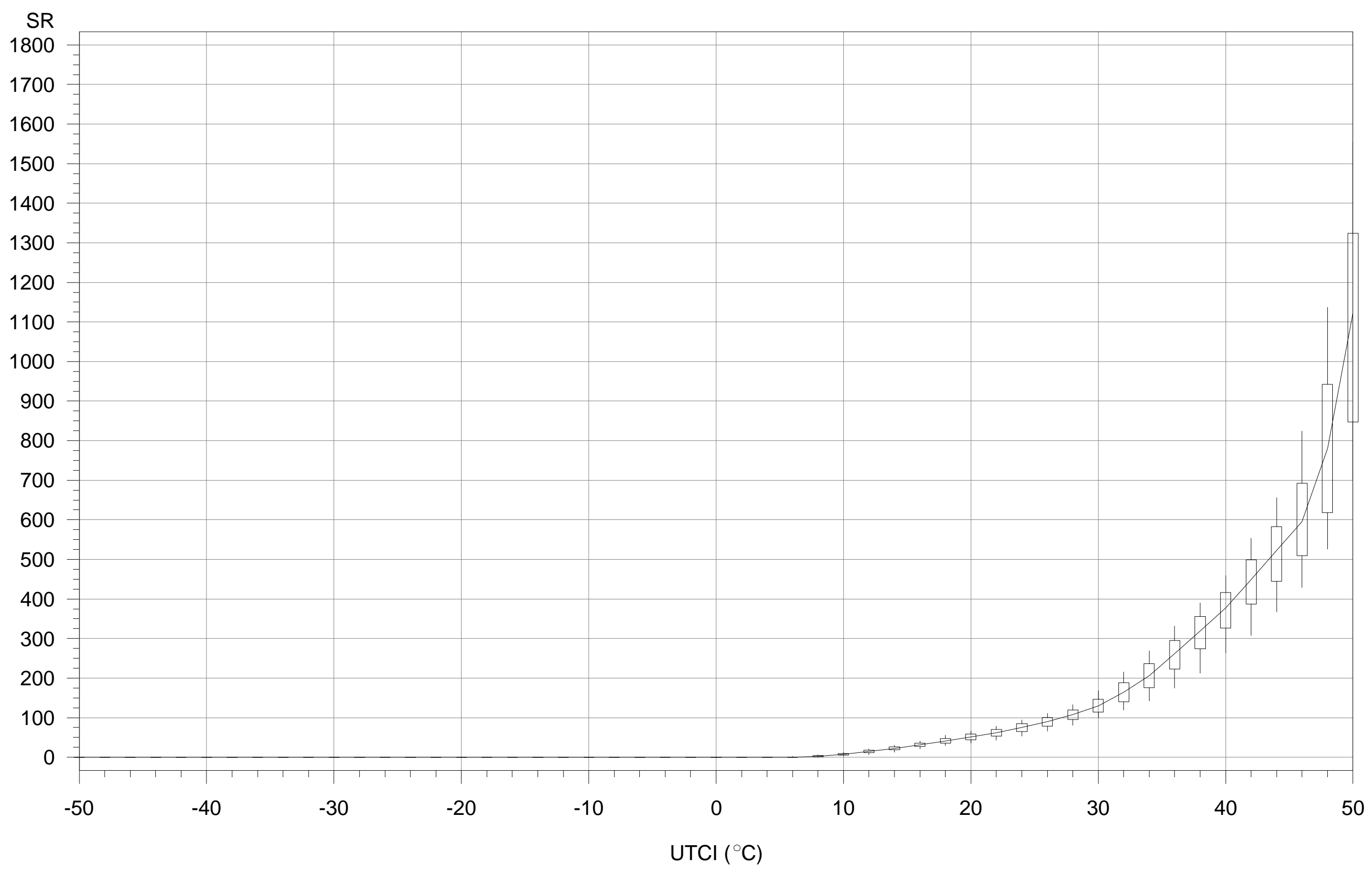

averaged over responses after 30,60, 90 and $120 \mathrm{~min}$ (Box-Plots with joined medians derived with UTCI rounded to $2 \mathrm{~K}$ wide bins) 


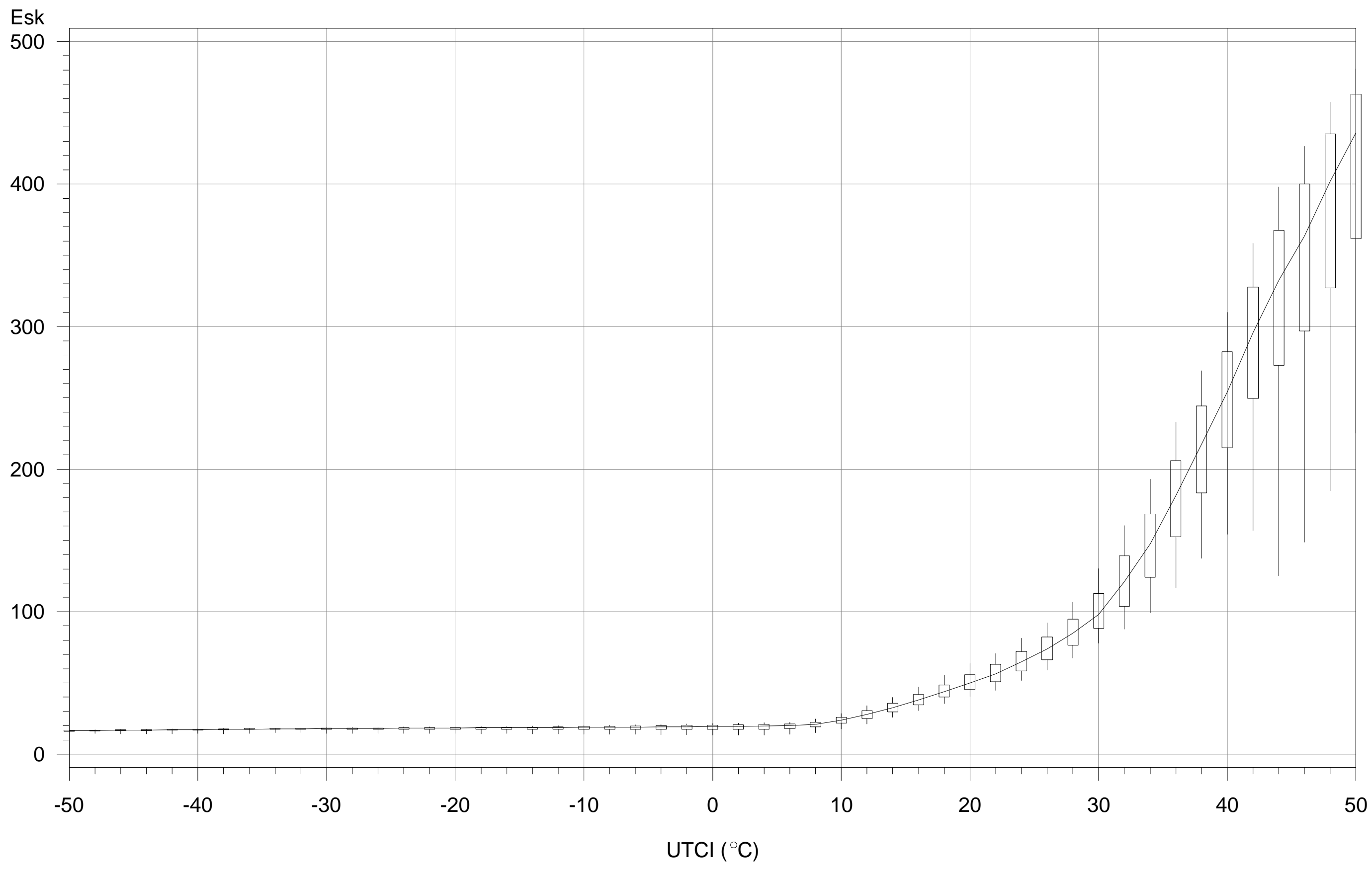

averaged over responses after 30,60, 90 and $120 \mathrm{~min}$ (Box-Plots with joined medians derived with UTCI rounded to $2 \mathrm{~K}$ wide bins) 


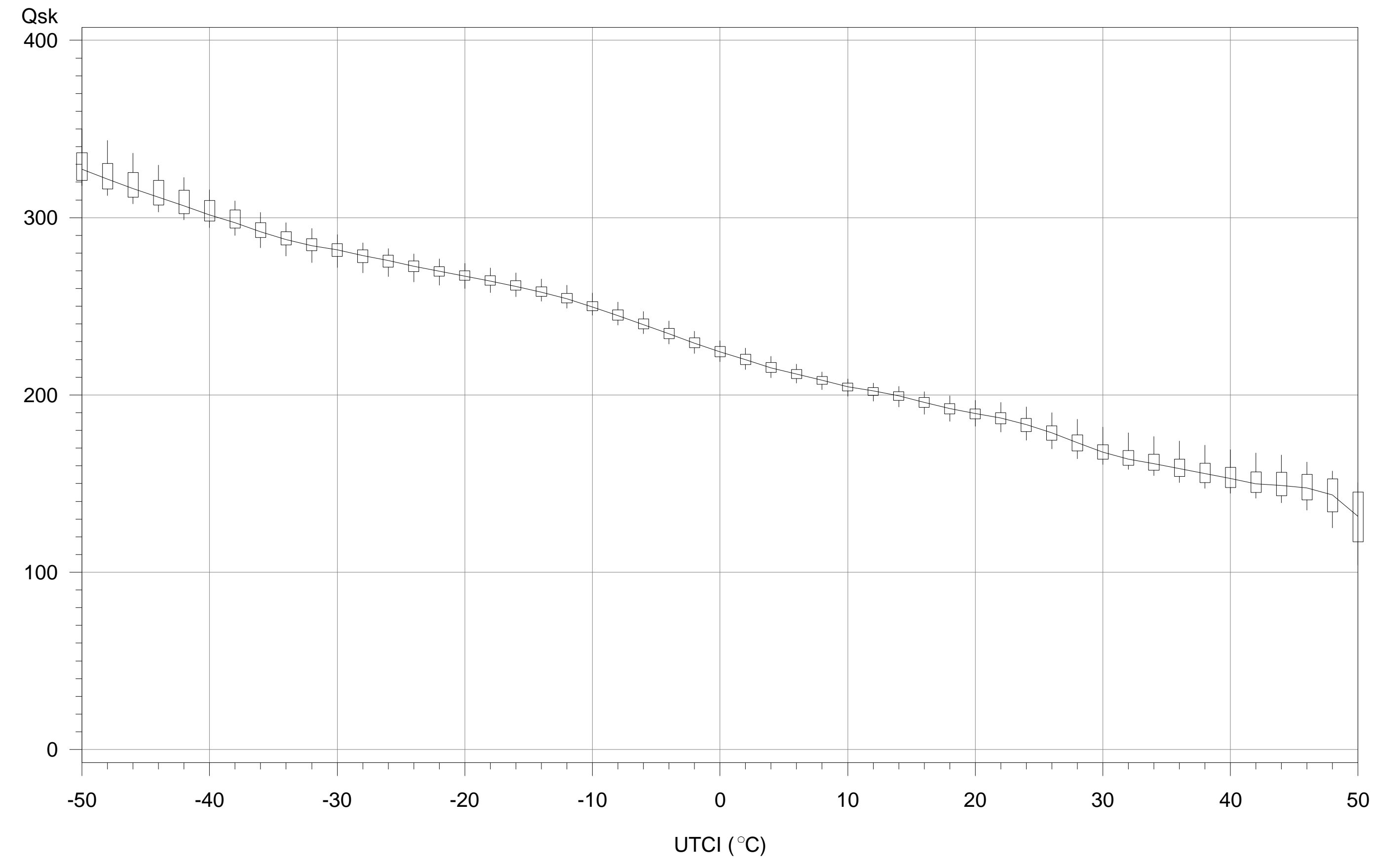

averaged over responses after 30,60, 90 and $120 \mathrm{~min}$ (Box-Plots with joined medians derived with UTCI rounded to $2 \mathrm{~K}$ wide bins) 


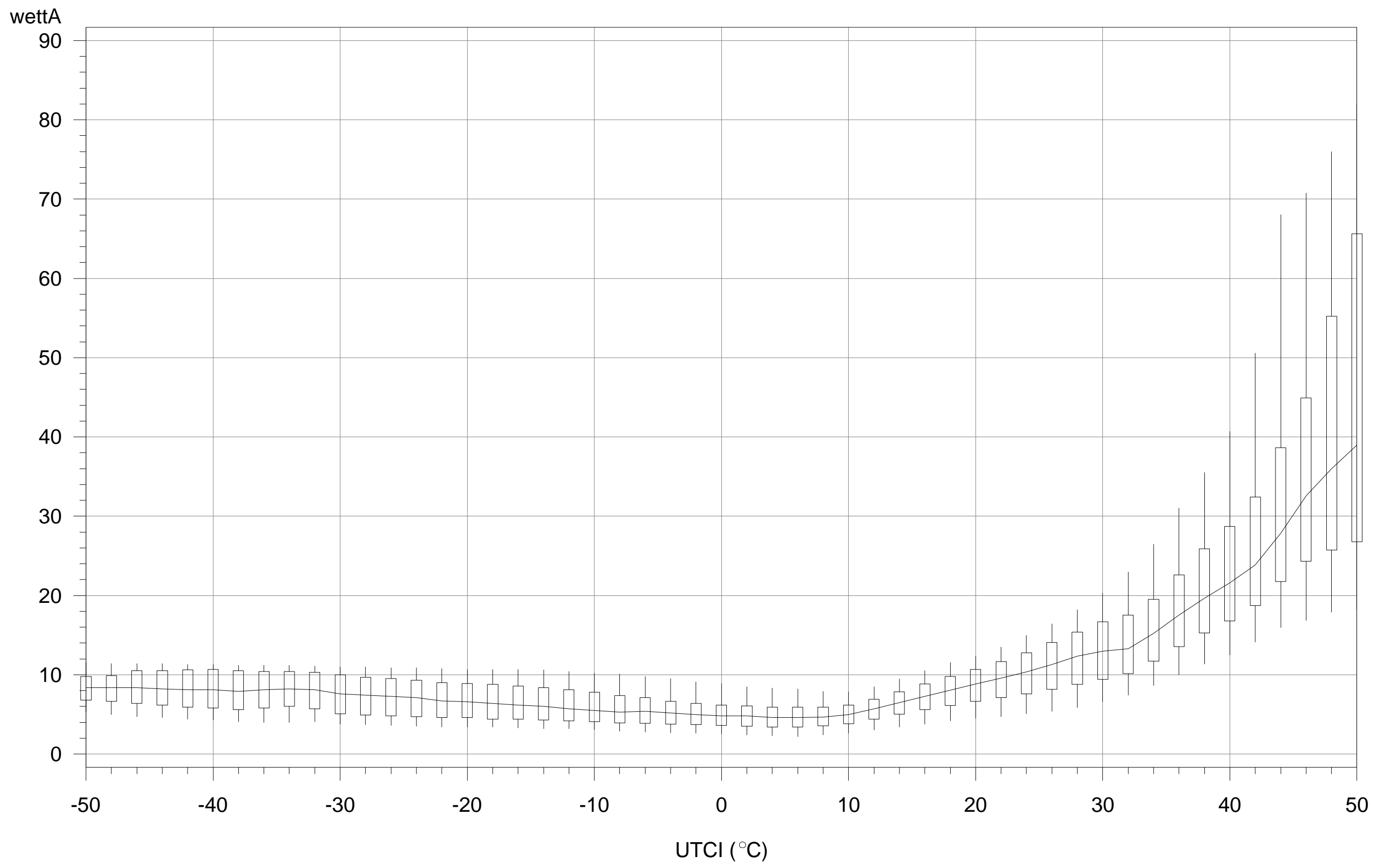

averaged over responses after 30,60, 90 and 120 min (Box-Plots with joined medians derived with UTCI rounded to $2 \mathrm{~K}$ wide bins) 


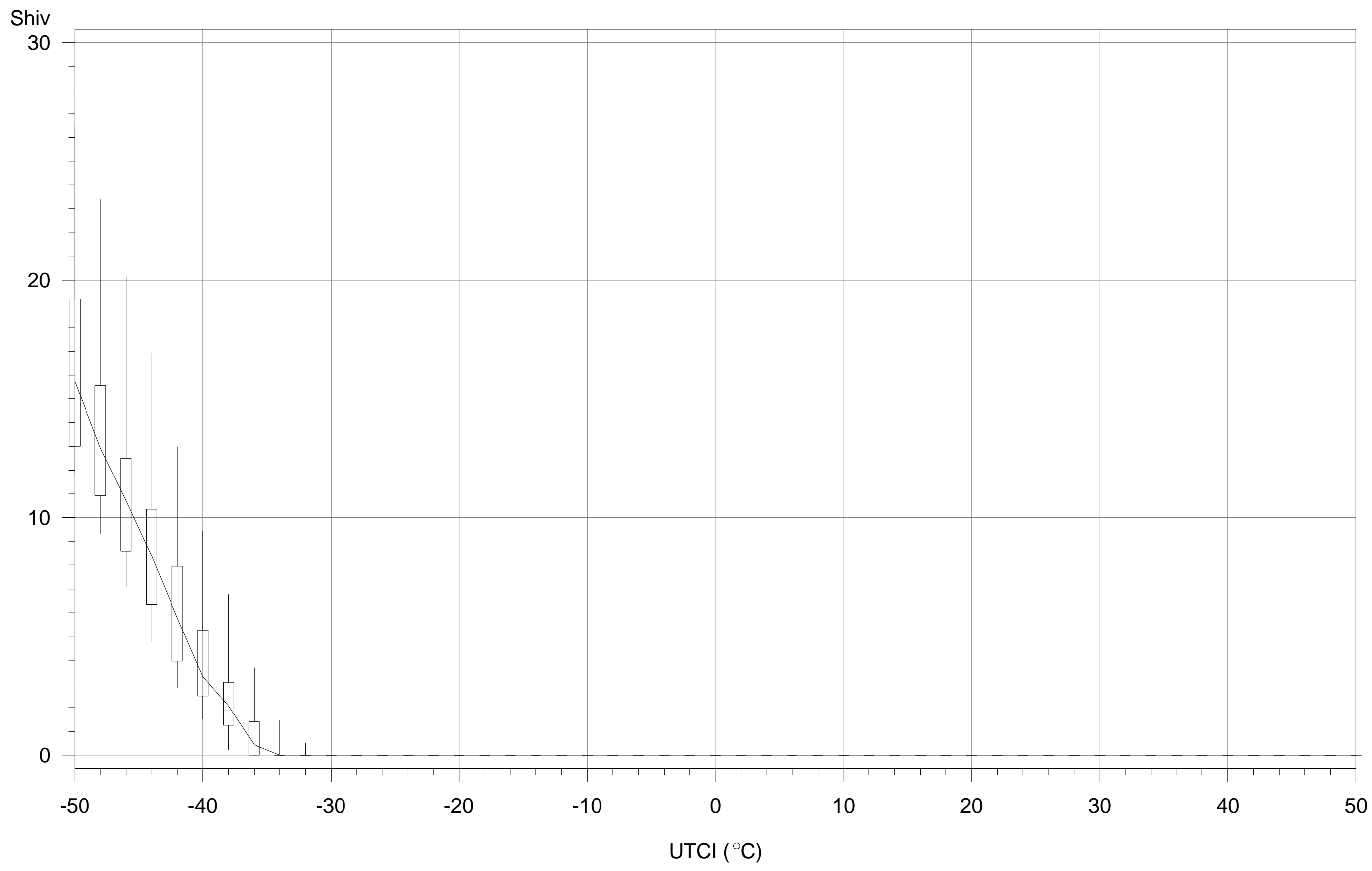

averaged over responses after 30,60, 90 and $120 \mathrm{~min}$ (Box-Plots with joined medians derived with UTCI rounded to $2 \mathrm{~K}$ wide bins) 


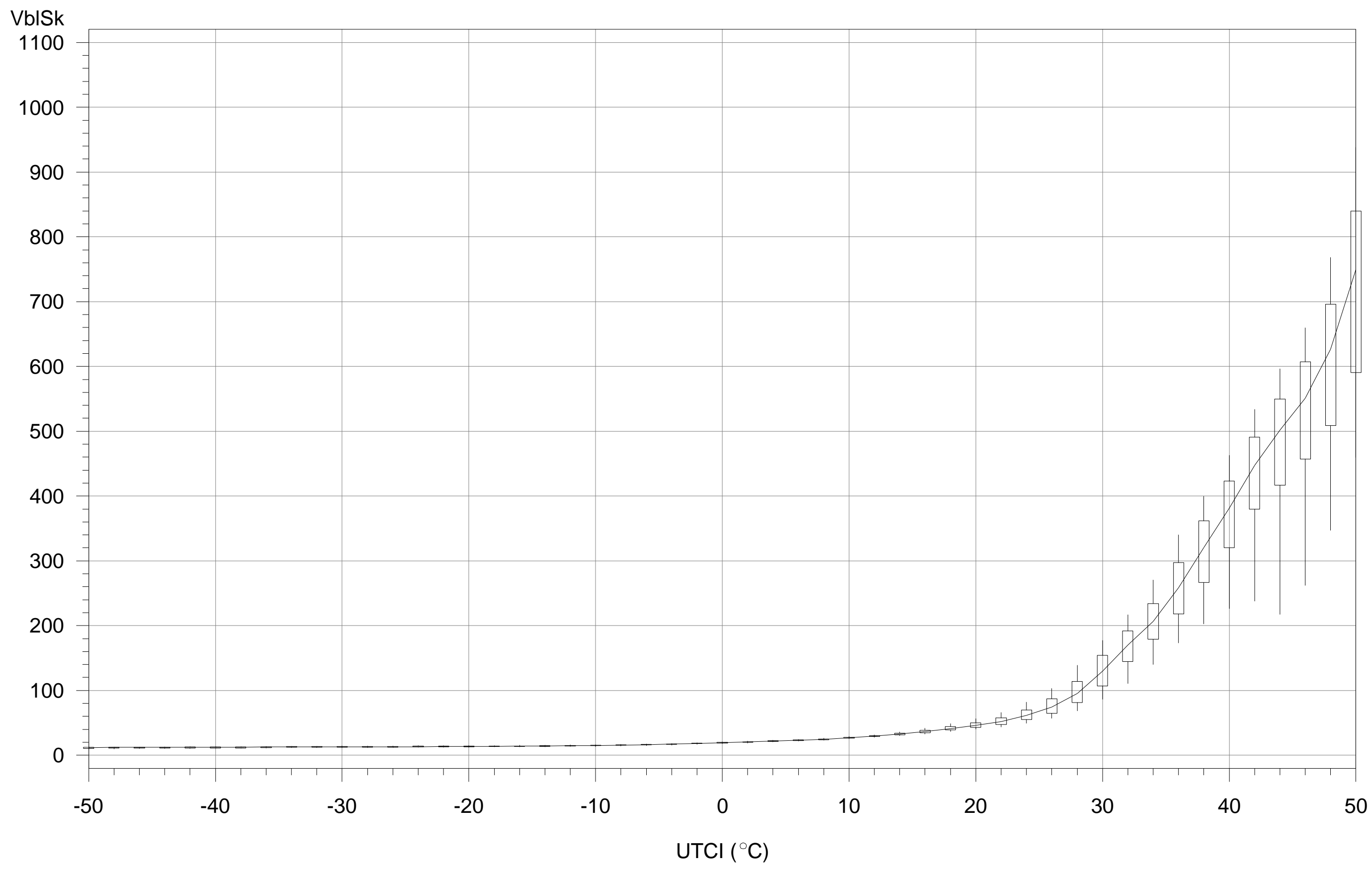

averaged over responses after 30,60, 90 and $120 \mathrm{~min}$ (Box-Plots with joined medians derived with UTCI rounded to $2 \mathrm{~K}$ wide bins) 


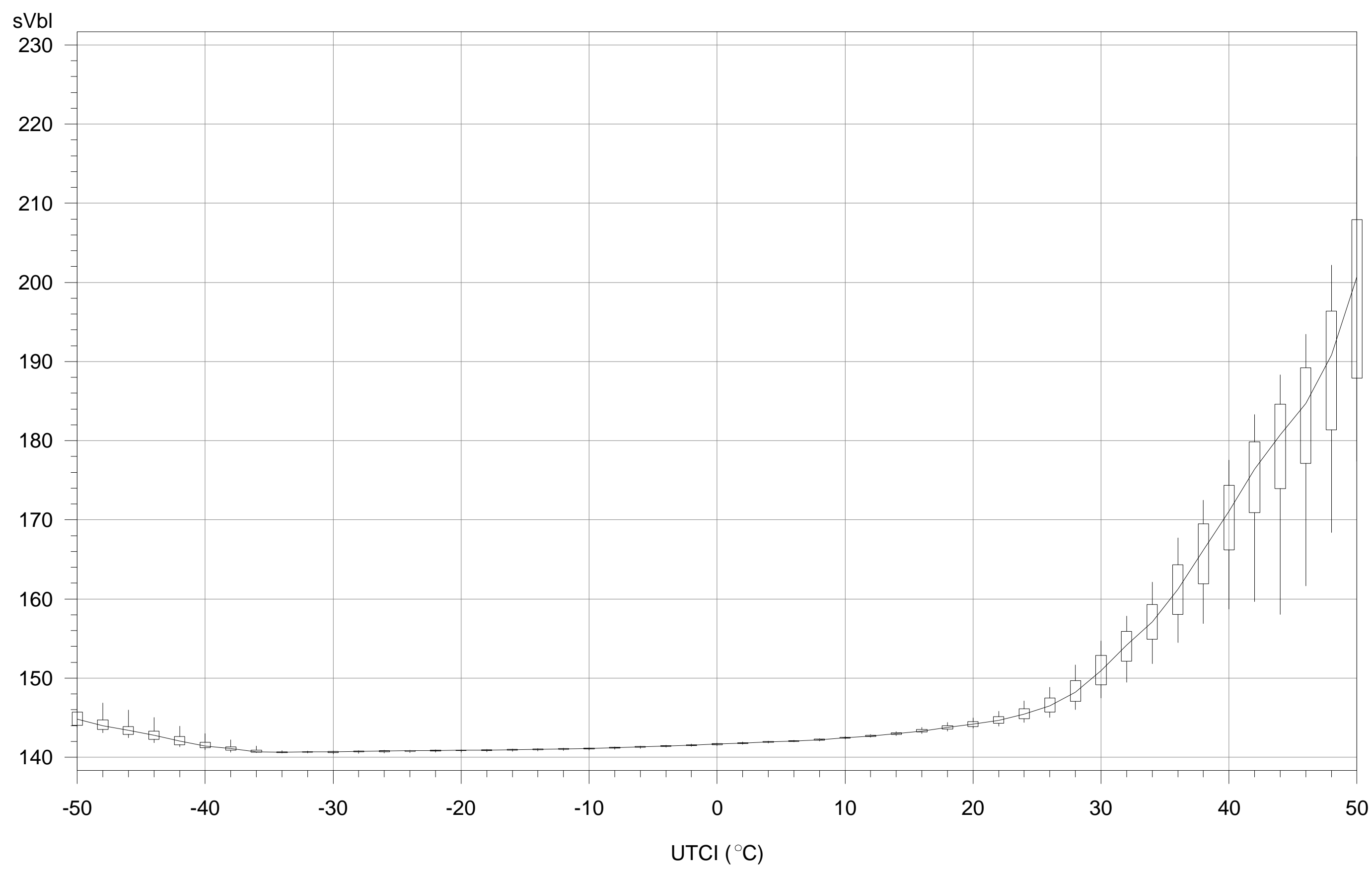

averaged over responses after 30,60, 90 and $120 \mathrm{~min}$ (Box-Plots with joined medians derived with UTCI rounded to $2 \mathrm{~K}$ wide bins) 


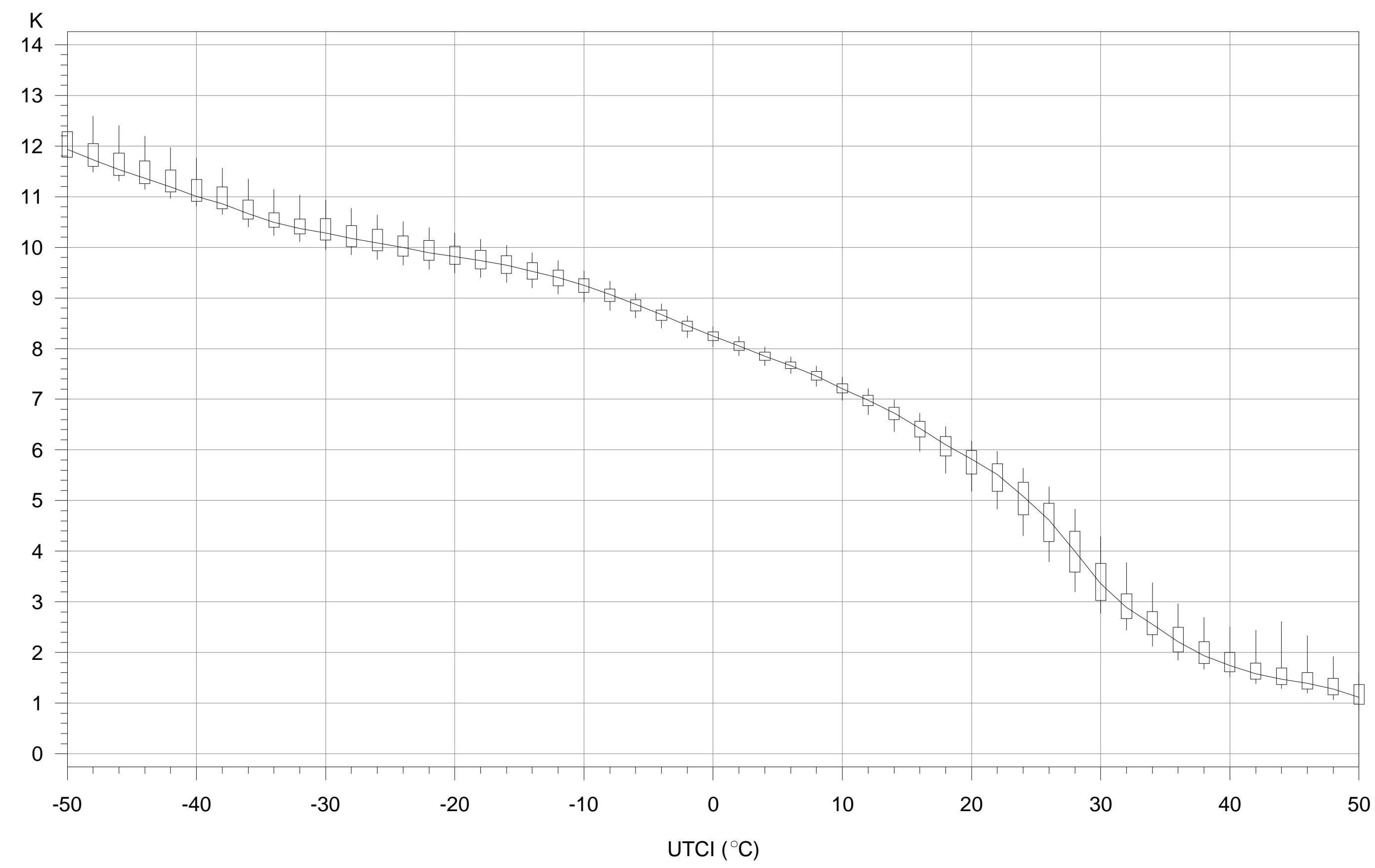

averaged over responses after 30,60, 90 and $120 \mathrm{~min}$ (Box-Plots with joined medians derived with UTCI rounded to $2 \mathrm{~K}$ wide bins) 


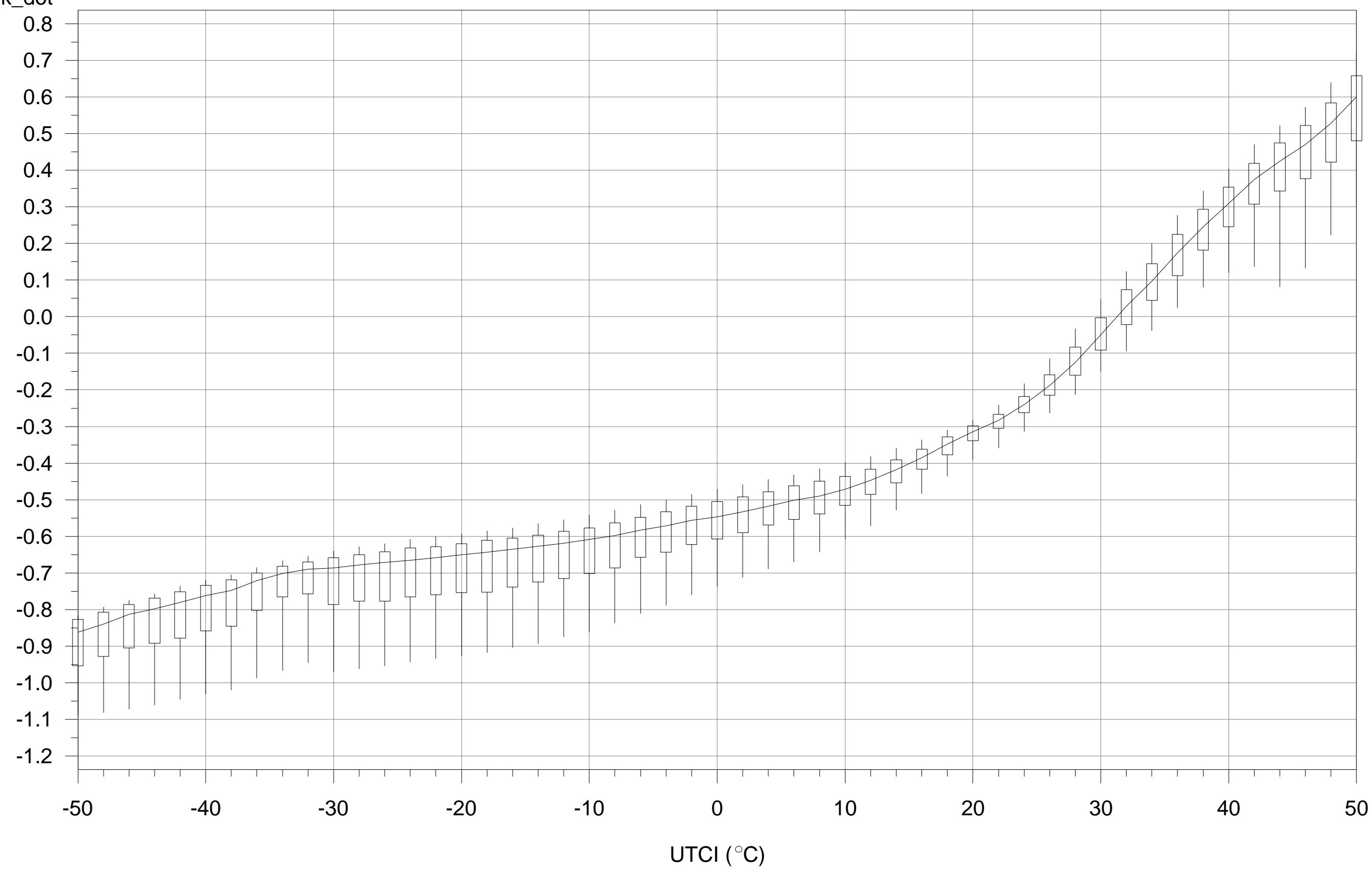

averaged over responses after 30,60, 90 and $120 \mathrm{~min}$ (Box-Plots with joined medians derived with UTCI rounded to $2 \mathrm{~K}$ wide bins) 


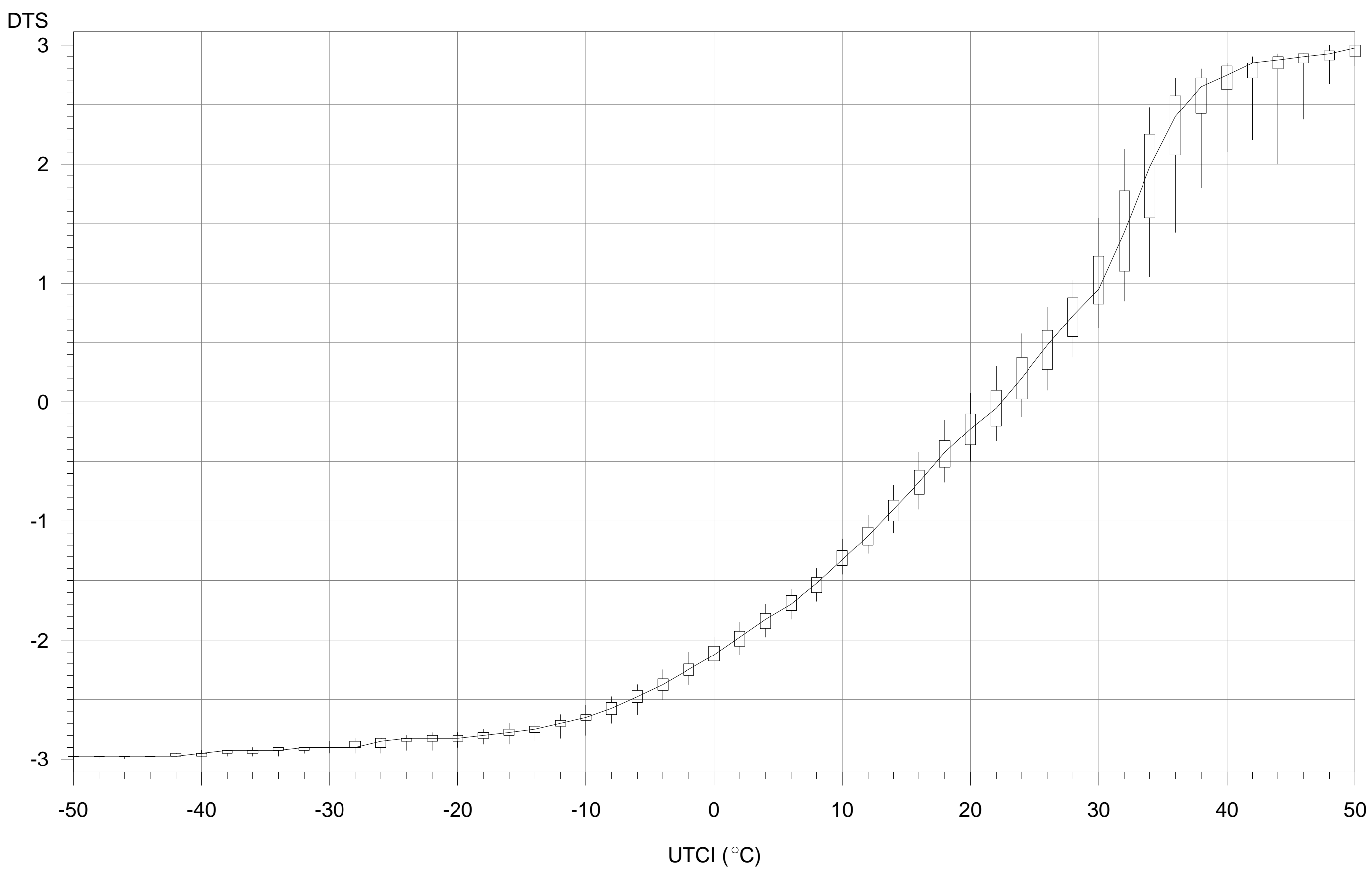

averaged over responses after 30,60, 90 and 120 min (Box-Plots with joined medians derived with UTCI rounded to $2 \mathrm{~K}$ wide bins) 


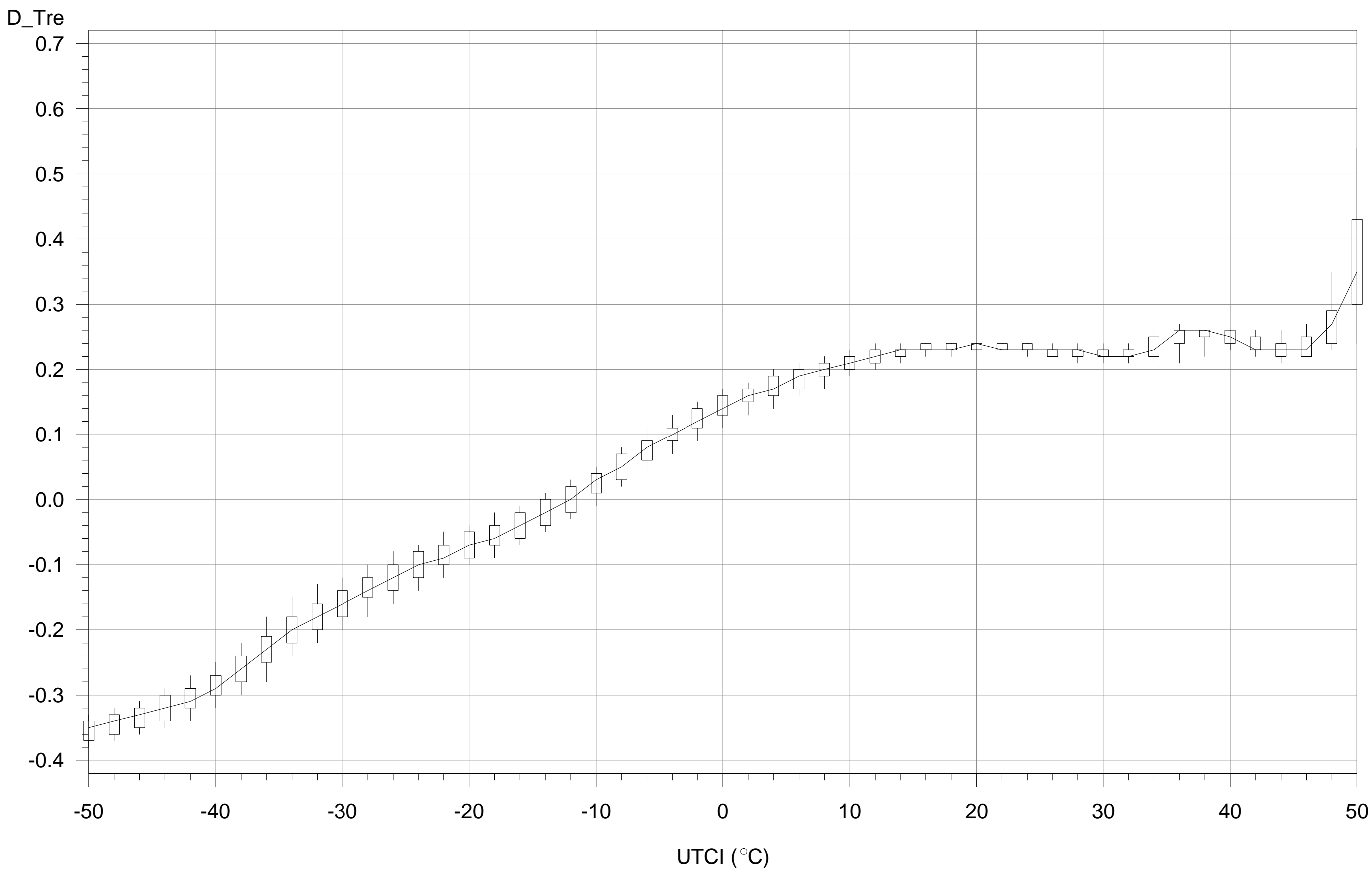

Time gradient of rectal temperature Tre 120 - Tre $60(\mathrm{~K} / \mathrm{h})$ (Box-Plots with joined medians derived with UTCI rounded to $2 \mathrm{~K}$ wide bins) 


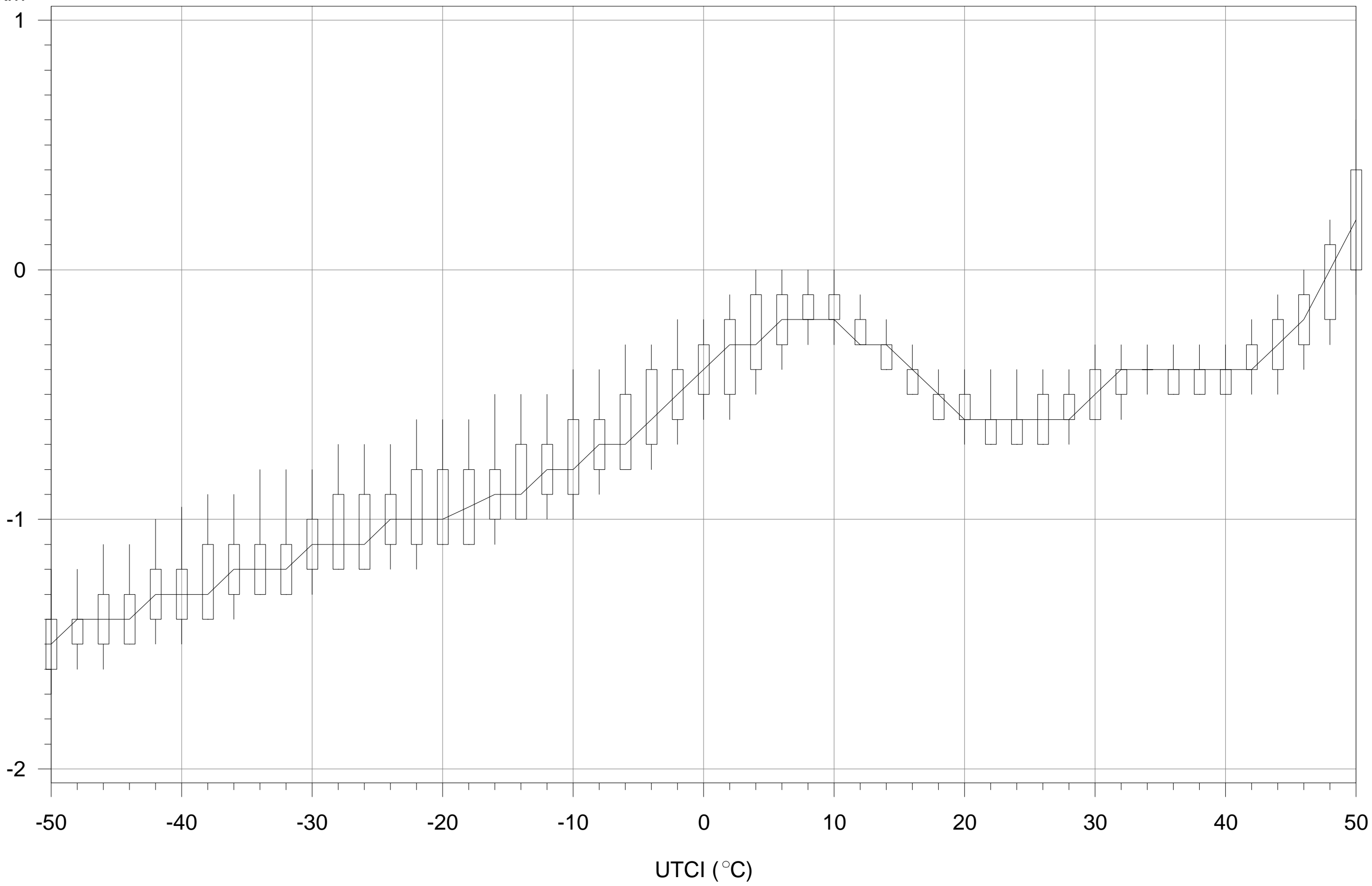

Time gradient of mean skin temperature Tskm_120 - Tskm_60 (K/h) (Box-Plots with joined medians derived with UTCI rounded to $2 \bar{K}$ wide bins) 


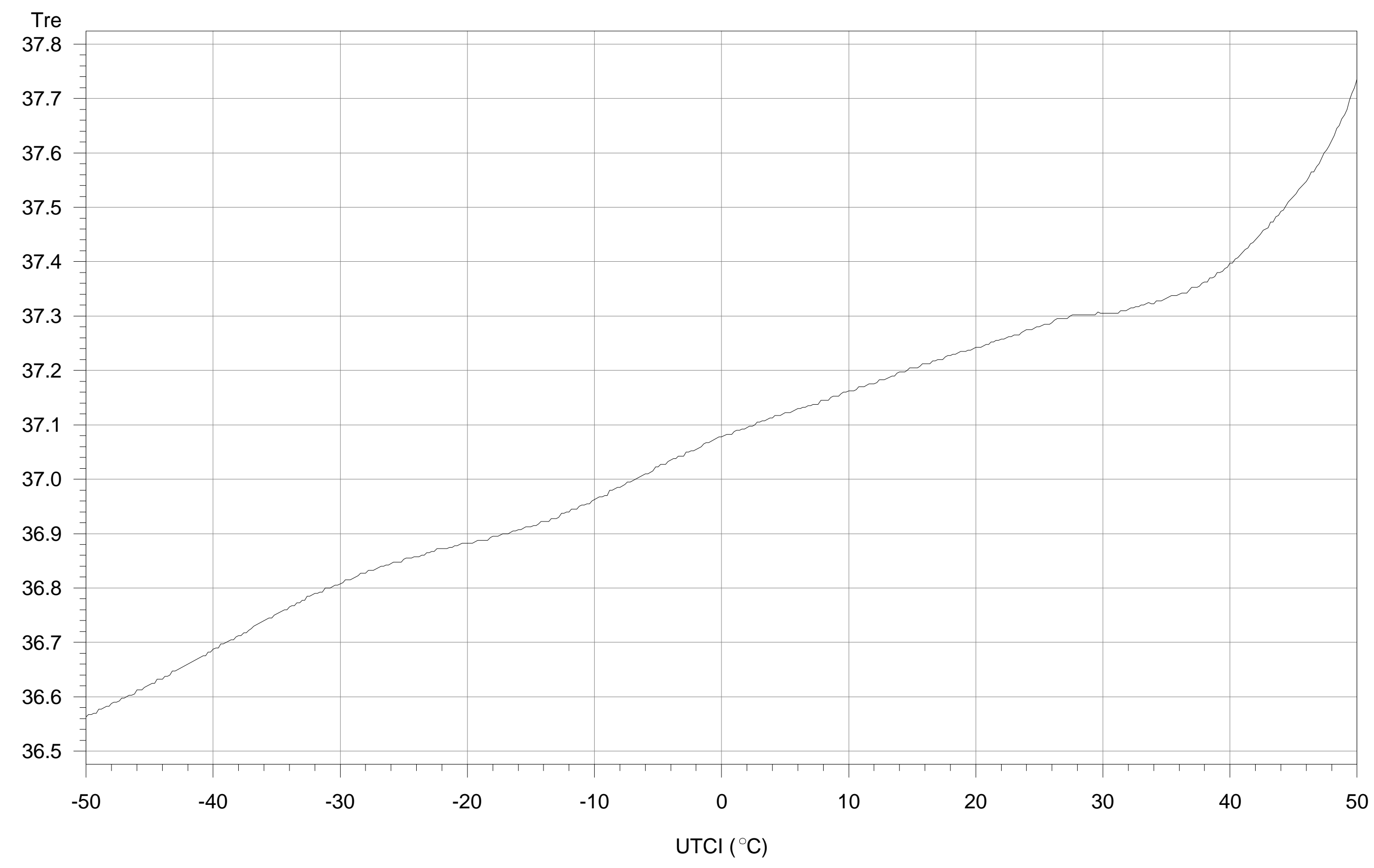

averaged over responses after 30,60, 90 and $120 \mathrm{~min}$ (for reference conditions) 


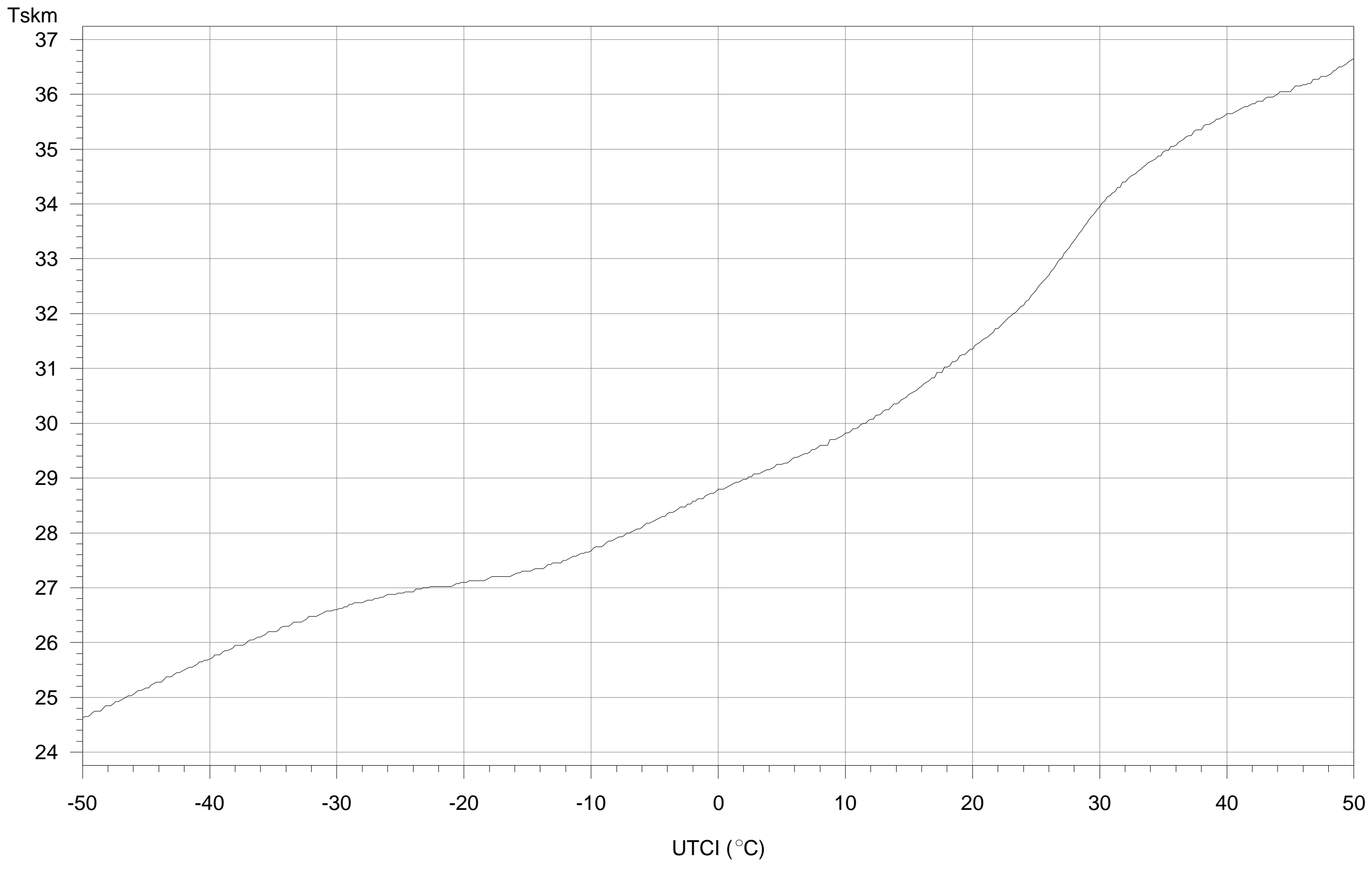

averaged over responses after 30,60, 90 and 120 min (for reference conditions) 


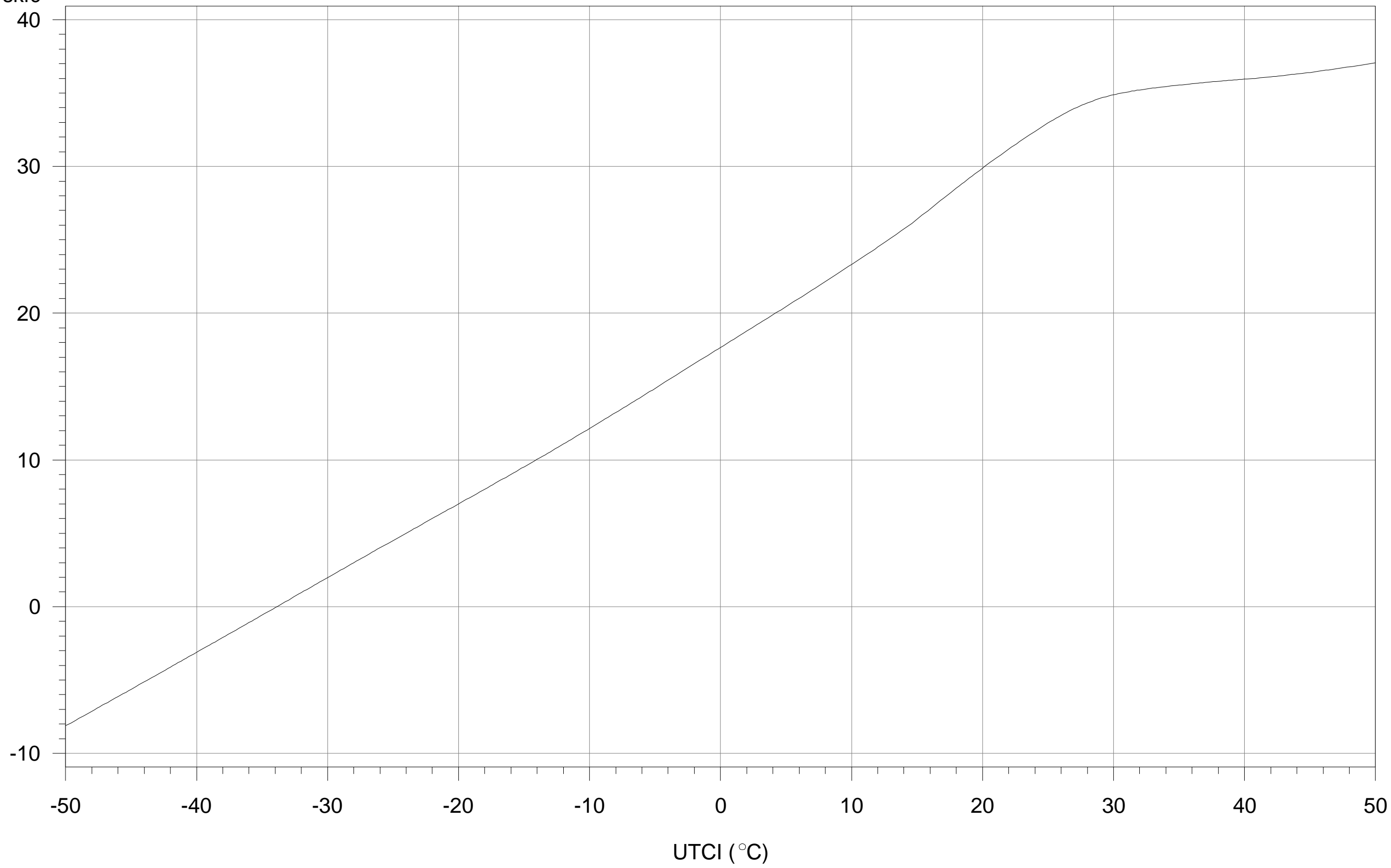

averaged over responses after 30,60, 90 and $120 \mathrm{~min}$ (for reference conditions) 


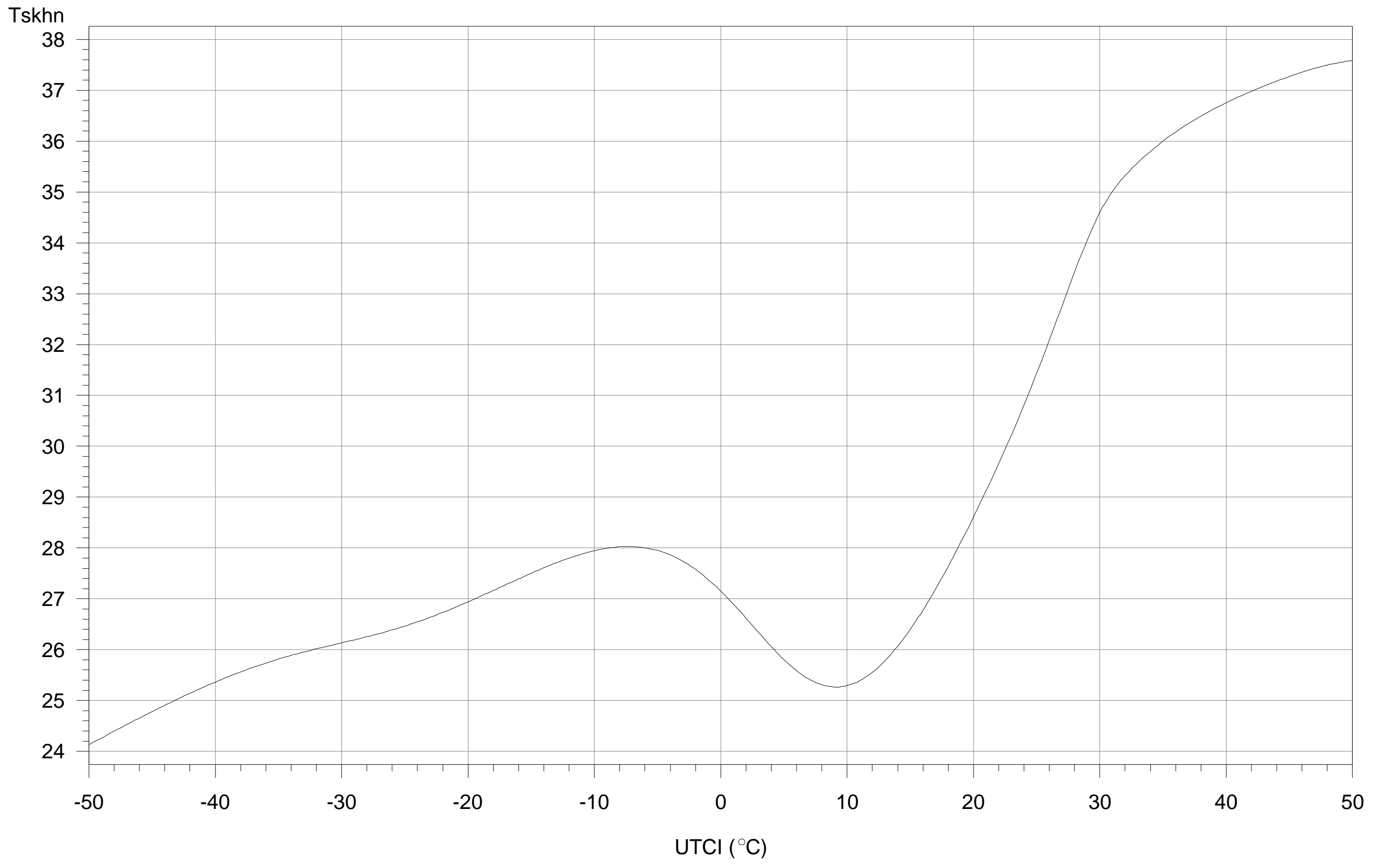

averaged over responses after 30,60, 90 and 120 min (for reference conditions) 


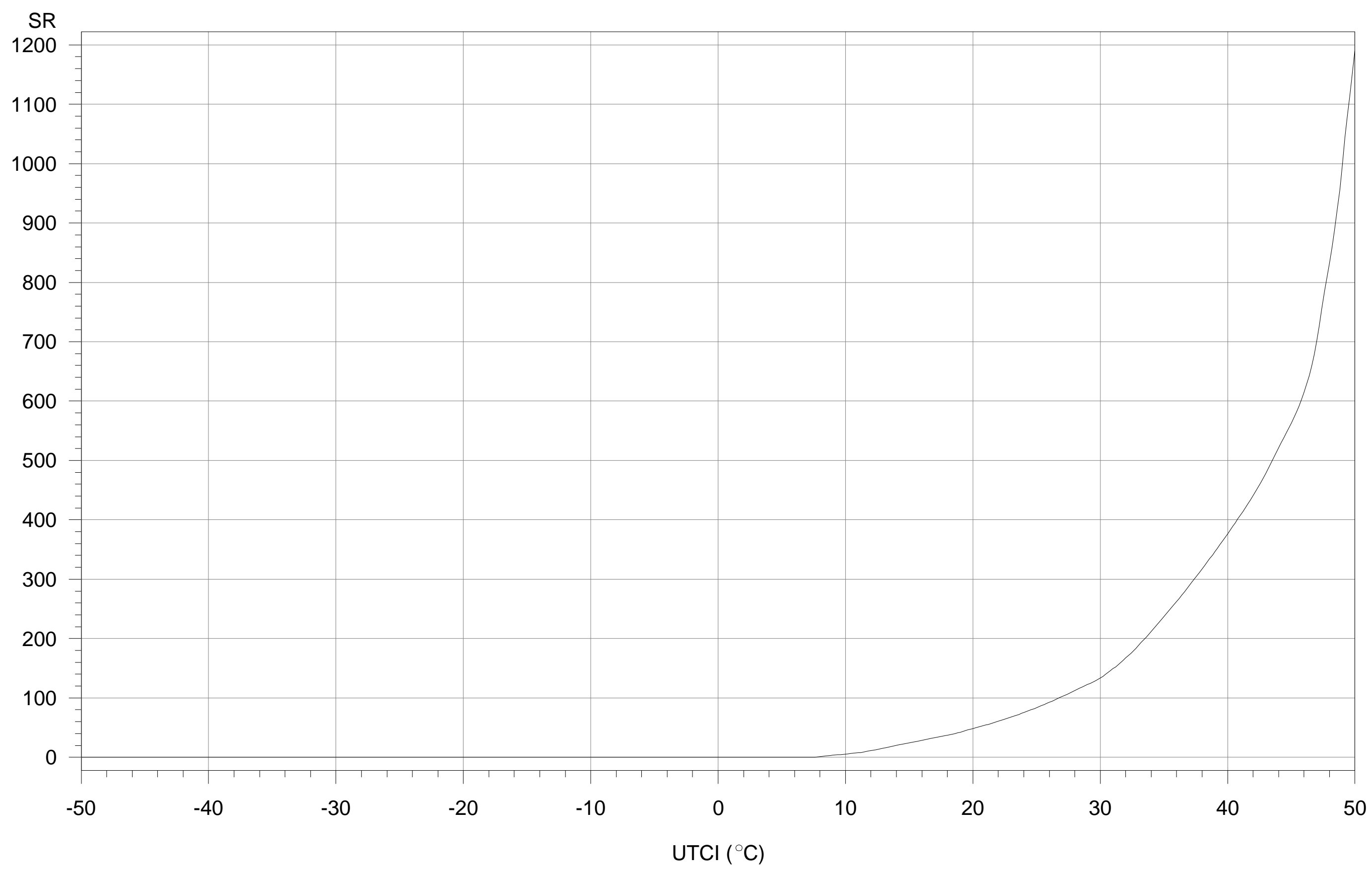

averaged over responses after 30,60, 90 and $120 \mathrm{~min}$ (for reference conditions) 


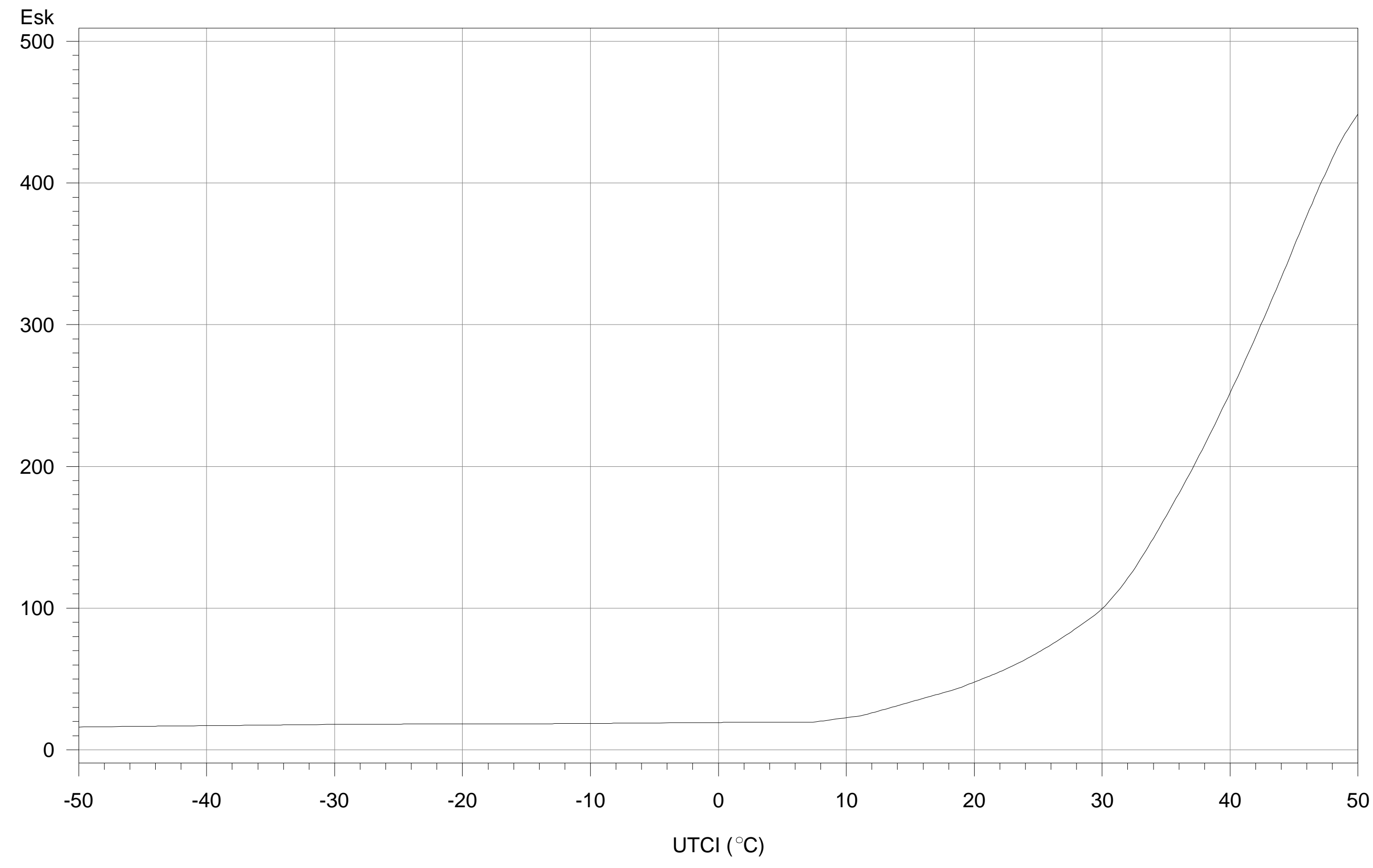

averaged over responses after $30,60,90$ and $120 \mathrm{~min}$ (for reference conditions) 


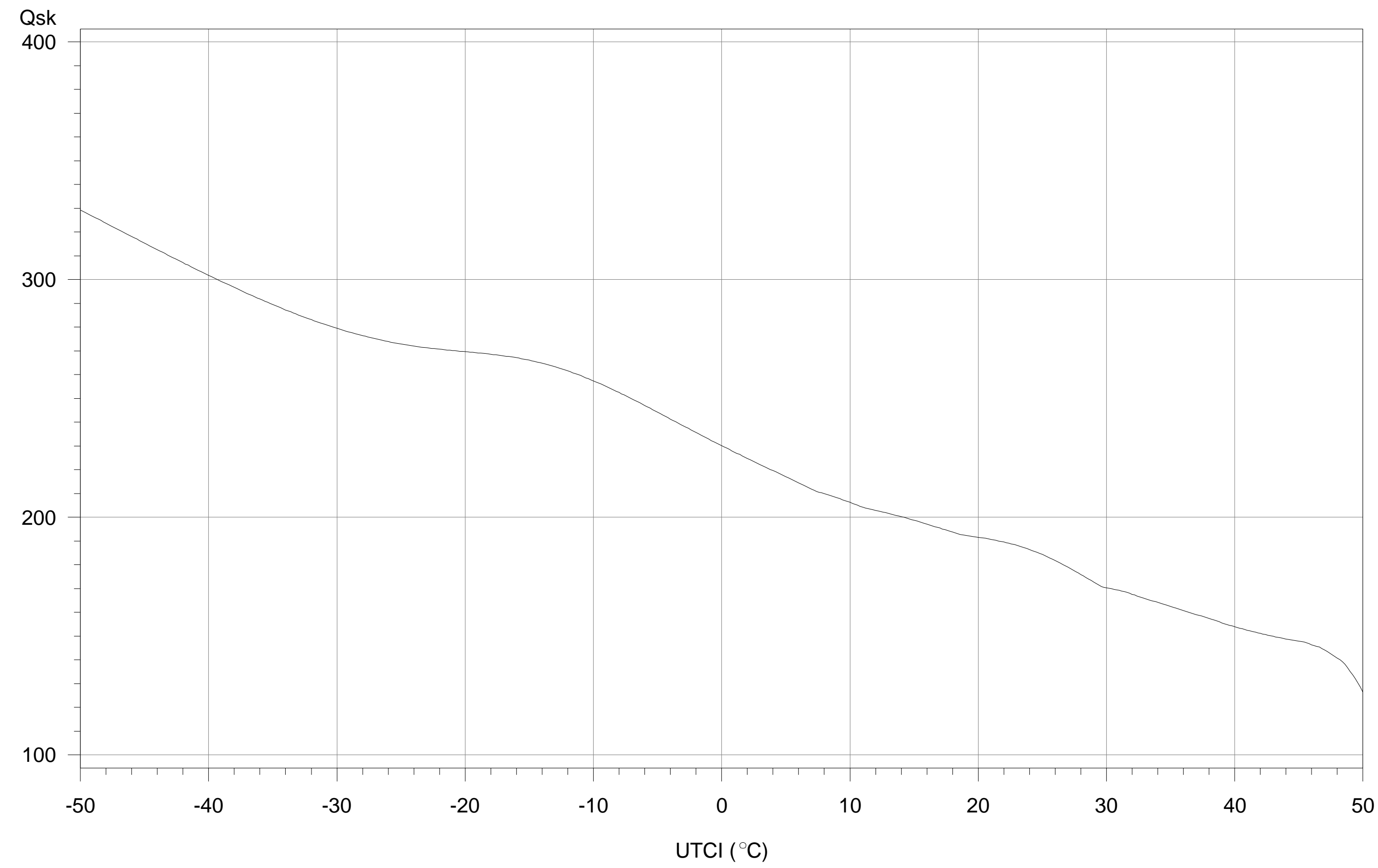

averaged over responses after 30,60, 90 and $120 \mathrm{~min}$ (for reference conditions) 
wettA

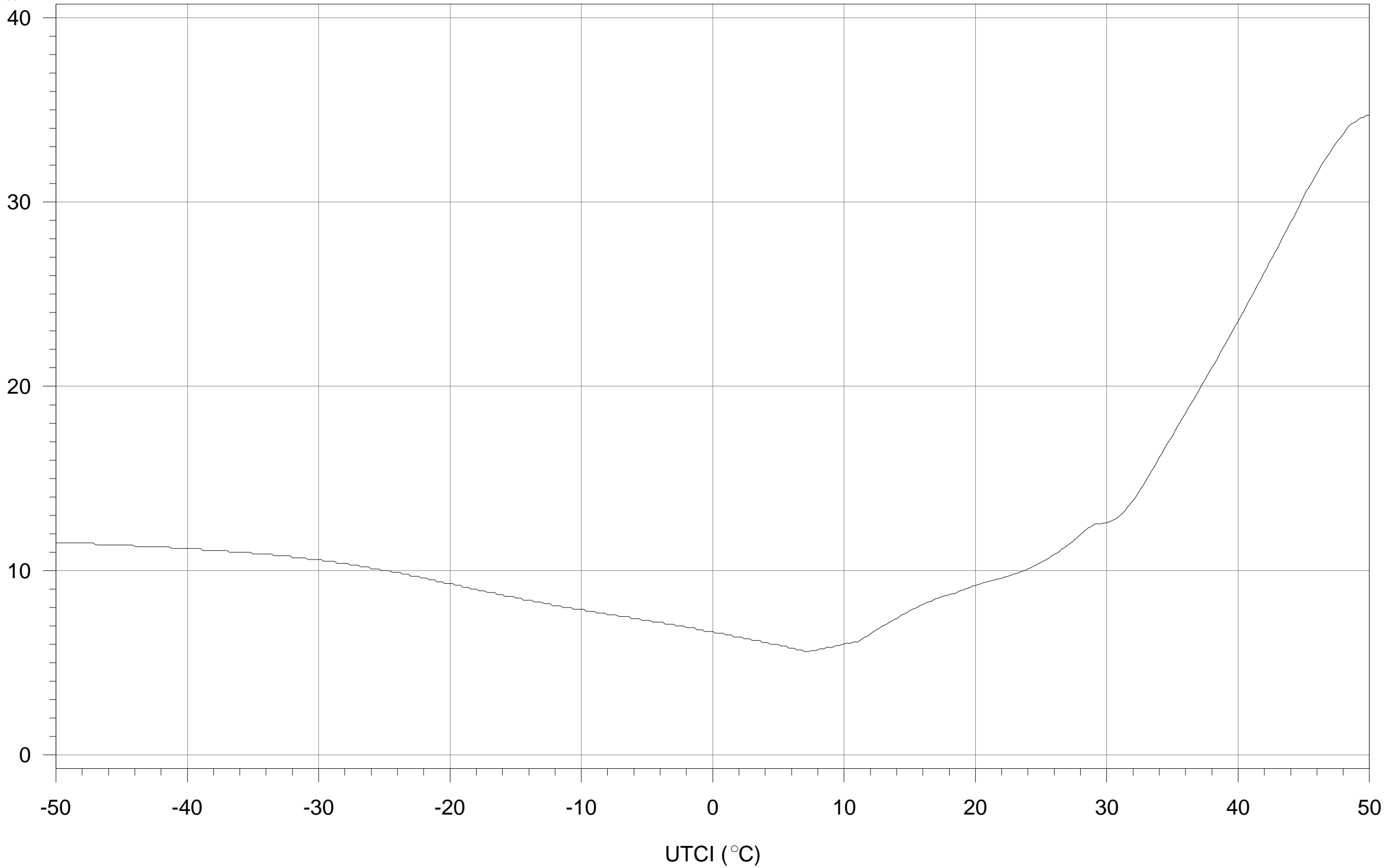

averaged over responses after 30,60, 90 and $120 \mathrm{~min}$ (for reference conditions) 


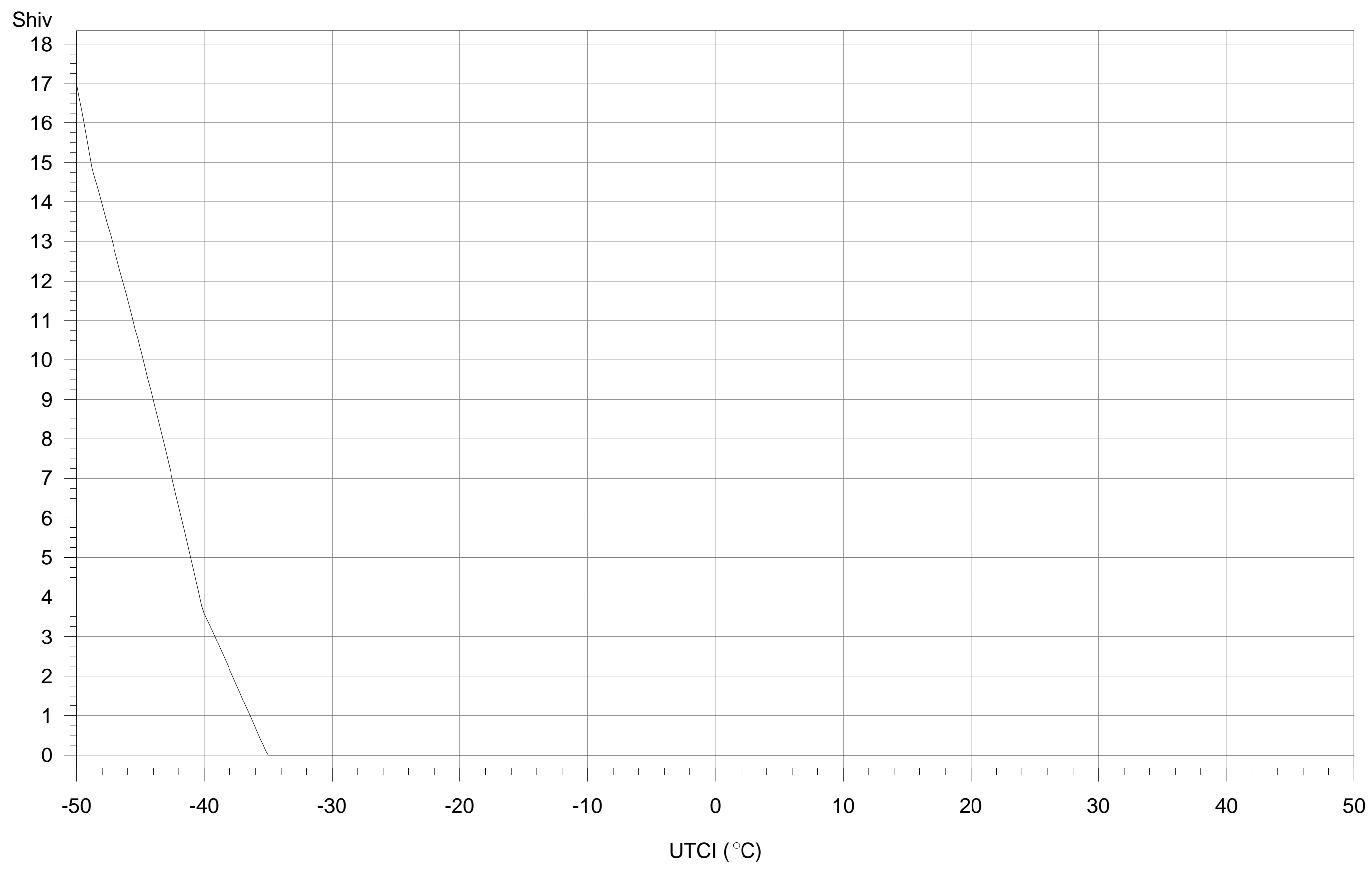

averaged over responses after 30,60, 90 and $120 \mathrm{~min}$ (for reference conditions) 


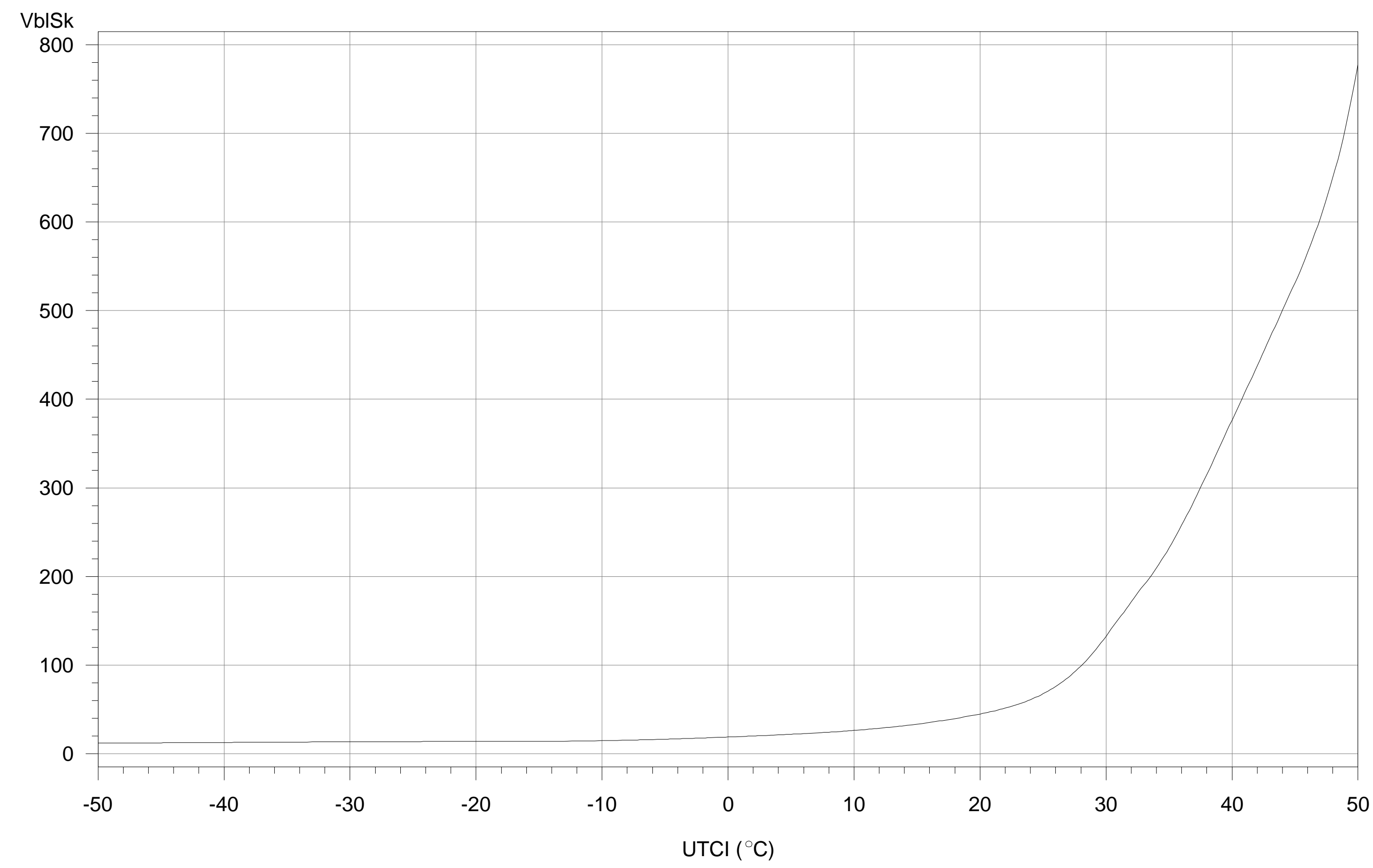

averaged over responses after 30,60, 90 and $120 \mathrm{~min}$ (for reference conditions) 


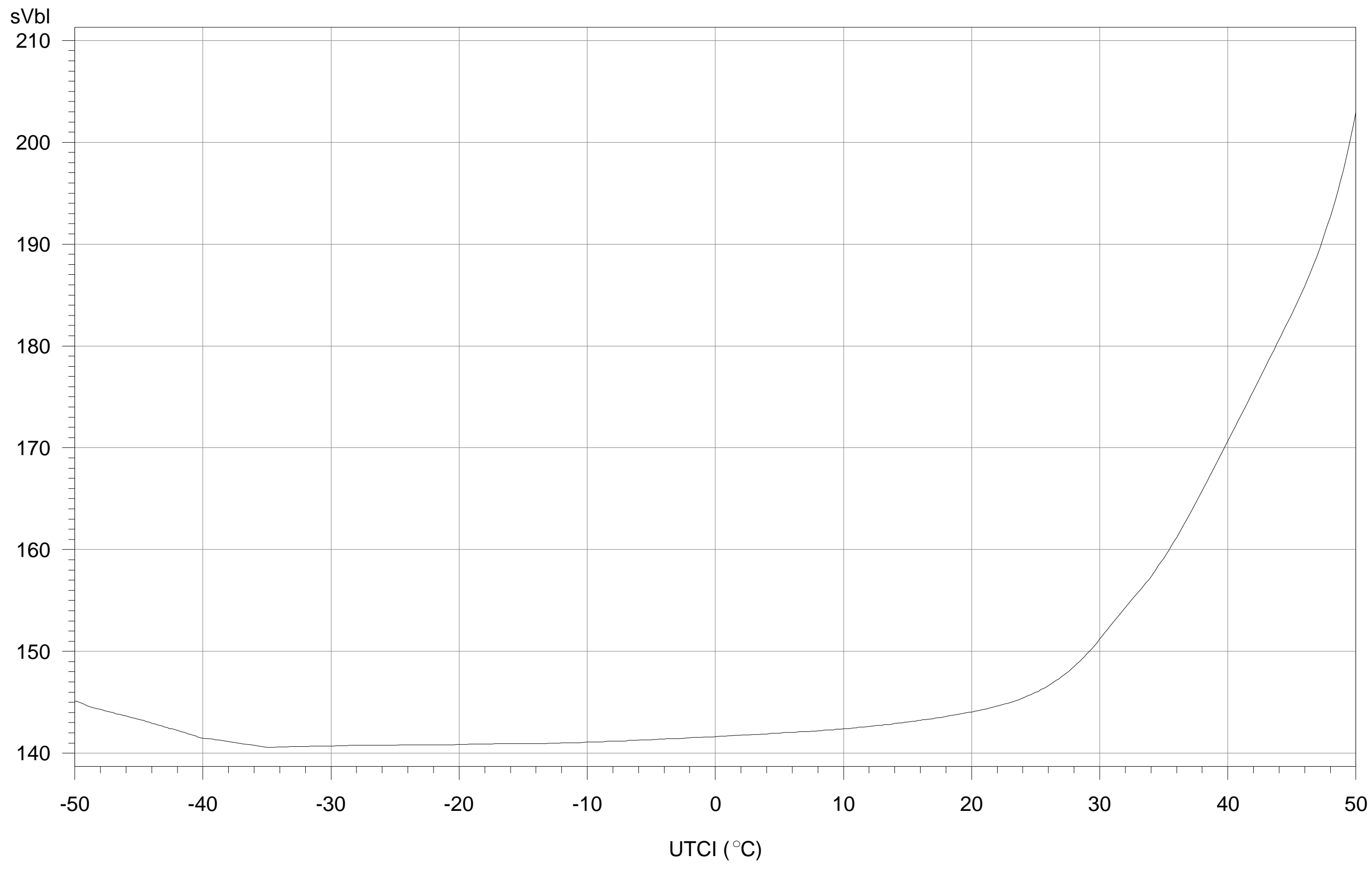

averaged over responses after 30,60, 90 and $120 \mathrm{~min}$ (for reference conditions) 


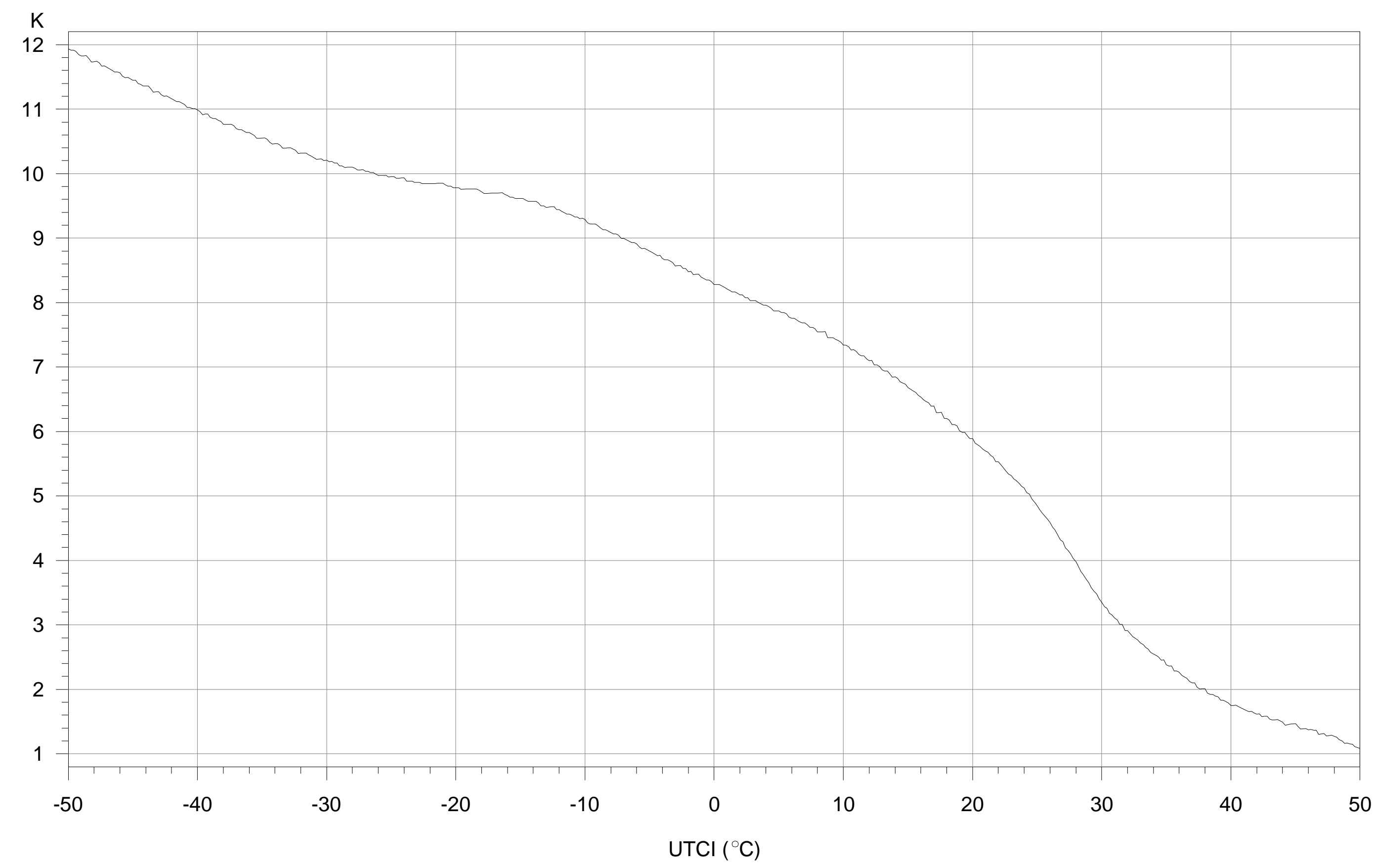

averaged over responses after 30,60, 90 and $120 \mathrm{~min}$ (for reference conditions) 


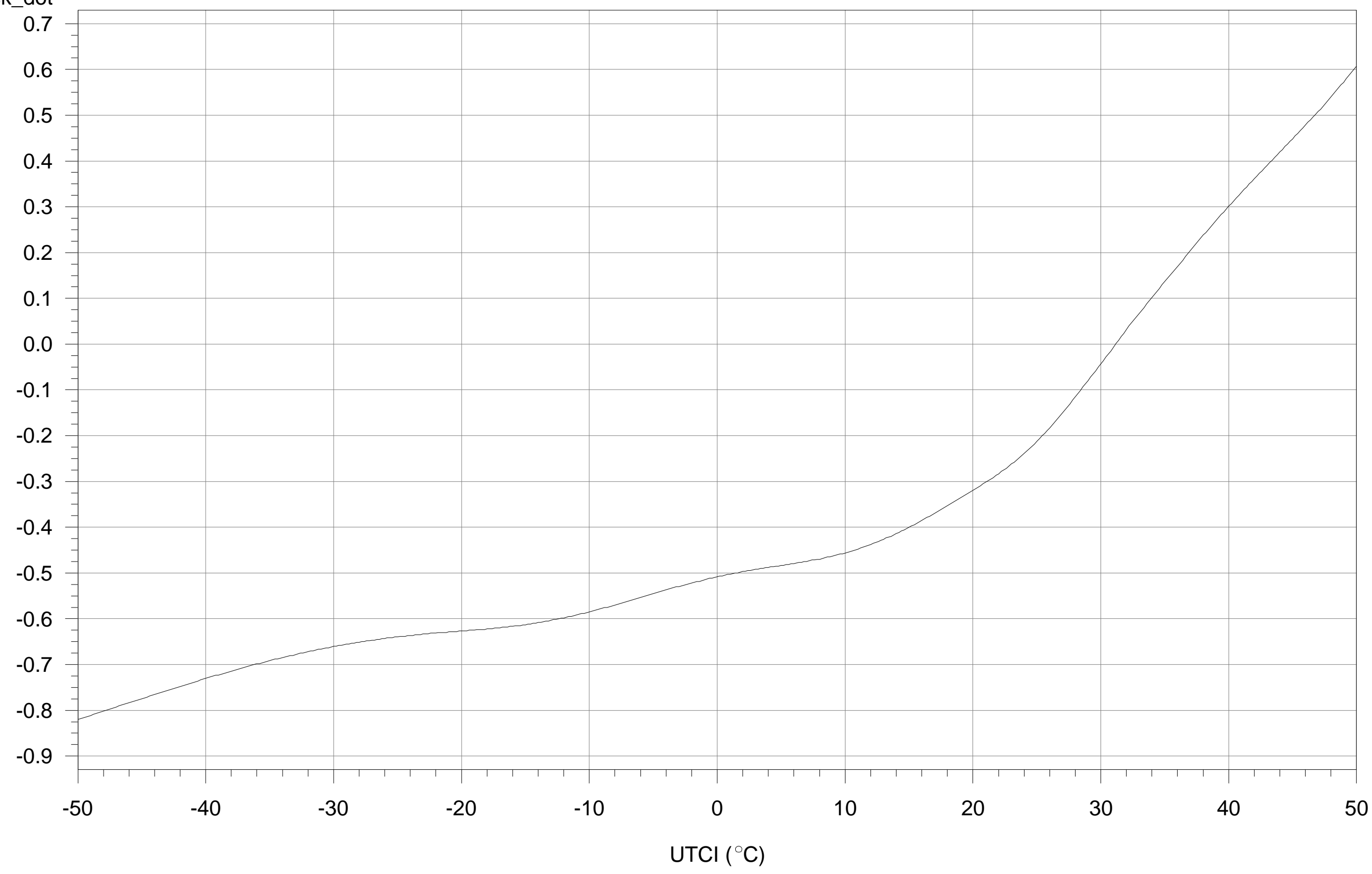

(for reference conditions) 


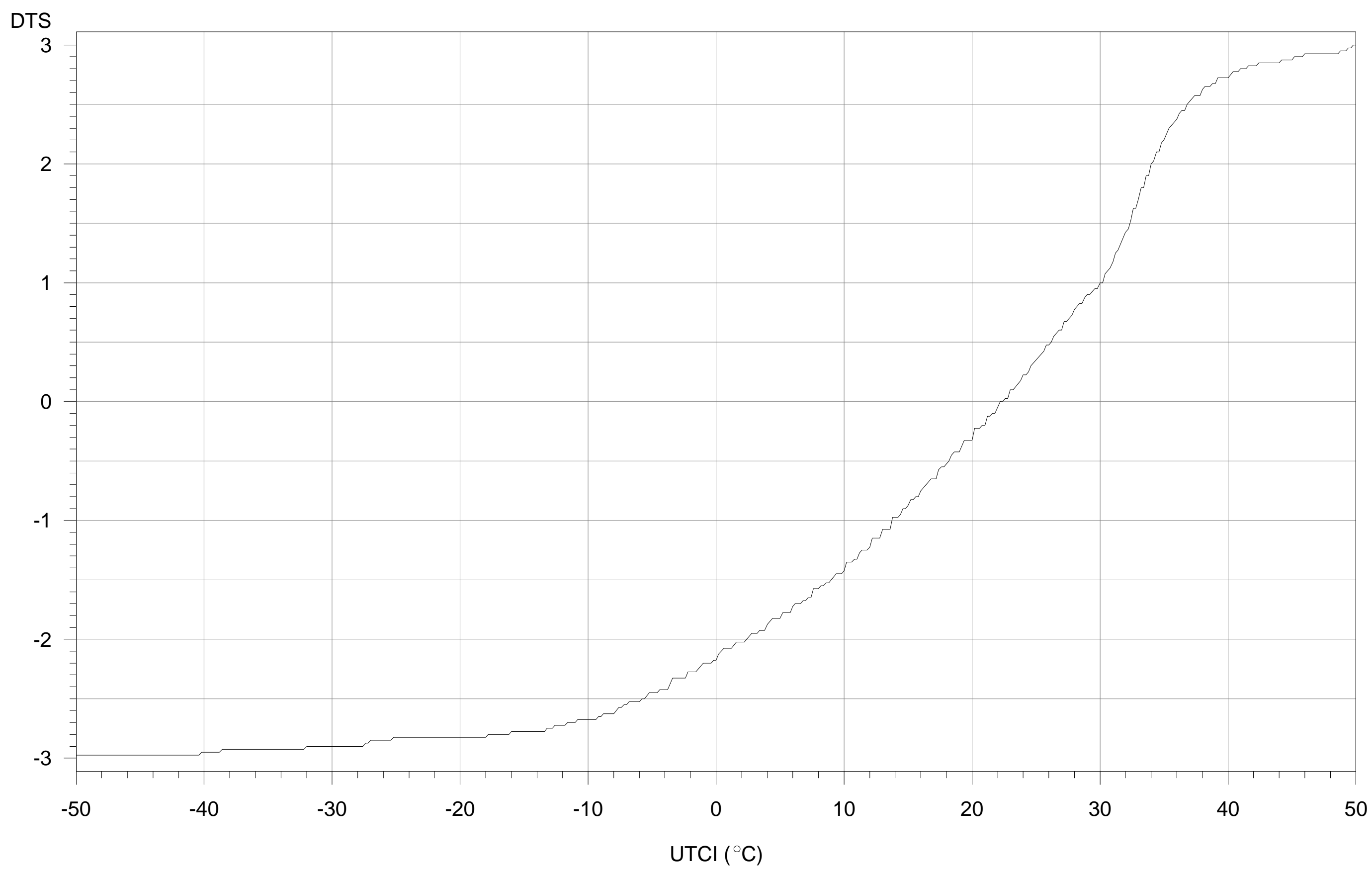

averaged over responses after 30,60, 90 and 120 min (for reference conditions) 


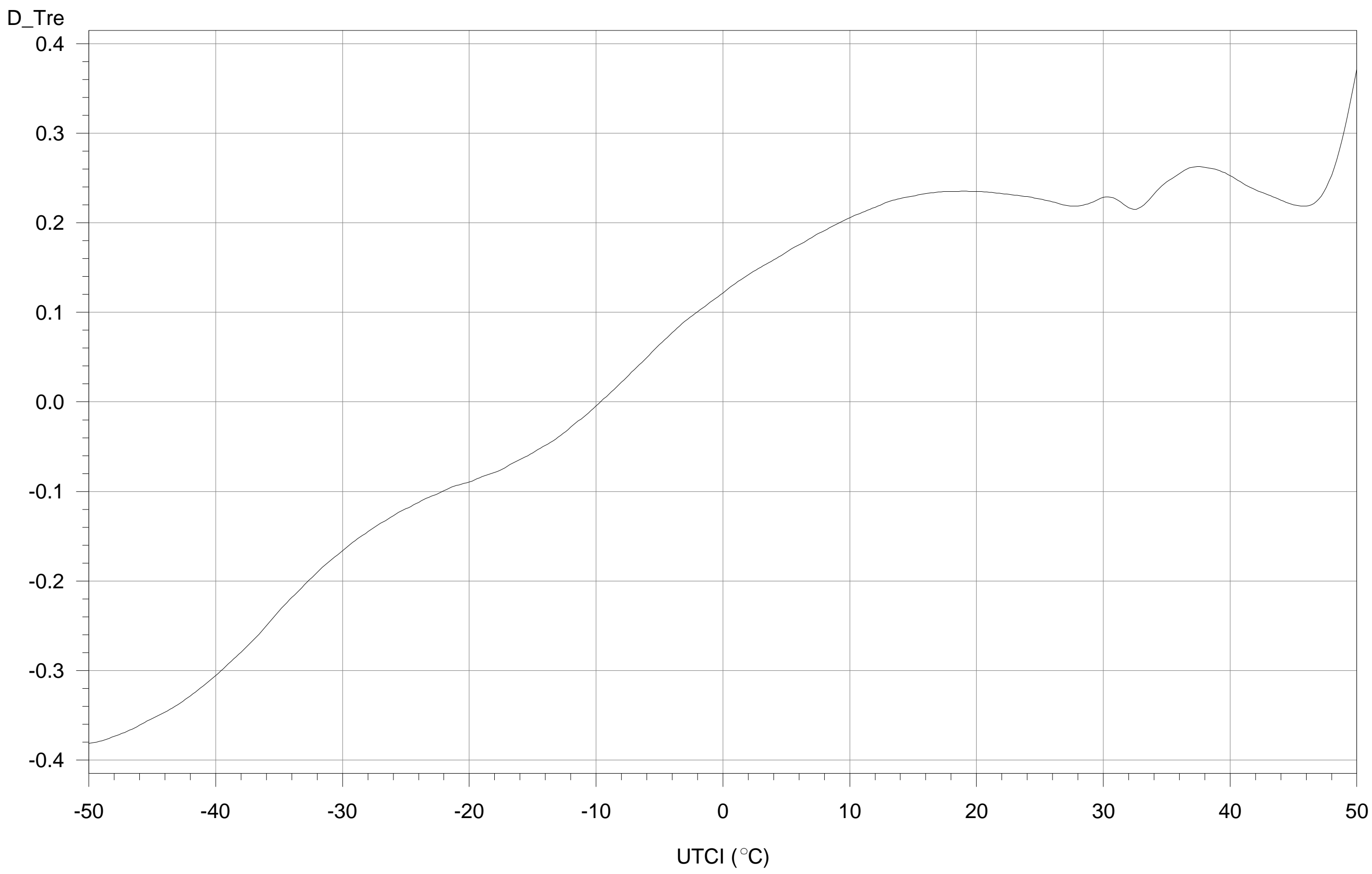

Time gradient of rectal temperature Tre_120 - Tre_60 (K/h) (for reference conditions) 


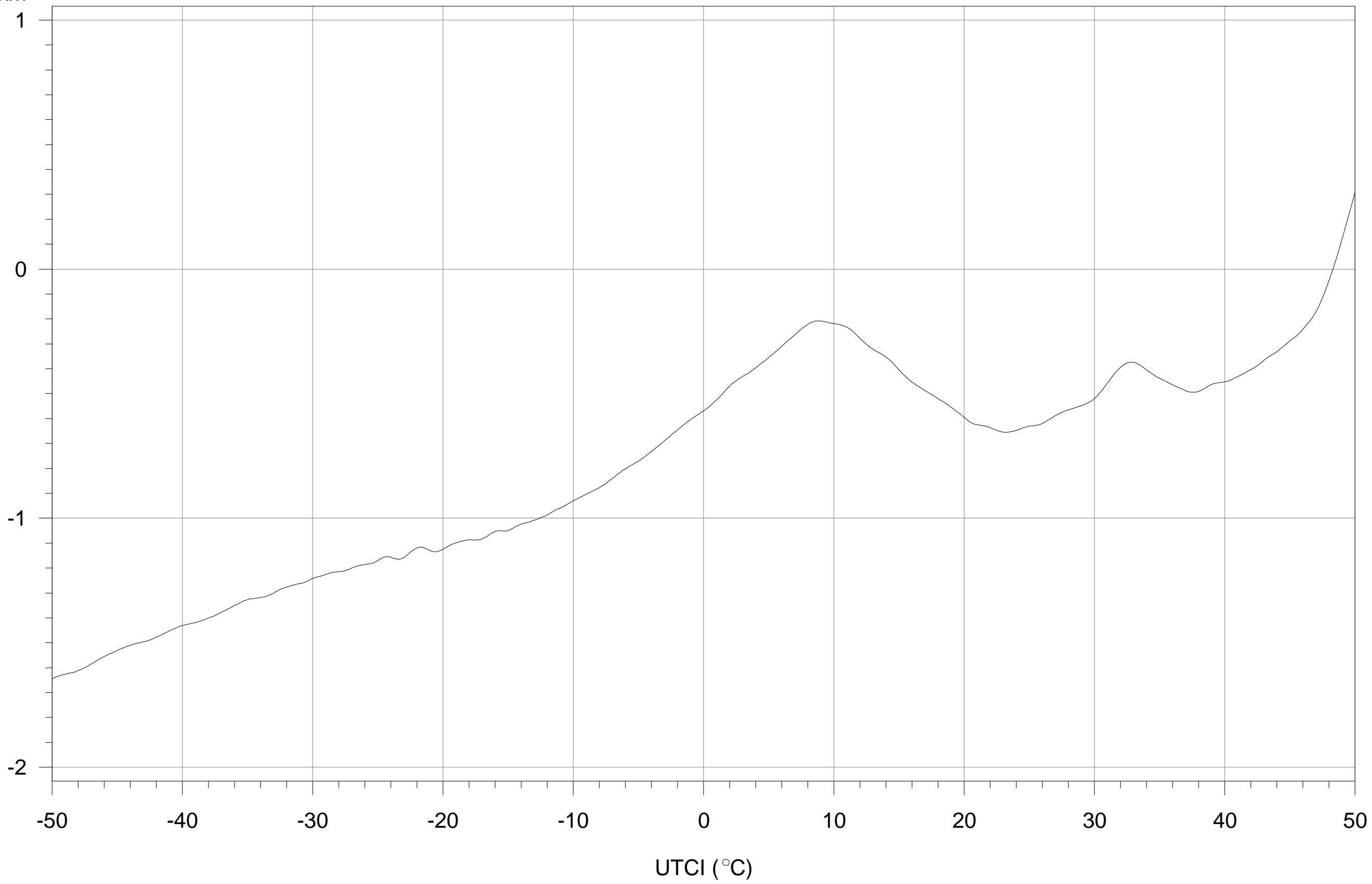

Time gradient of mean skin temperature Tskm_120 - Tskm_60 (K/h) (for reference conditions) 


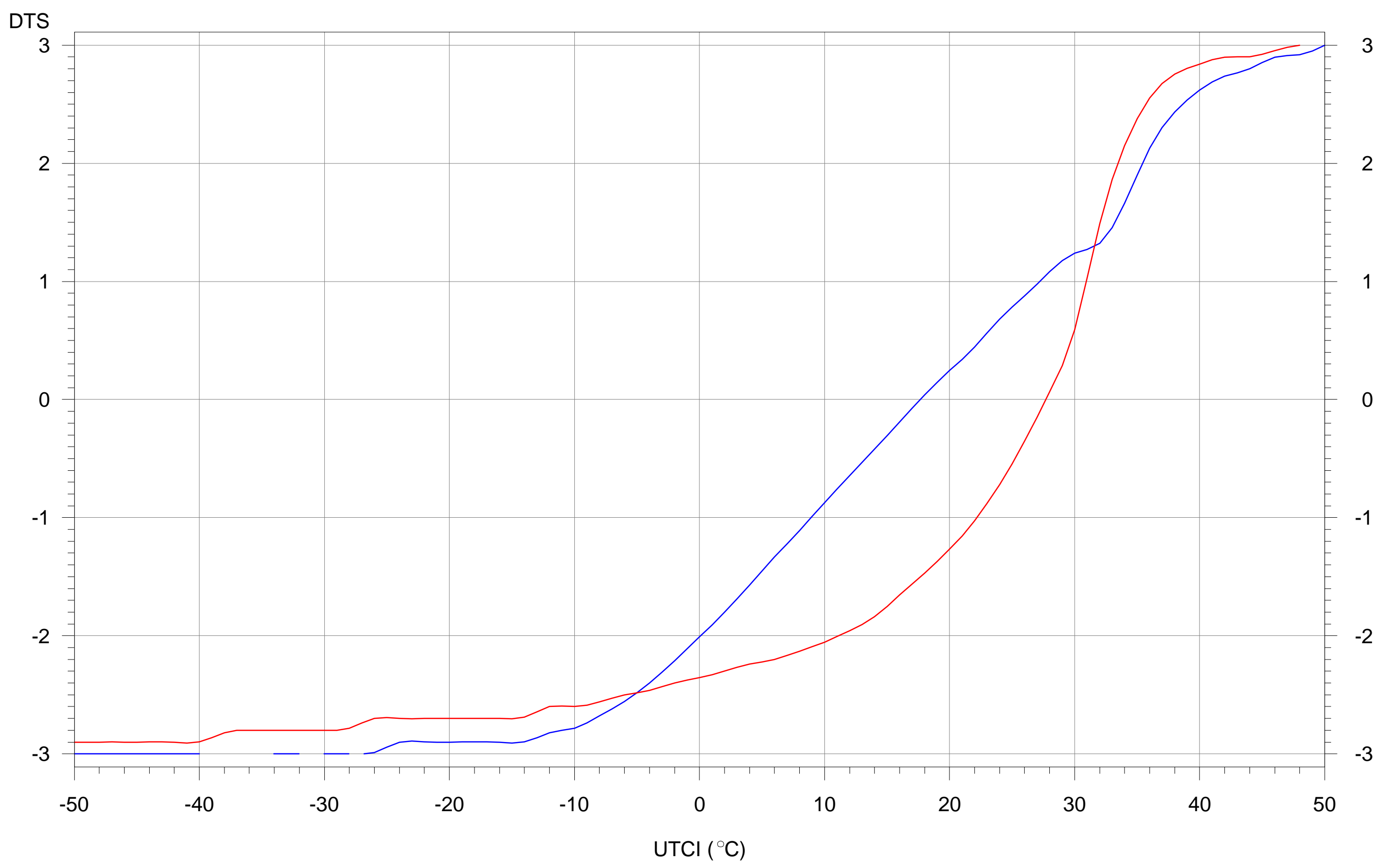

Dynamic Thermal Sensation (DTS) for the reference conditions $30 \mathrm{~min} 120 \mathrm{~min}$ 


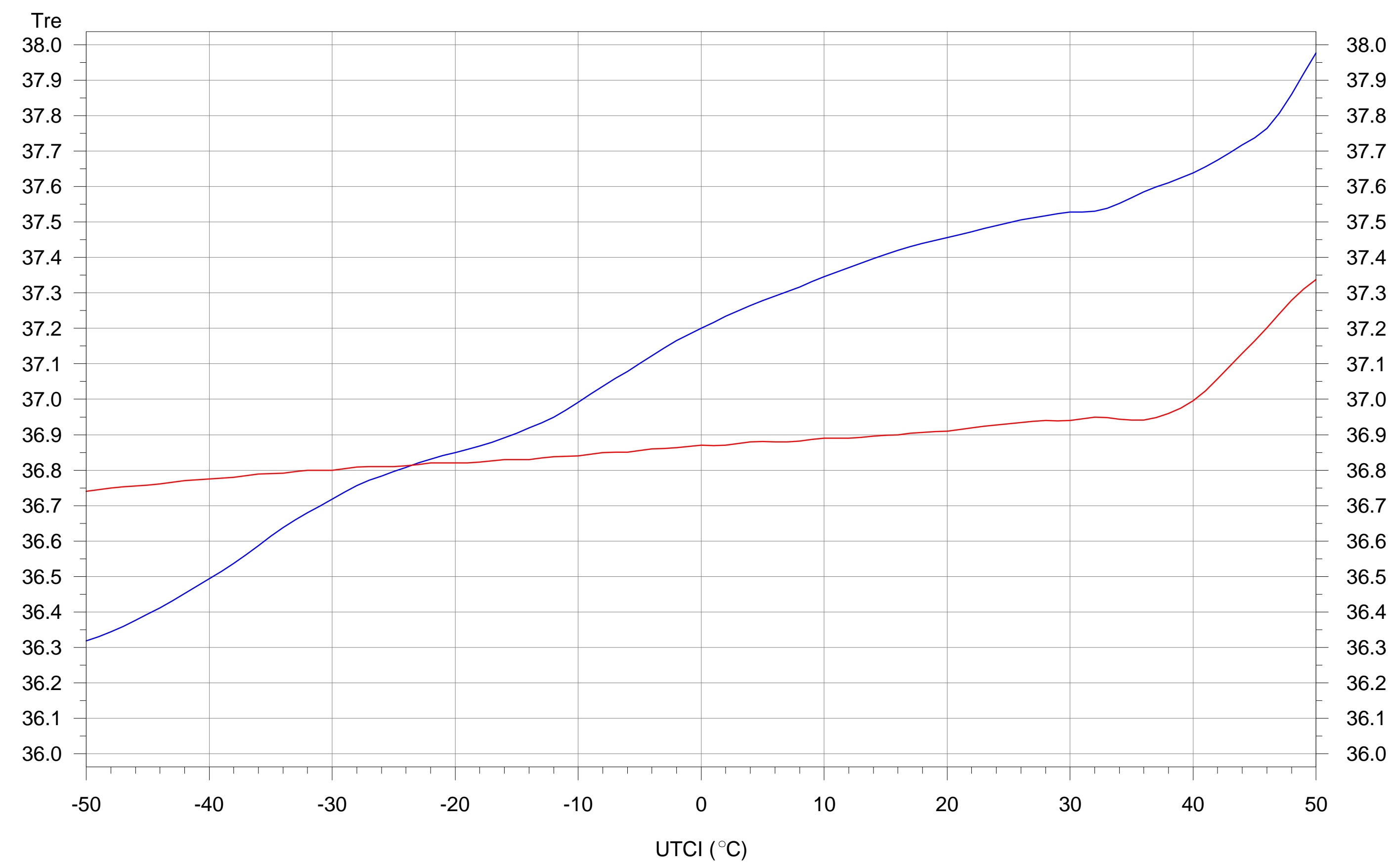

Rectal temperature $(\operatorname{deg} \mathrm{C})$ for the reference conditions $30 \mathrm{~min} 120 \mathrm{~min}$ 


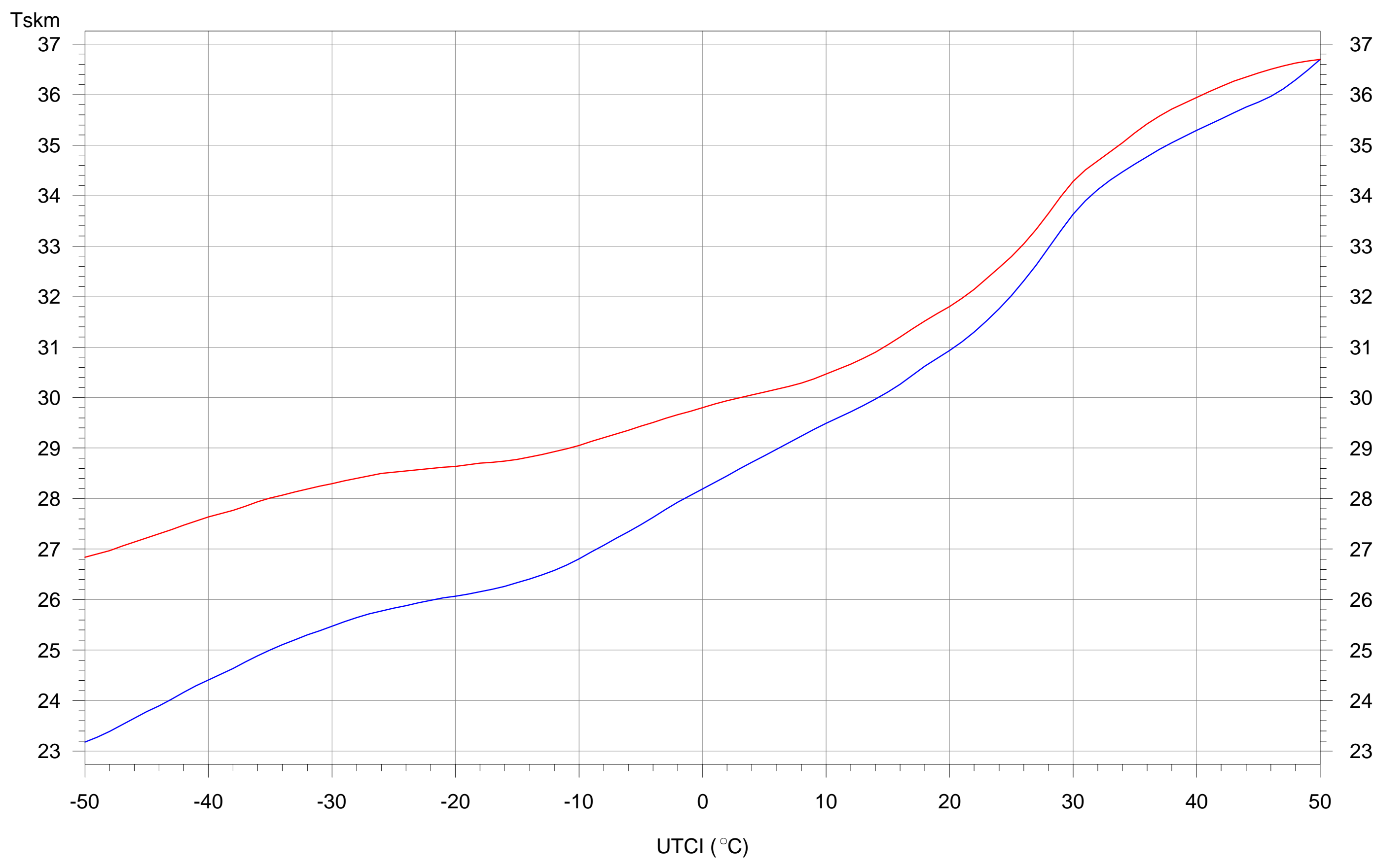

Mean skin temperature (degC) for the reference conditions $30 \mathrm{~min} 120 \mathrm{~min}$ 


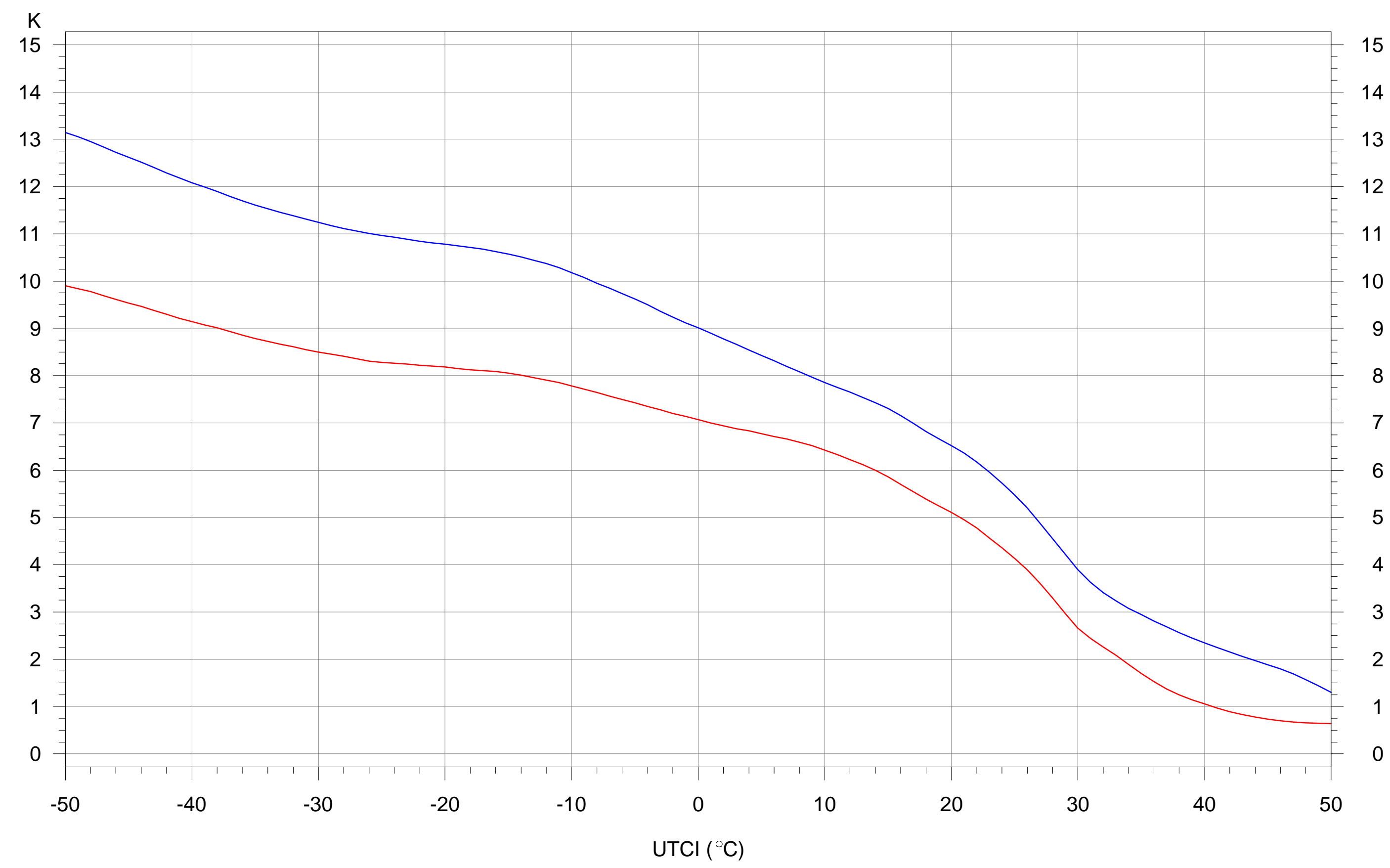

Tre-Tskm (degC) for the reference conditions $30 \mathrm{~min} 120 \mathrm{~min}$ 


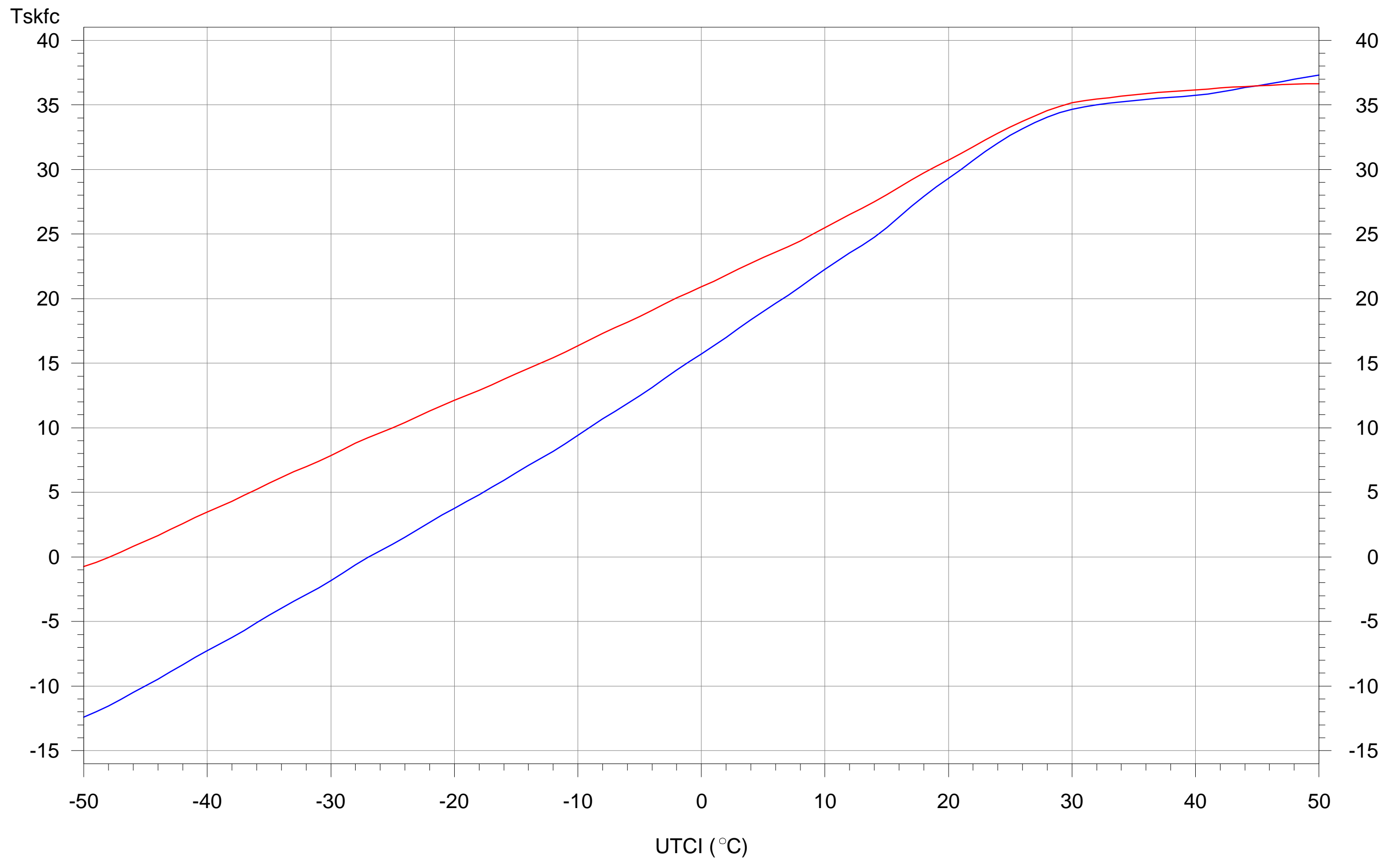

Face skin temperature (degC) for the reference conditions $30 \mathrm{~min} 120 \mathrm{~min}$ 


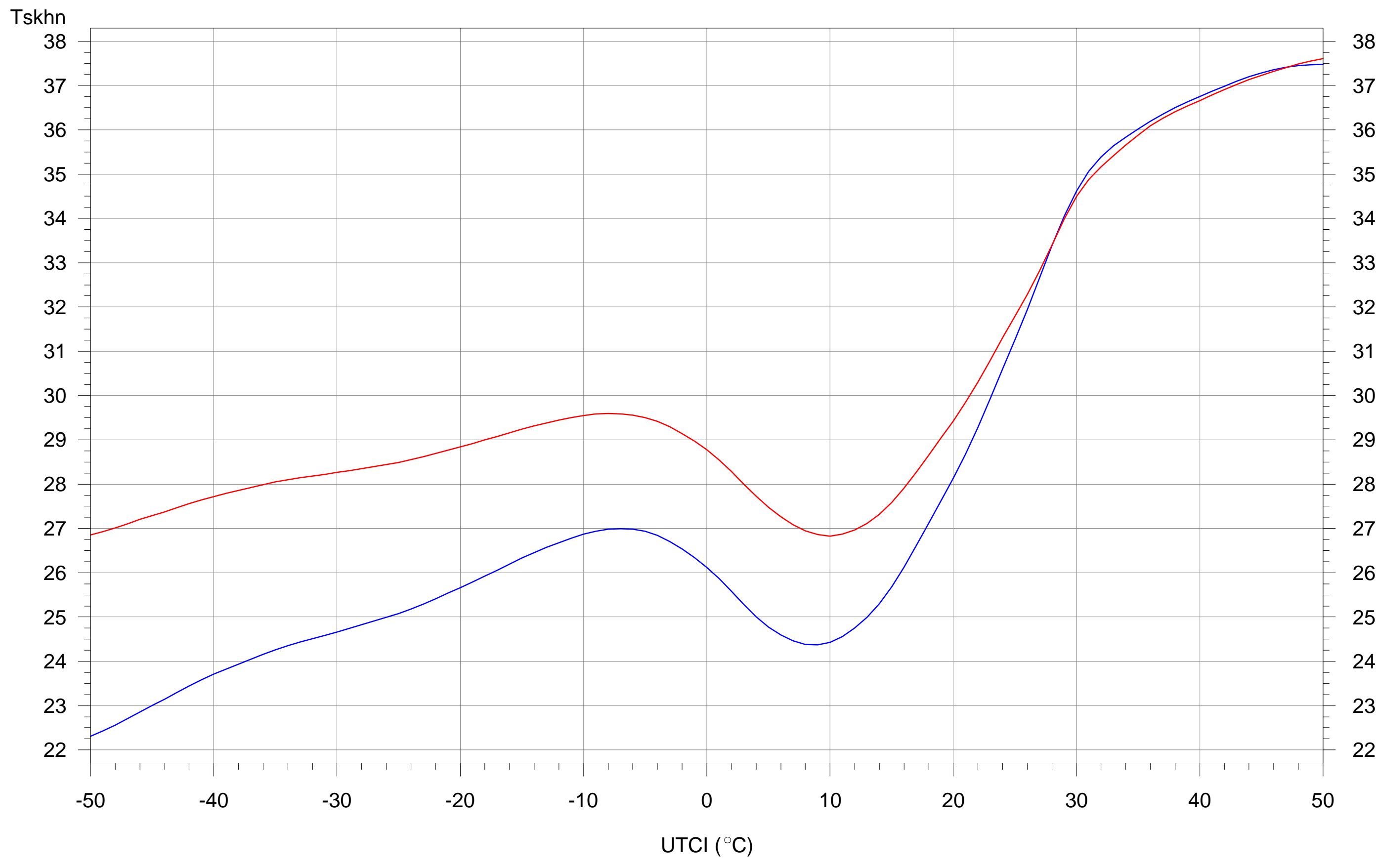

Hand skin temperature (degC) for the reference conditions $30 \mathrm{~min} 120 \mathrm{~min}$ 


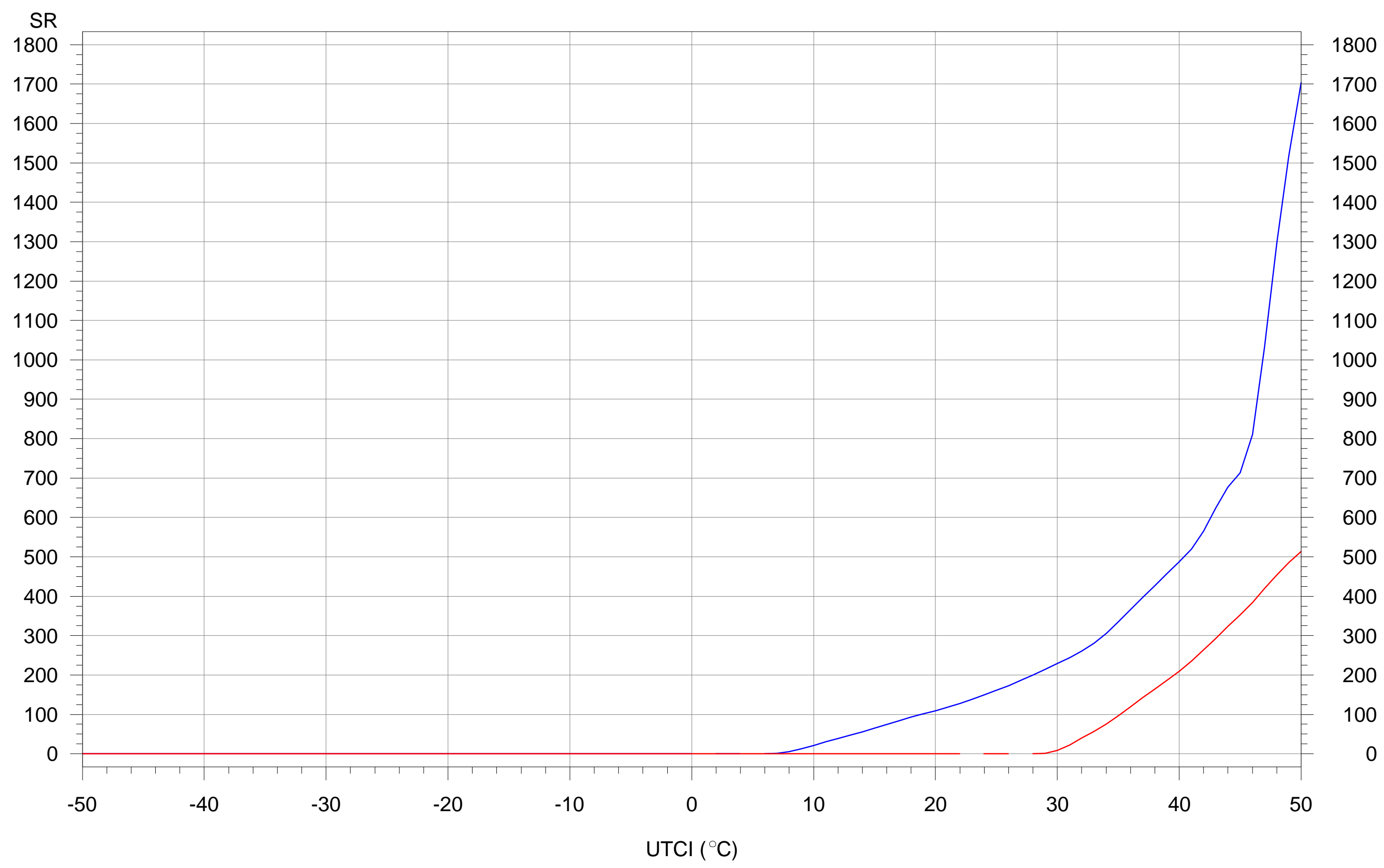

Sweat rate $(g / h)$ for the reference conditions $30 \mathrm{~min} 120 \mathrm{~min}$ 


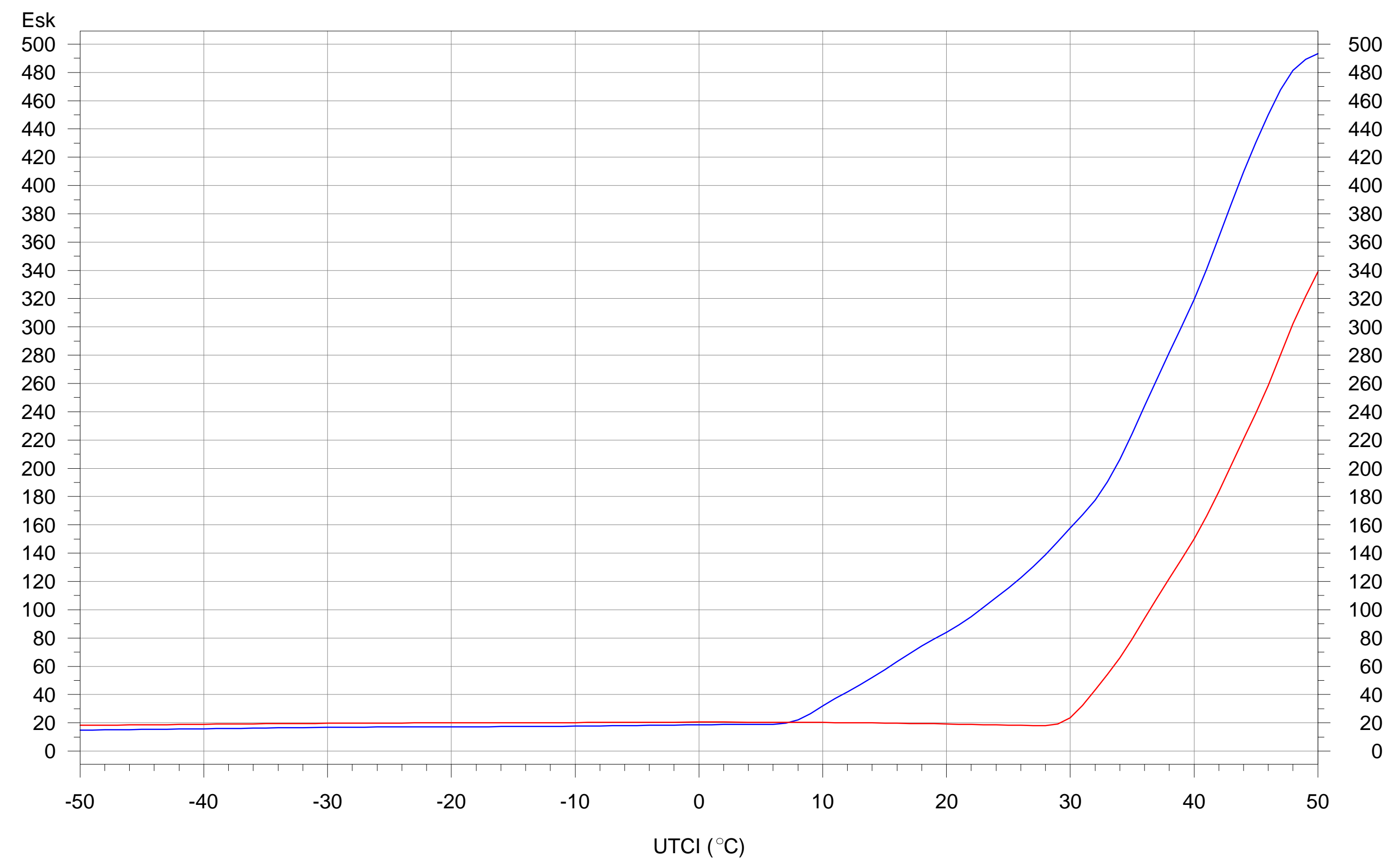

Latent heat loss $(\mathrm{W})$ for the reference conditions $30 \mathrm{~min} 120 \mathrm{~min}$ 


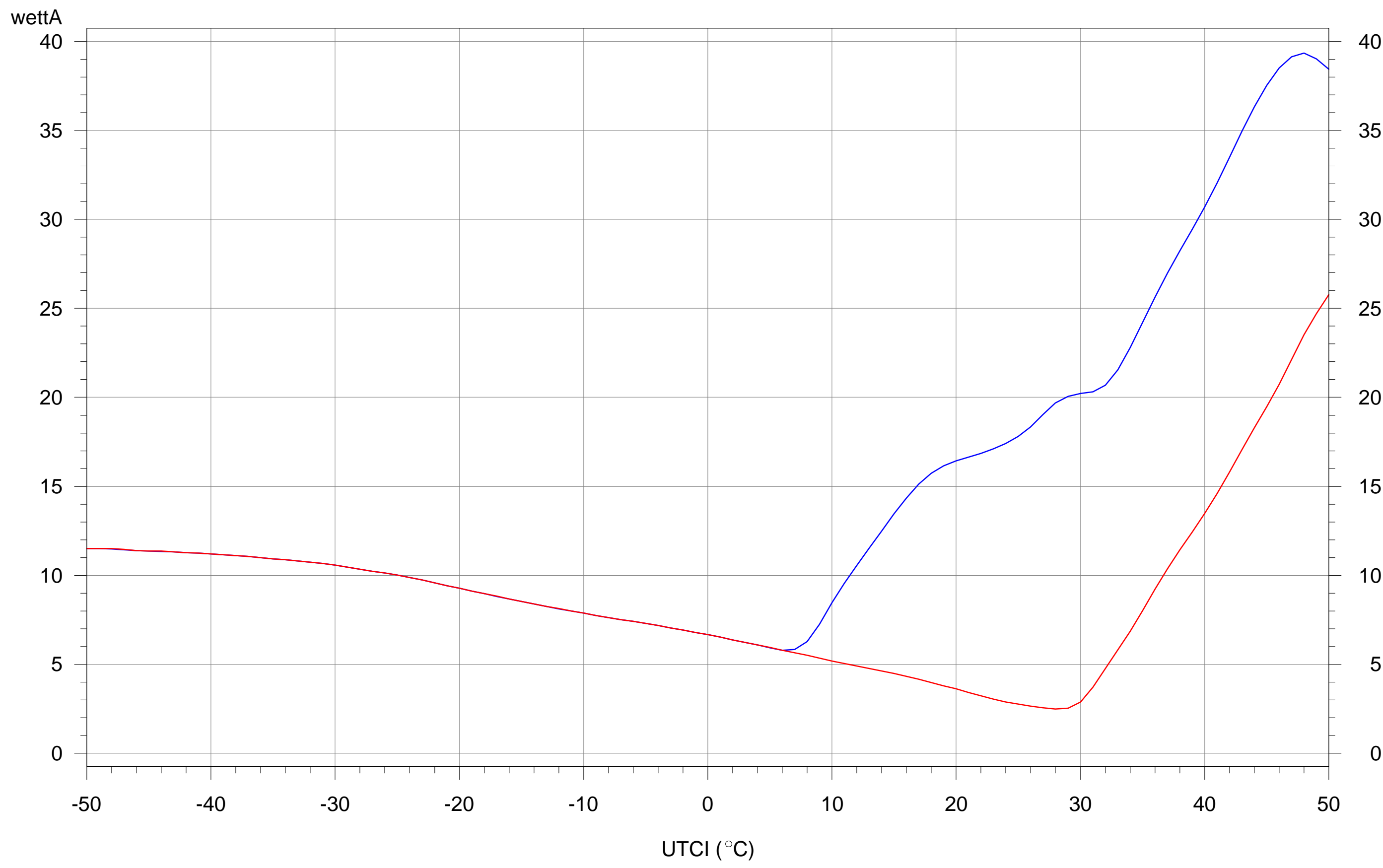

Skin wettedness (\%) for the reference conditions $30 \mathrm{~min} 120 \mathrm{~min}$ 


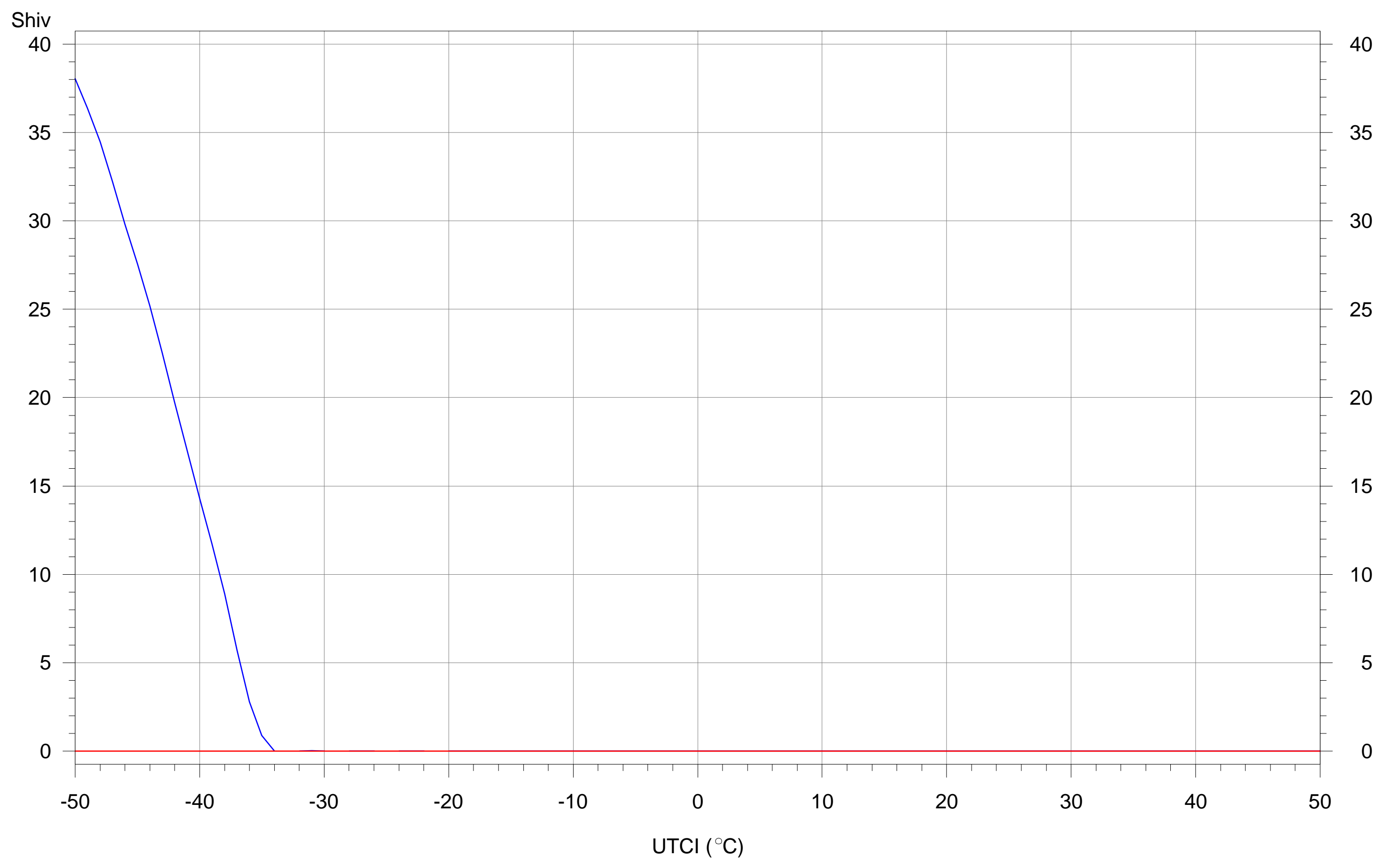

Shivering $(\mathrm{W})$ for the reference conditions $30 \mathrm{~min} 120 \mathrm{~min}$ 


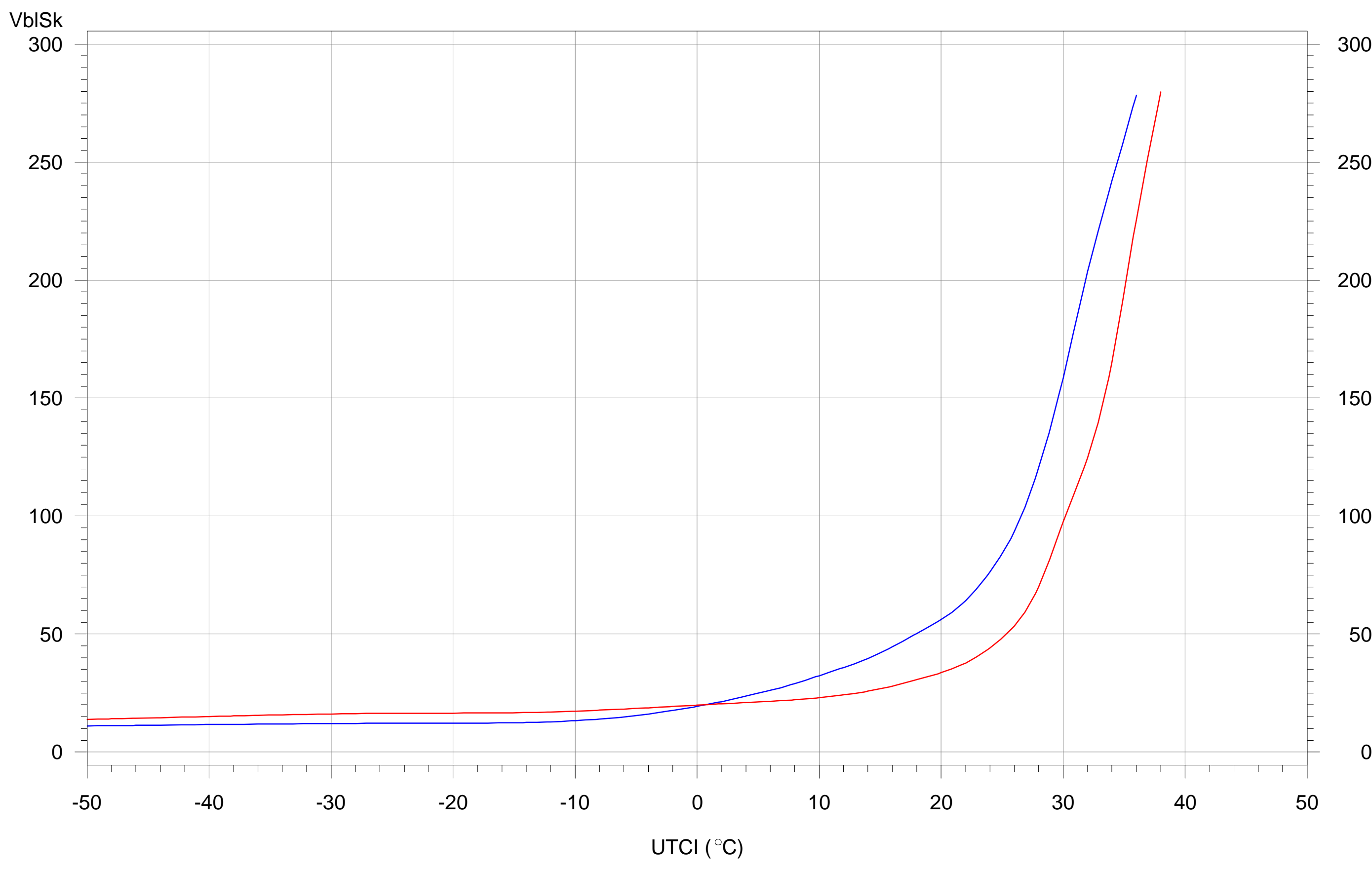

Skin blood flow (\% of basal value) for the reference conditions $30 \mathrm{~min} 120 \mathrm{~min}$ 


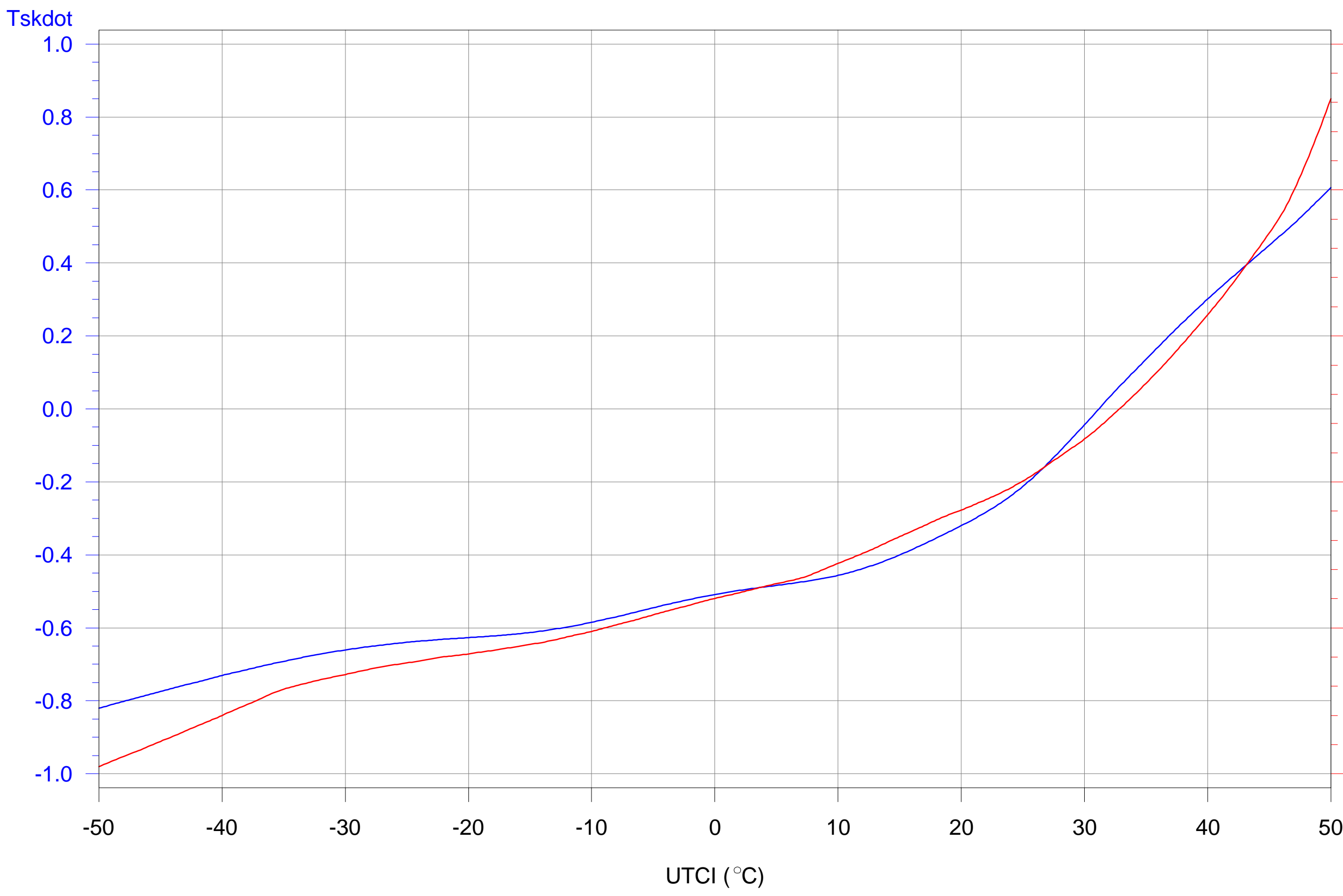

Immediate step change in skin temperature after entering the climate (Tskdot, $\mathrm{K} / \mathrm{min}$ ) Response Index value (nd)

plotted for the reference conditions 
Bröde P, Fiala D, Błażejczyk K, Holmér I, Jendritzky G, Kampmann B, Tinz B, Havenith G Deriving the Operational Procedure for the Universal Thermal Climate Index UTCI

ESM 2 Criteria used for categorizing values of UTCI in terms of thermal stress

\begin{tabular}{|c|c|c|c|}
\hline UTCI $\left({ }^{\circ} \mathrm{C}\right)$ & Criterion derived from UTCI-Fiala model response & Stress Category & UTCl range $\left({ }^{\circ} \mathrm{C}\right)$ \\
\hline 48 & Increase in rectal temperature time gradient & \multirow{3}{*}{ extreme heat stress } & \multirow{3}{*}{ above +46} \\
\hline 48 & steep decrease in total net heat loss & & \\
\hline 46 & averaged sweat rate $>650 \mathrm{~g} / \mathrm{h}$, steep increase & & \\
\hline 40 & core to skin temperature gradient $<1 \mathrm{~K}$ (at $30 \mathrm{~min}$ ) & \multirow{2}{*}{ very strong heat stress } & \multirow{2}{*}{+38 to +46} \\
\hline 38 & increase in rectal temperature at $30 \mathrm{~min}$ & & \\
\hline 36 & Dynamic Thermal Sensation $120 \mathrm{~min}>+2$ & \multirow{5}{*}{ strong heat stress } & \multirow{5}{*}{+32 to +38} \\
\hline 33 & Averaged sweat rate $>200 \mathrm{~g} / \mathrm{h}$ & & \\
\hline 33 & increase in rectal temperature at $120 \mathrm{~min}$ & & \\
\hline 32 & latent heat loss $>40 \mathrm{~W}$ at $30 \mathrm{~min}$ & & \\
\hline 32 & instantaneous change in skin temperature $>0 \mathrm{~K} / \mathrm{min}$ & & \\
\hline 30 & change of slope (vs. UTCI) in Tskm, Tskfc, Tskhn, sweat rate, Tre & \multirow{4}{*}{ moderate heat stress } & \multirow{4}{*}{+26 to +32} \\
\hline 30 & occurrence of sweating at $30 \mathrm{~min}$ & & \\
\hline 30 & steep increase in skin wettedness & & \\
\hline 26 & Averaged sweat rate $>100 \mathrm{~g} / \mathrm{h}$ & & \\
\hline 26 & Dynamic Thermal Sensation $120 \mathrm{~min}<1$ & \multirow{4}{*}{$\begin{array}{c}\text { ("thermal comfort zone") } \\
\text { no thermal stress }\end{array}$} & \multirow{7}{*}{+9 to +26} \\
\hline 26 & Dynamic Thermal Sensation > 0.5 (averaged value) & & \\
\hline 18 & Dynamic Thermal Sensation > -0.5 (averaged value) & & \\
\hline 18 & latent heat loss $>40 \mathrm{~W}$ averaged over time & & \\
\hline 14 & Plateau in rectal temperature time gradient & \multirow{3}{*}{ no thermal stress } & \\
\hline 13 & Dynamic Thermal Sensation $>-0.5$ at $120 \mathrm{~min}$ & & \\
\hline 12 & latent heat loss $>40 \mathrm{~W}$ at $120 \mathrm{~min}$ & & \\
\hline 9 & Dynamic Thermal Sensation 120 min $<-1$ & \multirow{3}{*}{ slight cold stress } & \multirow{3}{*}{+9 to 0} \\
\hline 9 & local minimum of hand skin temperature (put gloves on) & & \\
\hline 8 & Change in slope of mean skin temperature time gradient & & \\
\hline 0 & Dynamic Thermal Sensation $120 \mathrm{~min}<-2$ & \multirow{8}{*}{ moderate cold stress } & \multirow{8}{*}{0 to -13} \\
\hline 0 & skin blood flow at 120 min lower than at 30 min (vasoconstriction) & & \\
\hline-2 & 120 min face skin temperature $<15^{\circ} \mathrm{C}$ (pain) & & \\
\hline-5 & averaged face skin temperature $<15^{\circ} \mathrm{C}$ (pain) & & \\
\hline-10 & Decrease in hand skin temperature & & \\
\hline-10 & rectal temperature time gradient $<0 \mathrm{~K} / \mathrm{h}$ & & \\
\hline-13 & 30 min face skin temperature $<15^{\circ} \mathrm{C}$ (pain) & & \\
\hline-13 & mean skin temperature time gradient $<-1 \mathrm{~K} / \mathrm{h}$ (for reference) & & \\
\hline-14 & 120 min face skin temperature $<7^{\circ} \mathrm{C}$ (numbness) & \multirow{5}{*}{ strong cold stress } & \multirow{5}{*}{-13 to -27} \\
\hline-20 & averaged face skin temperature $<7^{\circ} \mathrm{C}$ (numbness) & & \\
\hline-22 & rectal temperature time gradient $<-0.1 \mathrm{~K} / \mathrm{h}$ & & \\
\hline-24 & Tre decreases from 30 to $120 \mathrm{~min}$ & & \\
\hline-26 & increase in core to skin temperature gradient & & \\
\hline-27 & 120 min face skin temperature $<0^{\circ} \mathrm{C}$ (frostbite) & \multirow{7}{*}{ very strong cold stress } & \multirow{7}{*}{-27 to -40} \\
\hline-30 & steeper decrease in Tre & & \\
\hline-32 & 30 min face skin temperature $<7^{\circ} \mathrm{C}$ (numbness) & & \\
\hline-32 & Occurrence of Shivering & & \\
\hline-33 & rectal temperature time gradient $<-0.2 \mathrm{~K} / \mathrm{h}$ & & \\
\hline-34 & averaged face skin temperature $<0^{\circ} \mathrm{C}$ (frostbite) & & \\
\hline-35 & 120 min face skin temperature $<-5^{\circ} \mathrm{C}$ (high risk of frostbite) & & \\
\hline-40 & rectal temperature time gradient $<-0.3 \mathrm{~K} / \mathrm{h}$ & \multirow{2}{*}{ extreme cold stress } & \multirow{2}{*}{ below -40} \\
\hline-48 & 30 min face skin temperature $<0^{\circ} \mathrm{C}$ (frostbite) & & \\
\hline
\end{tabular}


ESM 3 Coefficients of a $6^{\text {th }}$ order polynomial regression function approximating the Offset $(=\mathrm{UTCl}-$ $\mathrm{Ta}$ ) in ${ }^{\circ} \mathrm{C}$ from input values of air temperature (Ta) in ${ }^{\circ} \mathrm{C}$, of wind speed $10 \mathrm{~m}$ above ground level (va) in $\mathrm{m} / \mathrm{s}$, of water vapour pressure (pa) in $\mathrm{kPa}$ and of the difference between mean radiant temperature and air temperature $(\mathbf{t m})$ in ${ }^{\circ} \mathrm{C}$. The equation is valid for the input parameters ranging as follows: $-50{ }^{\circ} \mathrm{C} \leq \mathrm{Ta} \leq+50^{\circ} \mathrm{C}$, va $\leq 30.3 \mathrm{~m} / \mathrm{s},-30^{\circ} \mathrm{C} \leq \mathrm{tm} \leq+70{ }^{\circ} \mathrm{C}$, pa $\leq 5 \mathrm{kPa}$ (relative humidity $\leq 100 \%$ )

\section{Polynomial regression equation for Offset $=\mathrm{UTCl}-\mathrm{Ta}\left({ }^{\circ} \mathrm{C}\right)$}

Ta: air temperature $\left({ }^{\circ} \mathrm{C}\right)$

va: wind speed in $10 \mathrm{~m}$ height $(\mathrm{m} / \mathrm{s})$

tm: $\Delta \operatorname{Tmrt}=\operatorname{Tr}-\mathrm{Ta}\left({ }^{\circ} \mathrm{C}\right)$

polynomial term

constant term

$\mathrm{Ta}$

$\mathrm{Ta}^{*} \mathrm{Ta}$

$\mathrm{Ta}^{*} \mathrm{Ta}^{*} \mathrm{Ta}$

$\mathrm{Ta}^{*} \mathrm{Ta}^{*} \mathrm{Ta}{ }^{*} \mathrm{Ta}$

$\mathrm{Ta}^{*} \mathrm{Ta}^{*} \mathrm{Ta}^{*} \mathrm{Ta}^{*} \mathrm{Ta}$

$\mathrm{Ta}^{*} \mathrm{Ta}^{*} \mathrm{Ta}^{*} \mathrm{Ta}^{*} \mathrm{Ta}{ }^{*} \mathrm{Ta}$

va

Ta*va

$\mathrm{Ta}^{*} \mathrm{Ta}^{*} \mathrm{va}$

$\mathrm{Ta}^{*} \mathrm{Ta}^{*} \mathrm{Ta}{ }^{*} \mathrm{va}$

$\mathrm{Ta}^{*} \mathrm{Ta}^{*} \mathrm{Ta}^{*}{ }^{*} \mathrm{Ta}^{*} \mathrm{va}$

Ta*Ta*Ta*Ta*Ta*va

va*va

$\mathrm{Ta}^{*} \mathrm{va}^{*} \mathrm{va}$

$\mathrm{Ta}^{*} \mathrm{Ta}^{*} \mathrm{va}{ }^{*} \mathrm{va}$

$\mathrm{Ta}^{*} \mathrm{Ta}^{*} \mathrm{Ta}^{*}{ }^{*} \mathrm{va}^{*} \mathrm{va}$

$\mathrm{Ta}^{*} \mathrm{Ta}^{*} \mathrm{Ta}^{*} \mathrm{Ta}^{*}{ }^{*}{ }^{*} \mathrm{va}$

va*va*va

Ta*va*va*va

$\mathrm{Ta}^{*} \mathrm{Ta}^{*} \mathrm{va}^{*} \mathrm{va}$ va

$\mathrm{Ta}^{*} \mathrm{Ta}^{*} \mathrm{Ta}^{*} \mathrm{va}^{*} \mathrm{va}{ }^{*} \mathrm{va}$

$v^{*} \mathrm{va}^{*} \mathrm{va} a^{*} \mathrm{va}$

Ta*va*va*va*va

Ta*Ta*va*va*va*va

va*va*va*va*va

Ta*va* $a^{*}{ }^{*} a^{*} a^{*} v a$

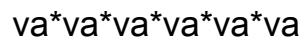

tm

$\mathrm{Ta}{ }^{*} \mathrm{tm}$

Ta*Ta*tm

$\mathrm{Ta}^{*} \mathrm{Ta}^{*} \mathrm{Ta} \mathrm{a}^{*} \mathrm{tm}$

$\mathrm{Ta}^{*} \mathrm{Ta}^{*} \mathrm{Ta}^{*} \mathrm{Ta}^{*} \mathrm{tm}$

$\mathrm{Ta}^{*} \mathrm{Ta}^{*} \mathrm{Ta}^{*} \mathrm{Ta}^{*} \mathrm{Ta}{ }^{*} \mathrm{tm}$

va*tm

$\mathrm{Ta}^{*} \mathrm{va}^{*} \mathrm{tm}$

$\mathrm{Ta}^{*} \mathrm{Ta}^{*} \mathrm{va}^{*} \mathrm{tm}$

$\mathrm{Ta}^{*} \mathrm{Ta}^{*} \mathrm{Ta}^{*} \mathrm{va}^{*} \mathrm{tm}$

$\mathrm{Ta}^{*} \mathrm{Ta}^{*} \mathrm{Ta}^{*} \mathrm{Ta}^{*} \mathrm{Va}^{*} \mathrm{tm}$

va*va*tm

$\mathrm{Ta}^{*} \mathrm{va}^{*} \mathrm{va}^{*} \mathrm{tm}$

$\mathrm{Ta}^{*} \mathrm{Ta}^{*} \mathrm{va}^{*} \mathrm{va}^{*} \mathrm{tm}$

$\mathrm{Ta}^{*} \mathrm{Ta}^{*} \mathrm{Ta}^{*} \mathrm{va}^{*} \mathrm{va}^{*} \mathrm{tm}$

va* ${ }^{*}{ }^{*} v^{*}{ }^{*} \mathrm{tm}$

$\mathrm{Ta}^{*} \mathrm{va}^{*} \mathrm{va}^{*} \mathrm{va} \mathrm{*}^{*} \mathrm{~m}$

$\mathrm{Ta}^{*} \mathrm{Ta}^{*} \mathrm{va}^{*} \mathrm{va}^{*} \mathrm{va}^{*} \mathrm{tm}$

va*va*va*va*tm

$\mathrm{Ta}^{*} \mathrm{va}^{*} \mathrm{va}^{*} \mathrm{va}^{*} \mathrm{va} \mathrm{A}^{*} \mathrm{~m}$ $v^{*} v^{*} v^{*} a^{*} a^{*} a^{*} t m$ $\mathrm{tm}^{\star} \mathrm{tm}$

pa: water vapour pressure $(\mathrm{kPa})$

coefficient

6.07562052E-01

$-2.27712343 \mathrm{E}-02$

8.06470249E-04

$-1.54271372 \mathrm{E}-04$

$-3.24651735 \mathrm{E}-06$

7.32602852E-08

1.35959073E-09

$-2.25836520 \mathrm{E}+00$

8.80326035E-02

2.16844454E-03

$-1.53347087 \mathrm{E}-05$

$-5.72983704 \mathrm{E}-07$

$-2.55090145 \mathrm{E}-09$

$-7.51269505 \mathrm{E}-01$

$-4.08350271 \mathrm{E}-03$

$-5.21670675 \mathrm{E}-05$

1.94544667E-06

1.14099531E-08

1.58137256E-01

$-6.57263143 \mathrm{E}-05$

2.22697524E-07

$-4.16117031 \mathrm{E}-08$

$-1.27762753 \mathrm{E}-02$

9.66891875E-06

2.52785852E-09

4.56306672E-04

$-1.74202546 \mathrm{E}-07$

$-5.91491269 \mathrm{E}-06$

3.98374029E-01

1.83945314E-04

$-1.73754510 \mathrm{E}-04$

$-7.60781159 \mathrm{E}-07$

3.77830287E-08

$5.43079673 \mathrm{E}-10$

$-2.00518269 \mathrm{E}-02$

8.92859837E-04

3.45433048E-06

$-3.77925774 \mathrm{E}-07$

$-1.69699377 \mathrm{E}-09$

1.69992415E-04

$-4.99204314 \mathrm{E}-05$

$2.47417178 \mathrm{E}-07$

1.07596466E-08

8.49242932E-05

1.35191328E-06

$-6.21531254 \mathrm{E}-09$

$-4.99410301 \mathrm{E}-06$

$-1.89489258 \mathrm{E}-08$

8.15300114E-08

7.55043090E-04

polynomial term coefficient

$\mathrm{tm}^{*} \mathrm{pa}$

$-3.69476348 \mathrm{E}-02$

1.62325322E-03

$-3.14279680 \mathrm{E}-05$

$\mathrm{Ta}^{*} \mathrm{Ta}^{*} \mathrm{tm}^{*} \mathrm{pa}$

$2.59835559 \mathrm{E}-06$

$\mathrm{Ta}^{*} \mathrm{Ta}^{*} \mathrm{Ta}^{*} \mathrm{tm}^{*} \mathrm{pa}$

$-4.77136523 \mathrm{E}-08$

va*tm* pa

$T a^{*} \mathrm{va}^{*} \mathrm{tm}^{*} \mathrm{pa}$

$\mathrm{Ta}^{*} \mathrm{Ta}^{*} \mathrm{va}^{*} \mathrm{tm}^{*} \mathrm{pa}$

$8.64203390 \mathrm{E}-03$

$-6.87405181 \mathrm{E}-04$

Ta*Ta*Ta*va*tm* pa

$5.15916806 \mathrm{E}-07$

$-3.59217476 \mathrm{E}-05$

Ta*va*va*tm* $\quad 3.28696511 \mathrm{E}-05$

$\mathrm{Ta}^{*} \mathrm{Ta}^{*} \mathrm{va}^{*} \mathrm{va}^{*} \mathrm{tm}^{*} \mathrm{pa} \quad-7.10542454 \mathrm{E}-07$

$\mathrm{va}^{*} \mathrm{va}^{*} \mathrm{va}^{*} \mathrm{tm}^{*} \mathrm{pa} \quad-1.24382300 \mathrm{E}-05$

$\mathrm{Ta}^{*} \mathrm{va}^{*} \mathrm{va}^{*} \mathrm{va}^{*} \mathrm{tm}^{*} \mathrm{pa} \quad-7.38584400 \mathrm{E}-09$

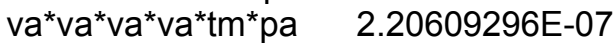

$\mathrm{tm}^{*} \mathrm{tm}^{*} \mathrm{pa}$

$\mathrm{Ta}^{*} \mathrm{tm}^{*} \mathrm{tm}^{*} \mathrm{pa}$

$-7.32469180 \mathrm{E}-04$

$-1.87381964 \mathrm{E}-05$

$\begin{array}{lr}\mathrm{Ta}^{*} \mathrm{Ta}^{*} \mathrm{tm}^{*} \mathrm{tm}^{*} \mathrm{pa} & 4.80925239 \mathrm{E}-06 \\ \mathrm{Ta}^{*} \mathrm{Ta}^{*} \mathrm{Ta}^{*} \mathrm{tm}^{*} \mathrm{tm}{ }^{*} \text { pa } & -8.75492040 \mathrm{E}-08\end{array}$

va*tm*tm ${ }^{*}$ pa

$\mathrm{Ta}^{*} \mathrm{va}^{*} \mathrm{tm}^{*} \mathrm{tm}^{*} \mathrm{pa}$

$2.77862930 \mathrm{E}-05$

$-5.06004592 \mathrm{E}-06$

$\mathrm{Ta}^{*} \mathrm{Ta}^{*} \mathrm{va}^{*} \mathrm{tm}^{*} \mathrm{tm}^{*} \mathrm{pa} \quad 1.14325367 \mathrm{E}-07$

va* ${ }^{*}{ }^{*} \mathrm{tm}^{*} \mathrm{tm}^{*} \mathrm{pa} \quad 2.53016723 \mathrm{E}-06$

$\mathrm{Ta}^{*} \mathrm{va}^{*} \mathrm{va}^{*} \mathrm{tm}^{*} \mathrm{tm}^{*} \mathrm{pa} \quad-1.72857035 \mathrm{E}-08$

va*va*va*tm*tm* pa $\quad-3.95079398 \mathrm{E}-08$

$\mathrm{tm}^{*} \mathrm{tm}^{*} \mathrm{tm}^{*} \mathrm{pa}$

$\mathrm{Ta}^{*} \mathrm{tm}^{*} \mathrm{tm}^{*} \mathrm{tm}^{*} \mathrm{pa}$

$\mathrm{Ta}^{*} \mathrm{Ta}^{*} \mathrm{tm}^{*} \mathrm{tm}^{*} \mathrm{tm}^{*} \mathrm{pa}$

va*tm*tm*tm* pa

$\mathrm{Ta}^{*} \mathrm{va}^{*} \mathrm{tm}^{*} \mathrm{tm}^{*} \mathrm{tm} \mathrm{m}^{*} \mathrm{pa}$

va* $\mathrm{va}^{*} \mathrm{tm}^{*} \mathrm{tm}^{*} \mathrm{tm} \mathrm{m}^{*} \mathrm{pa}$

$\mathrm{tm}^{*} \mathrm{tm}^{*} \mathrm{tm}^{*} \mathrm{tm}^{*} \mathrm{pa}$

$\mathrm{Ta}^{*} \mathrm{tm}^{*} \mathrm{tm}^{*} \mathrm{tm}^{*} \mathrm{tm}^{*} \mathrm{pa}$

va*tm ${ }^{*} \mathrm{tm}^{\star} \mathrm{tm}^{\star} \mathrm{tm} \mathrm{m}^{*} \mathrm{pa}$

$\mathrm{tm}^{*} \mathrm{tm}^{*} \mathrm{tm}^{*} \mathrm{tm}^{*} \mathrm{tm} \mathrm{m}^{*} \mathrm{pa}$

pa*pa

Ta*pa*pa

$\mathrm{Ta}^{*} T a^{*} \mathrm{pa}^{*} \mathrm{pa}$

Ta*Ta*Ta*pa*pa

$-3.59413173 \mathrm{E}-07$

$7.04388046 \mathrm{E}-07$

$-1.89309167 \mathrm{E}-08$

$-4.79768731 \mathrm{E}-07$

7.96079978E-09

$1.62897058 \mathrm{E}-09$

3.94367674E-08

$-1.18566247 \mathrm{E}-09$

$3.34678041 \mathrm{E}-10$

$-1.15606447 \mathrm{E}-10$

$-2.80626406 \mathrm{E}+00$

$5.48712484 \mathrm{E}-01$

$-3.99428410 \mathrm{E}-03$

$-9.54009191 \mathrm{E}-04$

$\mathrm{Ta}^{*}{ }^{*}{ }^{*}{ }^{*} \mathrm{Ta}^{*} \mathrm{Ta}^{*}$ pa* pa $1.93090978 \mathrm{E}-05$

va*pa*pa

$-3.08806365 \mathrm{E}-01$

$T a^{*} v a^{*} p^{*} p a$

$1.16952364 \mathrm{E}-02$

$\mathrm{Ta}^{*} \mathrm{Ta}^{*} \mathrm{va}^{*} \mathrm{pa}{ }^{*} \mathrm{pa}$

$\mathrm{Ta}^{*} \mathrm{Ta}^{*} T \mathrm{Ta}^{*} \mathrm{va}^{*} \mathrm{pa}^{*} \mathrm{pa}$

va*va*pa*pa

$\mathrm{Ta}^{*} \mathrm{va}^{*} \mathrm{va}{ }^{*} \mathrm{pa}{ }^{*} \mathrm{pa}$

$\mathrm{Ta}^{*} T a^{*} \mathrm{va}^{*} \mathrm{va}^{*} \mathrm{pa} \mathrm{a}^{*} \mathrm{pa}$

va*va*va*pa*pa

$\mathrm{Ta}^{*} \mathrm{va}^{*} \mathrm{va}^{*} \mathrm{va}^{*} \mathrm{pa}{ }^{*} \mathrm{pa}$

va*va*va*va*pa*pa
4.95271903E-04

$-1.90710882 E-05$

2.10787756E-03

$-6.98445738 \mathrm{E}-04$

2.30109073E-05

4.17856590E-04

$-1.27043871 \mathrm{E}-05$

$-3.04620472 E-06$ 
Bröde P, Fiala D, Błażejczyk K, Holmér I, Jendritzky G, Kampmann B, Tinz B, Havenith G Deriving the Operational Procedure for the Universal Thermal Climate Index UTCI

Polynomial regression equation for Offset $=\mathrm{UTCl}-\mathrm{Ta}\left({ }^{\circ} \mathrm{C}\right)$

Ta: air temperature $\left({ }^{\circ} \mathrm{C}\right)$

va: wind speed in $10 \mathrm{~m}$ height $(\mathrm{m} / \mathrm{s})$

polynomia

$\mathrm{Ta}{ }^{*} \mathrm{Ta}^{*} \mathrm{tm}^{*} \mathrm{tm}$

$\mathrm{Ta}^{*} \mathrm{Ta}^{*} \mathrm{Ta}^{*} \mathrm{tm}^{*} \mathrm{tm}$

Ta*Ta*Ta*Ta*tm*tm

va*tm*tm

$\mathrm{Ta}^{*} \mathrm{va}^{*} \mathrm{tm}^{*} \mathrm{tm}$

$\mathrm{Ta}^{*} \mathrm{Ta}^{*} \mathrm{va}^{*} \mathrm{tm}^{*} \mathrm{tm}$

$\mathrm{Ta}^{*} \mathrm{Ta}^{*} \mathrm{Ta}^{*} \mathrm{va}^{*} \mathrm{tm}{ }^{*} \mathrm{tm}$

$v a^{*} v a^{*} t^{*} t m$

$\mathrm{Ta}^{*} \mathrm{va}^{*} \mathrm{va} \mathrm{tm}^{*} \mathrm{tm}$

Ta*Ta*va*va*tm*tm

va*va*va*tm ${ }^{*}$ tm

Ta*va*va*va*tm*tm

va*va*va*va*tm*tm

$\mathrm{tm}^{*} \mathrm{tm}^{*} \mathrm{tm}$

$\mathrm{Ta}^{*} \mathrm{tm}^{*} \mathrm{tm}^{*} \mathrm{tm}$

$\mathrm{Ta}^{*} \mathrm{Ta}^{*} \mathrm{tm}^{*}{ }^{*}{ }^{*} \mathrm{tm}$

$\mathrm{Ta}{ }^{*} \mathrm{Ta}{ }^{*} \mathrm{Ta}^{*} \mathrm{tm}^{*} \mathrm{tm}^{*} \mathrm{tm}$

va*tm*tm*tm

Ta*va*tm*tm ${ }^{*} \mathrm{tm}$

$\mathrm{Ta}^{*} \mathrm{Ta}^{*} \mathrm{va}^{*} \mathrm{tm}^{*} \mathrm{tm}^{*} \mathrm{tm}$

va* $\mathrm{va}^{*} \mathrm{tm}^{*} \mathrm{tm}^{*} \mathrm{tm}$

Ta* va* $a^{*} \mathrm{tm}^{*} \mathrm{tm}^{*} \mathrm{tm}$

va*va*va*tm*tm*tm

$\mathrm{tm}^{*} \mathrm{tm}^{*} \mathrm{tm}^{*} \mathrm{tm}$

$\mathrm{Ta}^{*} \mathrm{tm}^{*} \mathrm{tm}^{*} \mathrm{tm}^{*} \mathrm{tm}$

$\mathrm{Ta}{ }^{*} \mathrm{Ta}^{*} \mathrm{tm}^{*} \mathrm{tm}^{*}{ }^{*}{ }^{*} \mathrm{tm}$

va*tm ${ }^{*} \mathrm{tm}^{*} \mathrm{tm}^{*} \mathrm{tm}$

$\mathrm{Ta}^{*} \mathrm{va}^{*} \mathrm{tm}^{*} \mathrm{tm}^{*} \mathrm{tm}^{\star} \mathrm{tm}$

va*va*tm ${ }^{*} \mathrm{tm}^{*} \mathrm{tm}^{*} \mathrm{tm}$

$\mathrm{tm}^{*} \mathrm{tm}^{*} \mathrm{tm}^{*} \mathrm{tm}^{*} \mathrm{tm}$

$\mathrm{Ta}^{*} \mathrm{tm}^{*} \mathrm{tm}^{*}{ }^{*} \mathrm{~m}^{*} \mathrm{tm}^{*} \mathrm{tm}$

va*tm ${ }^{*} \mathrm{tm}^{\star} \mathrm{tm}^{\star} \mathrm{tm}^{*} \mathrm{tm}$

$\mathrm{tm}^{*} \mathrm{tm}^{*} \mathrm{tm}^{*}{ }^{*}{ }^{*} \mathrm{tm}^{*} \mathrm{tm}$

pa

Ta*pa

Ta*Ta*pa

Ta*Ta*Ta*pa

Ta*Ta*Ta*Ta*pa

Ta*Ta*Ta*Ta*Ta*pa

va*pa

Ta*va*pa

Ta*Ta*va*pa

Ta*Ta*Ta*va*pa

Ta*Ta*Ta*Ta*va*pa

va*va*pa

$T a^{*} v a^{*} v a a^{*} p a$

$\mathrm{Ta}^{*} \mathrm{Ta}^{*} \mathrm{va}^{*} \mathrm{va}{ }^{*} \mathrm{pa}$

$\mathrm{Ta}^{*} \mathrm{Ta}^{*} \mathrm{Ta}^{*} \mathrm{va}^{*} \mathrm{va} \mathrm{a}^{*} \mathrm{pa}$

va*va*va*pa

$\mathrm{Ta}^{*} \mathrm{va}^{*} \mathrm{va}^{*} \mathrm{va}{ }^{*} \mathrm{pa}$

Ta*Ta*va*va*va*pa

va*va*va*va*pa

Ta*va*va*va*va*pa

va*va*va*va*va*pa

$-8.75874982 \mathrm{E}-08$

$-2.18203660 \mathrm{E}-07$

$-2.24730961 \mathrm{E}-11$ tm: $\Delta \mathrm{Tmrt}=\mathrm{Tr}-\mathrm{Ta}\left({ }^{\circ} \mathrm{C}\right)$

pa: water vapour pressure $(\mathrm{kPa})$

polynomial term coefficient

$-5.65095215 \mathrm{E}-05$

$-4.52166564 \mathrm{E}-07$

2.46688878E-08

$2.42674348 \mathrm{E}-10$

$1.54547250 \mathrm{E}-04$

5.24110970E-06

$-1.50743064 \mathrm{E}-09$

$-1.56236307 \mathrm{E}-05$

$-1.33895614 \mathrm{E}-07$

2.49709824E-09

6.51711721E-07

1.94960053E-09

$-1.00361113 \mathrm{E}-08$

$-1.21206673 \mathrm{E}-05$

7.51269482E-09

$9.79063848 \mathrm{E}-11$

1.25006734E-06

-1.81584736E-09

$-3.52197671 \mathrm{E}-10$

$-3.36514630 \mathrm{E}-08$

1.35908359E-10

4.17032620E-10

$-1.30369025 \mathrm{E}-09$

4.13908461E-10

$9.22652254 \mathrm{E}-12$

$-5.08220384 \mathrm{E}-09$

$1.17139133 \mathrm{E}-10$

6.62154879E-10

$4.03863260 \mathrm{E}-13$

$1.95087203 \mathrm{E}-12$

$-4.73602469 \mathrm{E}-12$

$5.12733497 \mathrm{E}+00$

$-3.12788561 \mathrm{E}-01$

$-1.96701861 \mathrm{E}-02$

9.99690870E-04

9.51738512E-06

$-4.66426341 \mathrm{E}-07$

5.48050612E-01

$-3.30552823 \mathrm{E}-03$

-1.64119440E-03

$-5.16670694 \mathrm{E}-06$

9.52692432E-07

$-4.29223622 \mathrm{E}-02$

5.00845667E-03

1.00601257E-06

$-1.81748644 \mathrm{E}-06$

$-1.25813502 \mathrm{E}-03$

$-1.79330391 \mathrm{E}-04$

2.34994441E-06

1.29735808E-04

1.29064870E-06

$-2.28558686 \mathrm{E}-06$

\section{tm*pa*pa}

$\mathrm{Ta}^{*} \mathrm{tm}^{*} \mathrm{pa} \mathrm{a}^{*} \mathrm{pa}$

Ta*Ta*tm*pa*pa

Ta*Ta*Ta*tm*pa*pa

va*tm* pa*pa

Ta*va*tm*pa*pa

Ta*Ta*va*tm*pa*pa

va*va*tm ${ }^{*}$ pa*pa

Ta*va*va*tm* pa*pa

va*va*va*tm ${ }^{*}$ pa*pa

$\mathrm{tm}^{*} \mathrm{tm}^{*}$ pa*pa

Ta*tm*tm*pa*pa

Ta* Ta*tm*tm ${ }^{*} a^{*} p a$

va*tm ${ }^{*} \mathrm{tm}^{*} \mathrm{pa}{ }^{*} \mathrm{pa}$

Ta*va*tm*tm* ${ }^{*} a^{*}$ pa

va*va*tm ${ }^{*} \mathrm{tm}^{*}$ pa*pa

$\mathrm{tm}^{*} \mathrm{tm}^{*} \mathrm{tm}^{*} \mathrm{pa}{ }^{*} \mathrm{pa}$

Ta*tm ${ }^{*} \mathrm{tm}^{*} \mathrm{tm}^{*}$ pa* $\mathrm{pa}$

va*tm ${ }^{*} \mathrm{tm}^{*} \mathrm{tm}^{*}$ pa* $\mathrm{pa}$

$\mathrm{tm}^{\star} \mathrm{tm}^{*} \mathrm{tm}^{*} \mathrm{tm}^{*} \mathrm{pa} \mathrm{a}^{*} \mathrm{pa}$

pa*pa*pa

Ta*pa*pa*pa

Ta*Ta*pa*pa*pa

Ta*Ta*Ta*pa*pa*pa

va*pa*pa*pa

Ta*va*pa*pa*pa

Ta*Ta*va*pa*pa*pa

va*va*pa*pa*pa

Ta*va*va*pa*pa*pa

va*va*va*pa*pa*pa

tm*pa*pa*pa

Ta*tm* ${ }^{*} a^{*} p a^{*} p a$

Ta*Ta*tm*pa*pa*pa

va*tm*pa*pa*pa

Ta*va*tm* ${ }^{*} a^{*} p a^{*} p a$

va*va*tm* ${ }^{*} a^{*}$ pa*pa

$\mathrm{tm}^{*} \mathrm{tm}^{*}$ pa* $\mathrm{a}^{*} \mathrm{pa}$

Ta*tm*tm* ${ }^{*} a^{*}$ pa*pa va*tm ${ }^{\star} \mathrm{tm}^{\star}{ }^{*} \mathrm{pa}^{*} \mathrm{pa} \mathrm{a}^{*} \mathrm{pa}$ $\mathrm{tm}^{\star} \mathrm{tm}^{\star} \mathrm{tm}^{\star} \mathrm{pa}^{*} \mathrm{pa} \mathrm{a}^{\star} \mathrm{pa}$ pa*pa*pa*pa

Ta*pa*pa*pa*pa

Ta*Ta*pa*pa*pa*pa

va*pa*pa*pa*pa

Ta*va*pa* $a^{*} p a^{*} p a$ va*va*pa*pa*pa*pa $\mathrm{tm}^{*} p a^{\star} p a^{\star} p a^{\star} p a$

Ta*tm* $a^{\star}$ pa*pa*pa va*tm* ${ }^{*} a^{*} p a^{*} p a^{*} p a$ $\mathrm{tm}^{\star} \mathrm{tm}^{*}$ pa* $\mathrm{a}^{*}$ pa* $\mathrm{pa}$ pa* $a^{*} p a^{*} p a^{*} p a$

Ta*pa*pa*pa*pa*pa va*pa*pa*pa*pa*pa $\mathrm{tm}^{*}$ pa*pa* $a^{*}$ pa* ${ }^{*}$ a pa*pa*pa* $a^{*} a^{*} a^{*} p a$
5.14507424E-02

$-4.32510997 \mathrm{E}-03$

8.99281156E-05

$-7.14663943 E-07$ $-2.66016305 E-04$

2.63789586E-04

$-7.01199003 E-06$

$-1.06823306 \mathrm{E}-04$

3.61341136E-06

2.29748967E-07

3.04788893E-04

$-6.42070836 \mathrm{E}-05$

1.16257971E-06

7.68023384E-06

$-5.47446896 \mathrm{E}-07$

$-3.59937910 \mathrm{E}-08$

$-4.36497725 \mathrm{E}-06$

1.68737969E-07

2.67489271E-08

3.23926897E-09

$-3.53874123 E-02$

$-2.21201190 \mathrm{E}-01$

1.55126038E-02

$-2.63917279 \mathrm{E}-04$

4.53433455E-02

$-4.32943862 \mathrm{E}-03$

$1.45389826 \mathrm{E}-04$

2.17508610E-04

$-6.66724702 \mathrm{E}-05$

3.33217140E-05

$-2.26921615 \mathrm{E}-03$

3.80261982E-04

$-5.45314314 E-09$

$-7.96355448 \mathrm{E}-04$

2.53458034E-05

$-6.31223658 \mathrm{E}-06$

3.02122035E-04

$-4.77403547 \mathrm{E}-06$

$1.73825715 \mathrm{E}-06$

$-4.09087898 \mathrm{E}-07$

6.14155345E-01

$-6.16755931 \mathrm{E}-02$

1.33374846E-03

3.55375387E-03

$-5.13027851 \mathrm{E}-04$

1.02449757E-04

$-1.48526421 \mathrm{E}-03$

$-4.11469183 E-05$

$-6.80434415 E-06$

$-9.77675906 \mathrm{E}-06$

8.82773108E-02

$-3.01859306 E-03$

1.04452989E-03

2.47090539E-04

1.48348065E-03 
Bröde P, Fiala D, Błażejczyk K, Holmér I, Jendritzky G, Kampmann B, Tinz B, Havenith G Deriving the Operational Procedure for the Universal Thermal Climate Index UTCI

ESM 4: The archive "ESM_4_Table_Offset.ZIP" contains a ReadMe text and a TAB-delimited ASCIIfile "ESM_4_Table_Offset.Dat" tabulating values of the Offset (= UTCI - Ta) in ${ }^{\circ} \mathrm{C}$ for different input values of:

- Ta: air temperature in ${ }^{\circ} \mathrm{C}$ (range: $-50{ }^{\circ} \mathrm{C}$ to $+50{ }^{\circ} \mathrm{C}$ )

- Tr-Ta: difference between mean radiant temperature $(\mathrm{Tr})$ and air temperature in ${ }^{\circ} \mathrm{C}$ $\left(-30^{\circ} \mathrm{C}\right.$ to $\left.+70{ }^{\circ} \mathrm{C}\right)$

- va: wind speed in $\mathrm{m} / \mathrm{s}$ measured $10 \mathrm{~m}$ above ground level $(0.5 \mathrm{~m} / \mathrm{s}$ to $30.3 \mathrm{~m} / \mathrm{s})$

- $\quad \mathrm{rH}: \quad$ relative humidity in $\%(5 \%$ to $100 \%)$

- pa: water vapour pressure in $\mathrm{kPa}(0 \mathrm{kPa}$ to $5 \mathrm{kPa})$ 
This file could not be included in the PDF because the file type is not supported.

ESM 4 ReadMe - ESM_4_ReadMe.Dat

(1)

This file could not included in the por because the file type is not

(1)

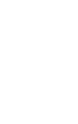

(1) 
This file could not be included in the PDF because the file type is not supported.

ESM 4 Data Table with Offset Values - ESM_4_Table_Offset.Dat

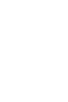

This file could not be included in the PDF because the file type is not supported.

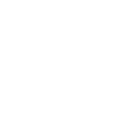

.

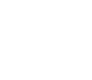

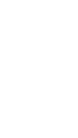

.

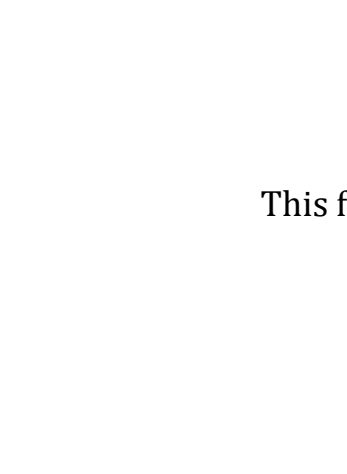

